
FLUIDIZED BEDS

\author{
Final Report \\ Sibashis Banerjee \\ Millennium Inorganic Chemicals \\ Rutton Patel \\ Alvin Chen \\ ExxonMobil Research and Engineering \\ Dale Snider \\ Ken Williams \\ CPFD Software, LLC \\ Tim O' Hern \\ Paul Tortora \\ Sandia National Laboratories
}

November 30, 2007

DOE Award: DE-FC36-04G014153 


\section{ENHANCED PRODUCTIVITY OF CHEMICAL PROCESSES USING DENSE FLUIDIZED BEDS}

\author{
Millennium Inorganic Chemicals, Inc. \\ ExxonMobil Research and Engineering
}

\author{
CPFD Software, LLC \\ Sandia National Laboratories
}

\section{Executive Summary}

Dense gas-solid reactors are used throughout the chemical industry for catalytic reaction processes including hydrocarbon cracking, Fischer-Tropsch synthesis, and production of titanium dioxide, polyethylene, and many other chemicals. In addition, fluidized beds are used for non-catalytic reaction processes including chlorination, oxidation, roasting, calcinations, combustion, incineration, heat treatment, coatings, and many others. However, understanding, control, and scale-up of these processes are limited by difficulties in measurement and modeling the dense solid-particle flow. Millennium Inorganic Chemicals, Inc. (MIC) and ExxonMobil Research and Engineering (EMRE), and Sandia National Laboratories (SNL) formed a multidisciplinary team with CPFD Software, LLC (CPFD), to conduct a three-year research program to provide advanced analysis capability in solid-fluid reactors, with broad extensions to catalysis, thermal cracking, gas-solid separation, and solid chemistry. This project focused specifically on chemical issues in fluidized-bed applications. The direct application is the chemistry in ExxonMobil's Fluid Coking ${ }^{\mathrm{TM}}$ processes and in the MIC titanium tetrachloride production pricess, but this development has broader benefits through the ability to better predict and control flow and chemistry in dense gas-solid reactors.

The work performed under this DOE grant focused on the Technology Vision 2020: This work relates to Reactions and Particulate Processes, specifically within Technology Area 1 - Chemical Synthesis. The work completed under this grant addresses Enabling Technologies within Computational Technology by integrating a "breakthrough" particle-fluid computational technology into traditional Process Science and Engineering Technology. The work completed under this DOE grant addresses five major development areas 1) gas chemistry in dense fluidized beds 2) thermal cracking of liquid film on solids producing gas products 3) liquid injection in a fluidized bed with particle-to-particle liquid film transport 4) solid-gas chemistry and 5) first level validation of models. Because of the nature of the research using tightly coupled solids and fluid phases with a Lagrangian description of the solids and continuum description of fluid, the work provides ground-breaking advances in reactor prediction capability.

The advanced computational models for chemistry and liquid-jet for reactor design and operation was implemented in the commercial computational particle fluid dynamics (CPFD) package (Barracuda ${ }^{\mathrm{TM}}$ ). This report includes five topical reports with the first four describing the chemistry and liquid jet functionality and where possible compares calculations with experimental data. The final report outlines some of the experiments that were performed as well as proposed experiments that had to be postponed or eliminated due to funding restrictions. In addition, the report outlines the steps taken to commercialize the product arising from this joint effort. 


\title{
ENHANCED PRODUCTIVITY OF CHEMICAL PROCESSES USING DENSE FLUIDIZED BEDS
}

\author{
Chemical Industry of the Future \\ DE-FC36-04G014153
}

\section{Introduction}

Fluidized beds are used for non-catalytic reaction processes including chlorination, oxidation, roasting, calculations, combustion, incineration, heat treatment, coatings, and many others. However, understanding, control, and scale-up of these processes are limited by difficulties in measurement and modeling such dense multiphase flows. Millennium Inorganic Chemicals, Inc. (MIC) and ExxonMobil Research and Engineering Co.(EMRE), a wholly owned subsidiary of ExxonMobil Corp., and Sandia National Laboratories (SNL) have formed a multidisciplinary team with CPFD Software, LLC (CPFD) to conduct a three-year research program to provide advanced methods of predicting solid-gas chemistry. The research and development of the math based models has been done by CPFD Software with industrial experience and experimental data provided from the industrial partners and National Laboratory.

Over the years, MIC, EMRE, universities, and others have focused significant research on understanding the processes associated with inefficiencies in particulate transport, thermal transport, and reaction behavior in dense fluidized beds (Gidaspow, 1993, Syamlal and Gidaspow, 1985). While this work has produced some important results, much remains to be achieved for the goals of enhanced productivity and process optimization to be realized. The reasons for this limited success are broad and far-reaching: (1) transport in dense beds is very complex and difficult to model and characterize experimentally; (2) computational tools needed to perform predictions and troubleshooting are slow, inaccurate, and require massive computational resources; (3) the U.S. chemical industry research budget is a pittance of what it once was, and work has mostly focused on near-term problems such as keeping the reactors onstream rather than long-term strategic issues such as reduction in energy use or reduced landfill volume. Despite these difficulties, many of the pieces necessary to make dramatic improvements in fluidized-bed reactor operations are now in place. Commercial computational tools have improved significantly in recent years (Snider, 2001), many of the physical closure models needed to capture transport physics appropriately are available (Wachem et al., 2001, Tsuji et al., 1993), computer horsepower has increased, and experimental diagnostics have evolved to the point where they can be used to study internal details of these complex flows (e.g., Werther, 1999; Shollenberger et al., 1997; Dudukovic, 2000). The intent of the proposed project is to assemble these pieces into a robust capability that will enable the chemical industry to design and operate optimized fluidized-bed reactors using validated computational tools.

\section{Commercialization}

An entirely new commercial computer-aided-engineering (CAE) software package has resulted from this DOE-sponsored Program. The Barracuda ${ }^{\mathrm{TM}}$ software package comprises a Graphical User Interface (GUI), a semi-automatic grid generator, a fluid-particle flow 'solver', and a graphical display to handle several million computational particles, with stereographic capability. The software package is based upon a 'break-through' numerical methodology that has now enabled the simulation of large, industrial-scale CPI units with computational results that are both fast and accurate. The numerical 
method represents a continuum gas or liquid fluid tightly coupled to discrete solids possessing any particle size distribution; the method was trademarked as CPFD $^{\circledR}$ (computational-particle-fluiddynamics). Both industry team members, ExxonMobil and Millennium Inorganic Chemicals, are using Barracuda for the program's focused application, namely deep-bed reactors - 'fluid cokers' and chlorinators. While details of their individual applications are proprietary, they are simulating thermal cracking of heavy petroleum or other hydrocarbon streams into more useful lighter liquid cuts, and the production of titanium dioxide, a ubiquitous white pigment. Both industry partners have re-licensed the commercial Barracuda software for 2008. Barracuda commercialization is being performed by CPFD Software, LLC (www.cpfd-software.com) with the sole purpose of marketing and supporting this new engineering software to the chemical, petrochemical, power generation, gasification, pharmaceutical, and indeed any industry based upon a fluid-solids process.

Even within the short time Barracuda has been commercialized there are numerous licensees who are expanding its application into diverse chemical and industrial processes. Barracuda is already being used for the following applications beyond its original scope: acrylonitrile (nylon) production in large ( $\sim 10$ meter diameter) deep-bed catalytic reactors; silicon semiconductor wafers and solar panel manufacturing; liquid/solids gravitational separation critical to many applications, such as the efficient extraction of bitumen from tar sands. Additionally, 'clean coal' goals are being helped today with this software, by so-called circulating fluidized bed (CFB) coal plants, with new gassifier concepts, and even with coal dust control. A major vendor of CFB coal plants is performing the first-ever full plant simulation - combustor, injectors, cyclone, and loop seal - to aid with plant startup and optimize performance, while achieving reduced emissions. Barracuda is being applied to new gassifier reactor designs for both coal and biomass feedstocks and two start-up companies have identified Barracuda as critical to their economic success in the energy marketplace; SilvaGas is a partner in a new DOE/SBIR proposal. The DOE's own NETL has licensed Barracuda for experimental validation efforts with application to transport gassifiers, including support for a major commercial demonstration project. In 2008, our planned efforts will expand to include reducing $\mathrm{NO}_{\mathrm{x}}$ emissions from $\mathrm{FCC}$ regenerators, a critical component in gasoline refineries and even with optimizing the reactor (riser) and 'stripper' components. A major cyclone vendor has licensed Barracuda to optimize efficiency, and increase reliability, plus to design tertiary cyclones for emissions control of very fine particles. Beyond the energy area, new innovative applications include fire extinguisher design, pharmaceutical production, and civil engineering for erosion control during severe floods. The DOE sponsorship, plus close coordination with ExxonMobil and Millennium, has delivered a commercial CAE software for the stated goal of deep-bed reactors, but it is already being broadly extended to new chemical and farreaching applications.

The commercial release of Barracuda with all features proposed to be accomplished under this DOE program will occur in early 2008. The exact release date depends upon successful completion of fundamental validations for the new liquid droplet sprays, the complex chemistry (solids consumption, liquid thermal-cracking to a vapor, and heterogeneous catalytic reactions), plus GUI completion and quality-assurance testing of the final commercial product. The Barracuda CAE software product will continue to be used by a wide range of industrial companies, and will make significant contributions to increasing energy efficiency from dense-bed chemical reactor applications, as well as to obtaining environmental savings from reduced emissions of $\mathrm{NO}_{\mathrm{x}}$ and $\mathrm{SO}_{2}$.

Commercialization efforts continue with the strong marketing of Barracuda. This includes: advertisements in Chemical Engineering and Mechanical Engineering magazines; a new website, AIChE winter meeting support of the Particle Technology Forum dinner in Utah; trade show exhibitor at ASME in Seattle in November 2007. This broad marketing has paid dividends already with a wide Barracuda user-base across diverse energy and environmental applications in the USA, and now internationally. The resulting product, Barracuda CPFD, has been successfully commercialized. 


\section{Software Development}

This report contains four topical reports which summarize the DOE sponsored research and development on the software front. The physics described is within the Barracuda ${ }^{\mathrm{TM}}$ software. Barracuda $^{\mathrm{TM}}$ is a fully three-dimensional commercial software for calculating dense solid-gas flow using a Lagrangian description of solids and a continuum description of the fluid. The first report describes validation of the heterogeneous gas chemistry. The ozone decomposition experiment by Fryer and Potter (1976) was used to validate the heterogeneous chemistry. The second report describes gassolid chemistry. The gas-solid chemistry has particular interest to MIC because rutile ore chemically reacts with $\mathrm{CO}$ and $\mathrm{Cl}_{2}$ in the process to produce titanium dioxide. The test problem was supplied by Dr. S. Banerjee of MIC. The third report describes liquid injection into a fluidized bed. The injection of liquid into a fluidized bed and the subsequent particle-to-particle collisional mixing of liquid films is a complex process. The process is modeled by collision terms on the right-hand side of the transport equation for the single-particle distribution function for the bed particles. The form of the collision terms is the same as in the so-called BGK model for collisions in the Boltzmann equation of gas dynamics. The predicted liquid jet into a packed bed is compared with the experiment by Ariyapadi et al. (2003). The fourth report describes a bulk liquid chemistry model where thermal chemical cracking of a liquid film on a solid produces gas species. The simple 6-lumped chemistry example was supplied by Dr. A Chen of EMRE.

\section{Experimental Work}

The primary role of Sandia National Laboratories in this project was to provide and evaluate highquality data sets for validation of new models implemented in Barracuda ${ }^{\mathrm{TM}}$. The original intent was to build a large fluidized bed but the project team decided to suspend that effort when funding was delayed in the first two project years. However, several sets of small-scale experiments were still performed. These, along with literature data reviews, are included in the final topical report (Topical Report No. 5.) Some of the experiments that were proposed to perform additional validation are included in the above report. Most of the proposed experiments had to be deferred when funding was slowed and diverted. Key literature findings will be mentioned. Other aspects of the Sandia work included evaluation of data available in the open literature to determine their suitability for validation. Also, Sandia personnel have been applying image processing routines to help understand some propriety EMRE data. Finally, several Barracuda $^{\mathrm{TM}}$ validation simulations were run at Sandia over the course of the program.

\section{Publications}

The team members have presented two papers at AIChE conferences held in conjunction with the Department of Energy project review meetings. These are:

1) Tortora, P., et al. " Comparison on Experiments and Multiphase Particle-in-Cell Simulations in a Two-Dimensional Fluidized Bed", presented at the AIChE Spring 2005 Conference.

2) Banerjee S., et al. "Effect on Fluidization of Cold and Hot Gas Injection into Fluidized Beds", presented at the AIChE Spring 2007 Conference. 


\section{Participants}

Millennium Inorganic Chemicals Inc.

Dr. Sibashis Banerjee

Dr. Yun Xiong

Thomas Messer

ExxonMobil Research and Engineering Co.

Dr. Alvin Chen

Dr. Rutton Patel

Sandia National Laboratories

Dr. Tim O'Hern

Dr. Paul Tortora

\section{CPFD Software, LLC}

Dr. Peter O'Rourke

Dr. Dale Snider

Dr. Ken Williams

Dr. Paul Zhao

\section{Department of Energy}

Bill Prymak (Project Officer)

Toni Newville (Project Monitor)

Mathew Barron (Contracting Officer)

Pamela Brodie (Financial Specialist) 


\section{References}

Ariyapadi S., D. W. Holdsworth, C. J. D. Norley, F. Berruti, C. Briens, 2003, "Digital X-ray Imaging Technique to Study the Horizontal Injection of Gas-Liquid Jets into Fluidized Beds, " Int.. J. Chem. React. Engr. 1, Article A56.

Dudukovic, M. P., 2000, “Opaque Multiphase Reactors: Experimentation, Modeling and Troubleshooting," Oil \& Gas Science and Technology-Revue de Institut Francais du Petrole, 55(2), 125-158.

Fryer, C. and Potter, O.E, "Experimental investigation of models for fluidized bed catalytic reactors," AIChE J., 22, 1976.

Gidaspow, D, 1993, Multiphase Flows and Fluidization, Academic Press.

Shollenberger, K. A., Torczynski, J. R., Adkins, D. R., O’Hern, T. J., and Jackson, N. B., 1997, "Gamma-Densitometry Tomography of Gas Holdup Spatial Distribution in Industrial-Scale Bubble Columns," Chemical Engineering Science, 52(13), 2037-2048.

Snider, D., 2001, “An Incompressible Three-dimensional Multi-phase Particle-in-Cell Model for Dense Phase Flows,” J. Computational Physics, 170, 523-549, 2001.

Syamlal, M. and Gidaspow, D., 1985, "Hydrodynamics of Fluidization: Prediction of Wall to Bed Heat Transfer Coefficients”, AIChE Journal, 31, 1, 127-135.

Technology Vision 2020: The U. S. Chemical Industry

Tsuji, Y., et al., 1993, "Discrete Particle Simulation of Two-Dimensional Fluidized Bed”, Powder Technology, 77, 79-87.

van Wachem, B. G. M., et al., 2001, "Comparative Analysis of CFD Models of Dense Gas-Solid Systems," AIChE Journal, 47, 5, 1035-1051.

Werther, J., 1999, “Measurement Techniques in Fluidized Beds," Powder Technology, 102, 15-36. 


\section{ENHANCED PRODUCTIVITY OF CHEMICAL PROCESSES USING DENSE FLUIDIZED BEDS}

Topical Report No. 1

Heterogeneous Gas Chemistry

(Ozone Decomposition)

Dale Snider

CPFD Software LLC

March 2007

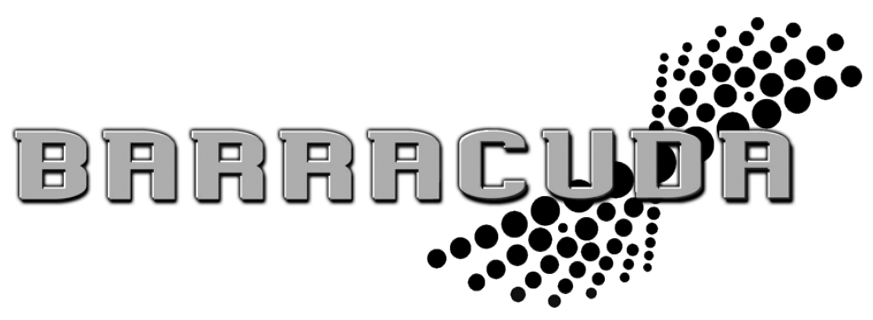

Performed as part of DOE Contract: DE-FC36-04G014153 


\title{
Heterogeneous Gas Chemistry (Ozone Decomposition)
}

\author{
Dale Snider \\ CPFD Software, LLC \\ March 2007
}

\section{Introduction}

Ozone decomposition is a standard problem for chemical analysis. It has been used to characterize the gas-solids contact in a fluidized bed. The ozone decomposition can be described by

$$
2 \mathrm{O}_{3} \rightarrow 3 \mathrm{O}_{2}
$$

and the ozone rate equation is

$$
\frac{d\left[O_{3}\right]}{d t}=-c_{s}\left[O_{3}\right]
$$

where [] denotes mole concentration. The rate coefficient is

$$
c_{s}=k \theta_{S}
$$

where $\theta_{\mathrm{S}}$ is the solids volume fraction and $k$ is a constant based on catalyst activity.. The catalyst volume fraction in the chemical rate coefficient equation Eq. (3) does not account for the the effect of catalyst surface area (catalyst sites) from a particle size distribution (PSD). The solid-catalyst size distribution was not available, and a constant size was used in calculations.

The chemical process is simple, and at low concentration, the reaction is essentially irreversible and isothermal. Calculations were made for two stagnant beds and a fluidized bed. One static bed calculation is in a closed vessel where the ozone decomposition reaction increases the pressure. The second static bed calculation is in an open vessel which allows excess volume from the ozone decomposition to exit the vessel and leads to a decrease in mixture density. The ozone decomposition in the static beds has a known analytic decomposition rate and known pressurization in a closed vessel and known density in an open vessel. Because the full set of momentum and mass equations are solved, the static bed calculations provide a check on correctness of the predicted chemistry. The fluidized bed calculation is compared with measured data.

\section{Closed stagnant bed}

The ozone decomposition is predicted in a stagnant bed of catalyst with a premixed mixture of nitrogen, oxygen and ozone. The cylindrical vessel dimensions and the properties of gas mixture and solid-catalyst are listed in Table 1. All calculations are three dimensional. For the stagnant bed, neither a high grid resolution or a high particle resolution is required. 
Table 1. Simulation conditions for a stagnant bed

\begin{tabular}{ll}
\hline Vessel diameter & $22.9 \mathrm{~cm}$ \\
Vessel height & $60 \mathrm{~cm}$ \\
Initial pressure & $101 \mathrm{kPa}$ \\
Top boundary for open vessel & $101 \mathrm{kPa}$ \\
Temperature & $300 \mathrm{~K}$ \\
Initial mixture $\mathrm{N}_{2}$ & 0.8 mass fraction \\
Initial mixture $\mathrm{O}_{2}$ & 0.1 mass fraction \\
Initial mixture $\mathrm{O}_{3}$ & $0.1 \mathrm{mass}$ fraction \\
Mixture flow rate & 0 \\
Solid-catalyst & $\mathrm{Fe}_{2} \mathrm{O}_{3} \mathrm{with}^{2}$ a silica base \\
Solid-catalyst density & $2655 \mathrm{~kg} / \mathrm{m}^{3}$ \\
Solid-catalyst radius & $60 \mu \mathrm{m}^{[1]}$ \\
Solid-catalyst sphericity & 1 \\
Reaction rate constant, $k$ & $0.33 \mathrm{~s}^{-1}$ \\
intial solid-catalyst volume fraction & $0.62{ }^{[2]}$ \\
Number computation cells & 1280 \\
Number of numerical particles & 28,400 \\
\hline
\end{tabular}

1. No information was given on the particle size distribution

2. The initial solid volume fraction is 0.62 . Because solids are initially seeded randomly, there is an adjustment of volume fraction from the collision physics at the start of the calculation.

Figure 1 shows the Barracuda ${ }^{\mathrm{TM}}$ predicted decomposition of $\mathrm{O}_{3}$ as a function of time for $k=0.33$. The reaction of $\mathrm{O}_{3}$ to $\mathrm{O}_{2}$ compares very well to the analytically predicted decomposition from Eq. (2). Figure 2 shows that the loss of mass fraction by $\mathrm{O}_{3}$ is gained by $\mathrm{O}_{2}$. The nitrogen is a passive gas in the gas mixture. Figure 3 shows the transient pressure in the closed vessel and in the open vessel. In the closed vessel, the mole increase in oxygen from ozone decompositions gives a pressure increase. The analytic pressure ${ }^{1}$ compares well with the Barracuda ${ }^{\mathrm{TM}}$ Fryer and Potter (1976) pressure. In the open system, the gas mixture flows out of the vessel as the ozone decomposes which gives a near constant pressure.

1. Chemical reaction from $0.8 \mathrm{~N}_{2}, 0.1 \mathrm{O}_{3}$ to $0.1 \mathrm{O}_{2}$ to $0.8 \mathrm{~N}_{2}$ and $0.2 \mathrm{O}_{2}$, gives a pressure increases of $1.0309 \mathrm{kPa}$ in the closed vessel. 


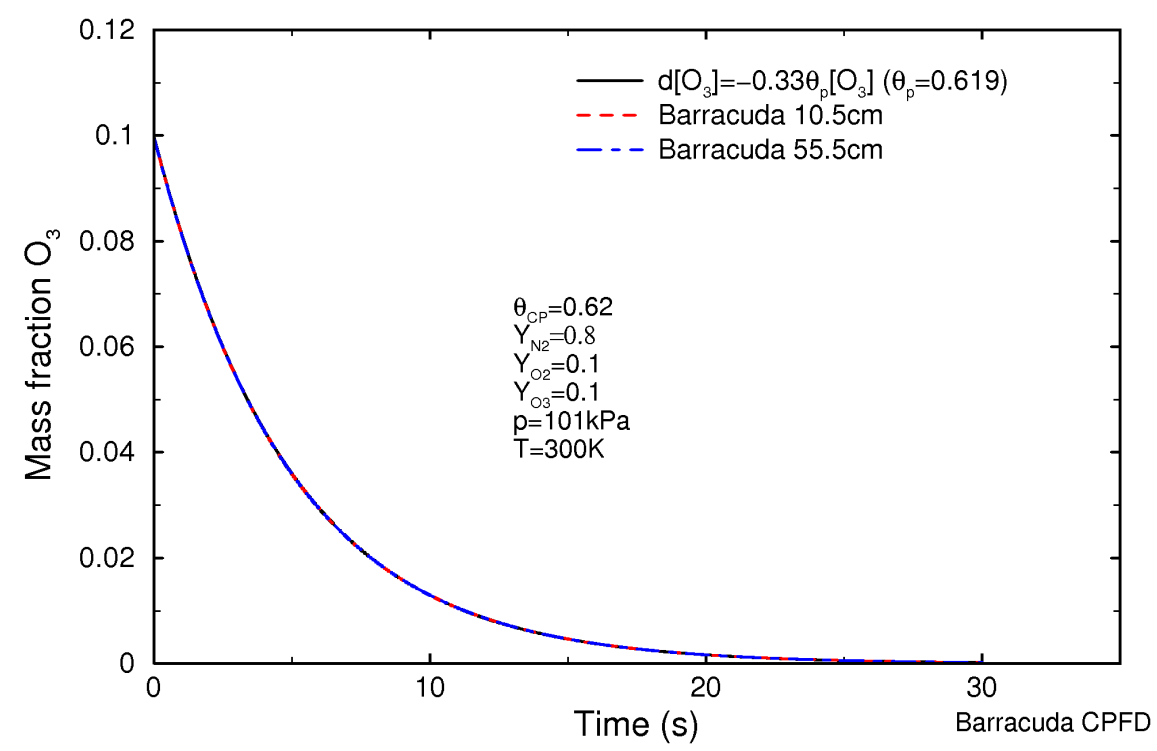

Figure 1. Ozone decomposition in a static bed of solid-catalyst in an open and closed vessel.

Figure 4 shows the predicted particle volume fraction. The initial particle volume fraction is seeded randomly. This produces variations in the initial volume fraction. Near close pack, collisional forces adjust the bed particles by moving particles to an equilibrium arrangement. Figure 4 shows the volume fraction in the center of the bed drops from the initial 0.62 value to 0.6184 . Figure 5 shows the mixture density in the closed vessel and the open vessel. In the closed vessel, the mass is constant and consequently the density is constant. In the open vessel, mass leaves the vessel and the density decreases. The slight rearrangement of solids gives small fluctuations in the local volume fraction. 


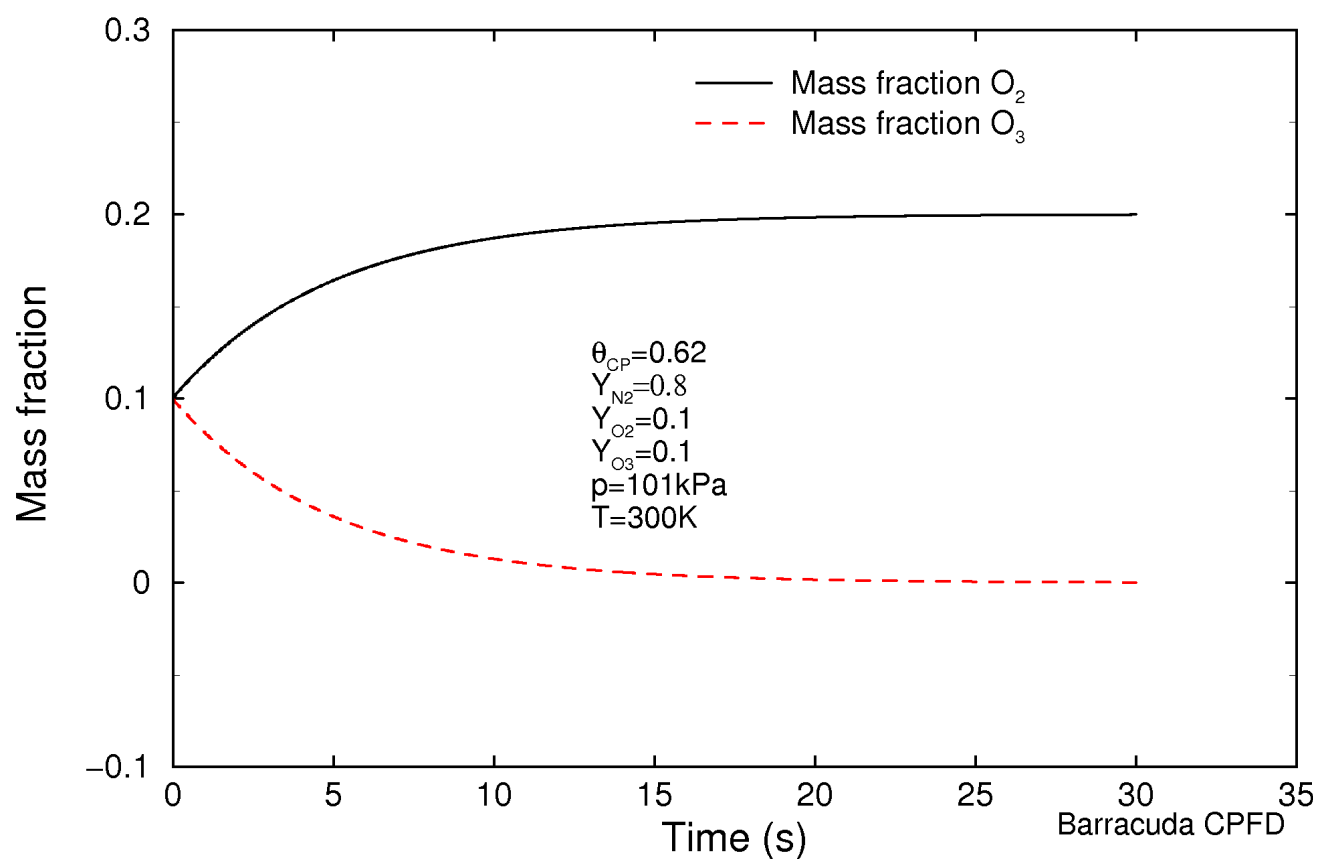

Figure 2. Ozone loss and oxygen gain in a closed vessel

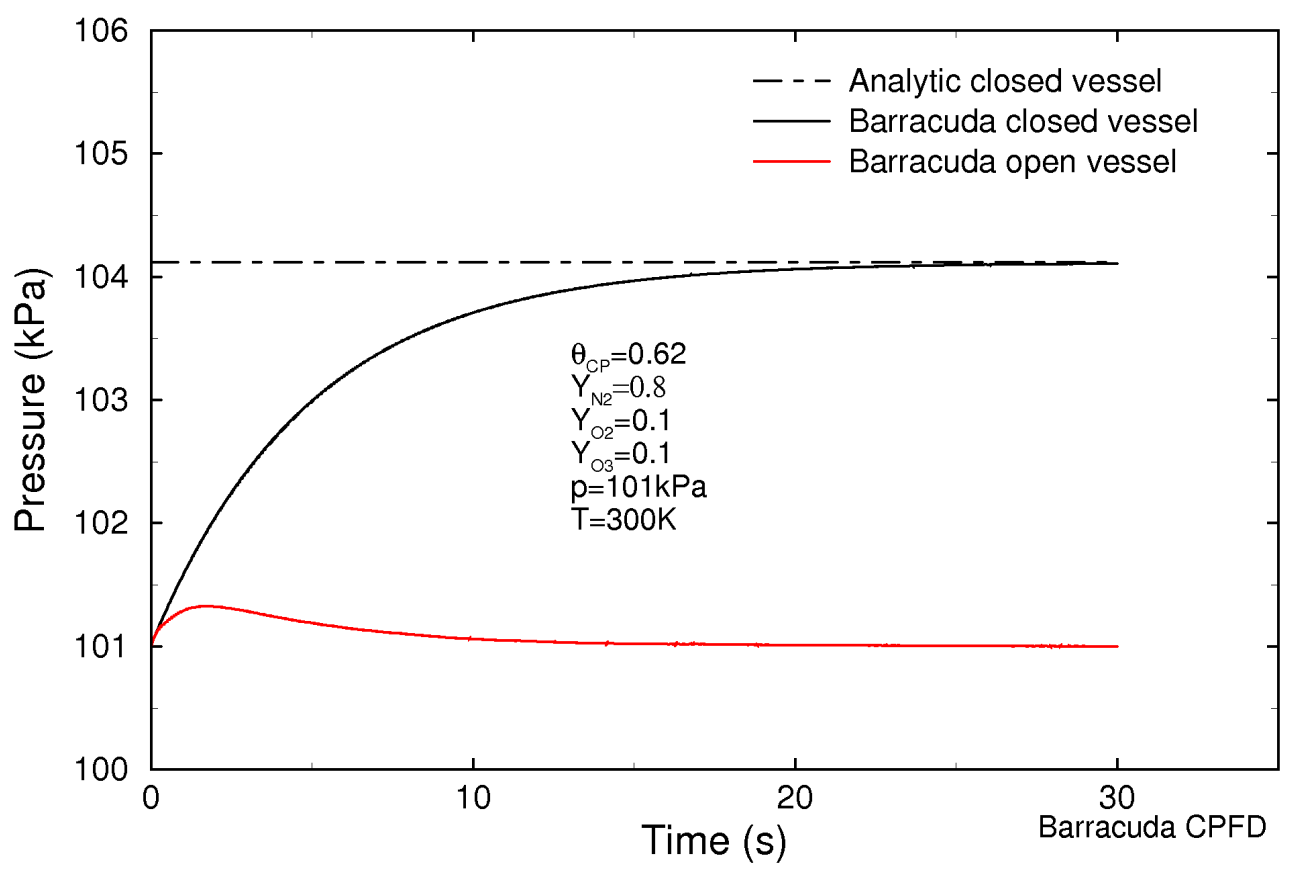

Figure 3. Ozone decomposition transient pressure at the top of the vessel in the open and closed vessels. 


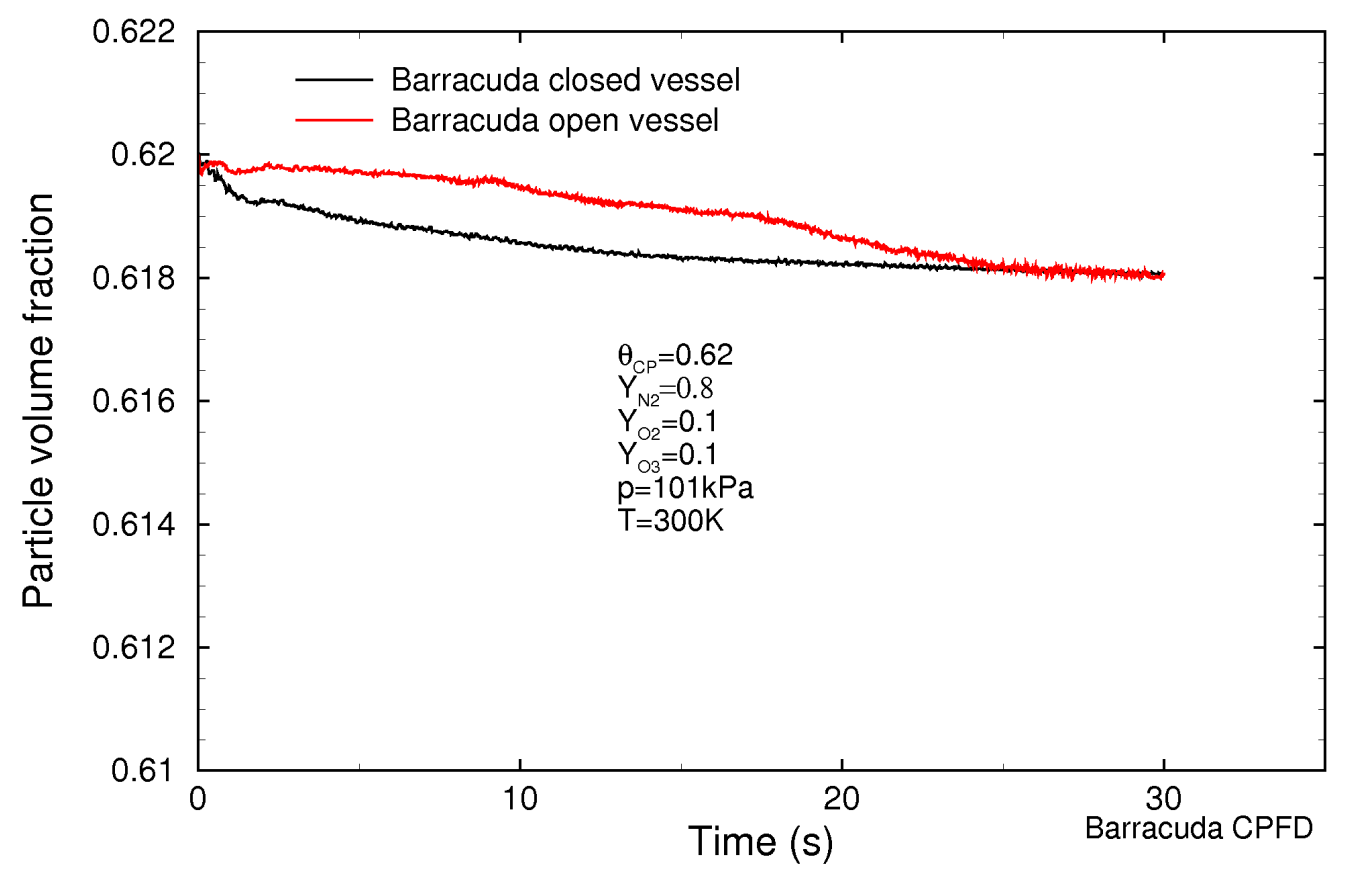

Figure 4. Ozone decomposition transient solid volume fraction in an open and closed vessel. The volume fraction location is near the top at $55.5 \mathrm{~cm}$

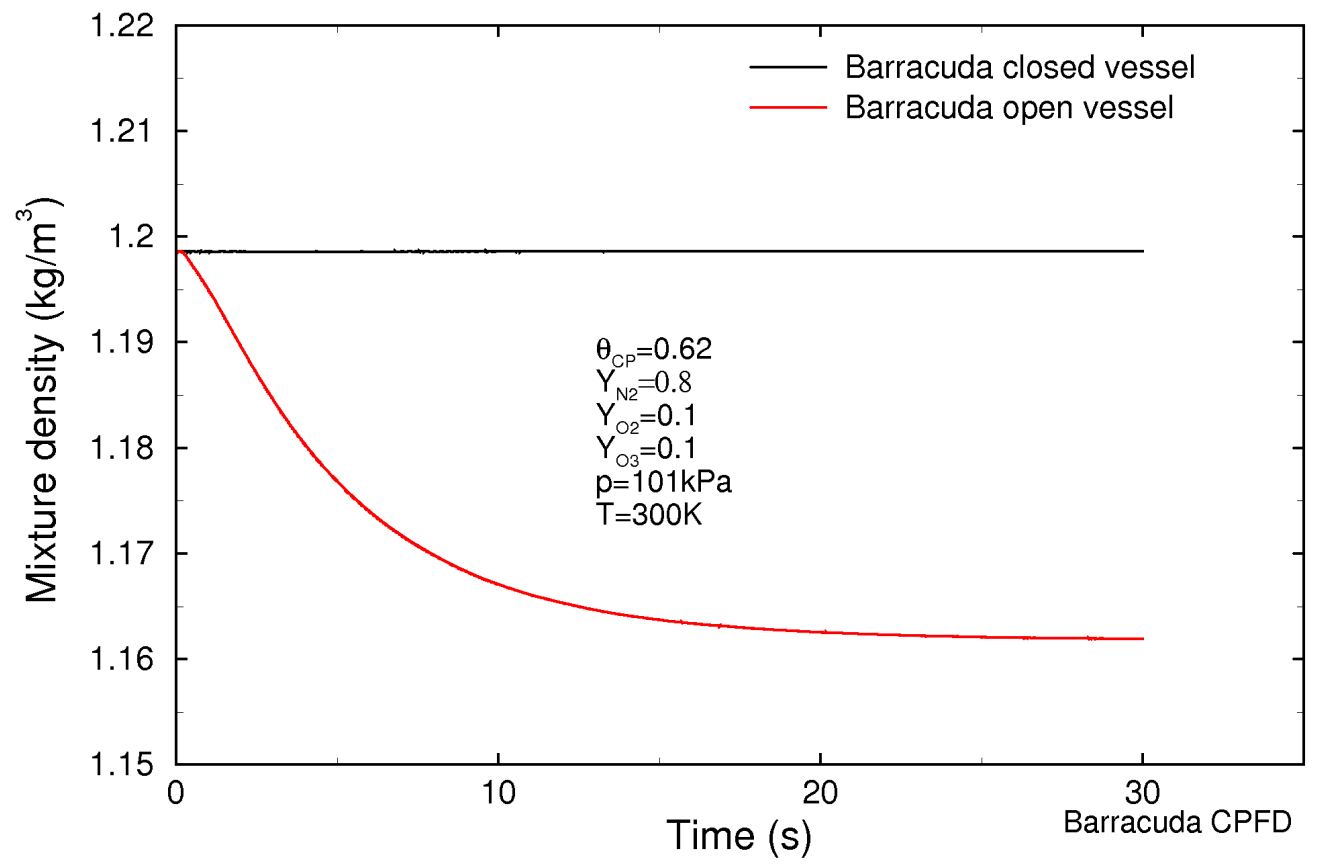

Figure 5. Ozone decomposition transient density at the top of the vessel in the open and closed vessels. 


\section{Analytic solution for uniform packed bed}

If the bed has a uniform solid distribution, there is an analytic solution for the decomposition of ozone. The one dimensional transport of ozone through a bed is described by

$$
\rho_{\text {mix }} \theta_{f} u \frac{d Y_{O_{3}}}{d z}=\theta_{f} \rho_{\text {mix }} \frac{d Y_{O 3}}{d t}
$$

where $\rho_{\text {mix }}$ is the gas mixture density, $u$ is the fluid velocity, $z$ is the axial distance, $Y_{O 3}$ is the mass fraction of $\mathrm{O}_{3}$ and $\theta_{f}$ is the fluid volume fraction. The first order reaction, given by Eq. (2), is substituted into Eq. (4) giving the rate of production of ozone

$$
\rho_{\text {mix }} u \frac{d Y_{O_{3}}}{d z}=-\rho_{\text {mix }} k \theta_{p} Y_{O_{3}}
$$

The mass fraction is

$$
Y_{O_{3}}=Y_{O_{3}}^{o} e^{-\frac{k \theta_{p}}{u} z}
$$

where $Y^{0}$ is the initial value (at $t=0$ ). The superficial velocity is $U=\theta_{f} u$, which is substituted into Eq (5) giving ${ }^{2}$

$$
Y_{O_{3}}=Y_{O_{3}}^{o} e^{-\frac{k \theta_{p} \theta_{f}}{U} z}
$$

Figure 8 shows that the Barracuda calculation for a uniform bed of solids compares well to the analytic solution Eq. (7). Because the gas velocity was well above the minimum fluidization velocity, the forces on solids were all set to zero within the code. While not being physically correct for solid dynamics, it gave a constant uniform distribution of solids from which the chemistry could be tested.

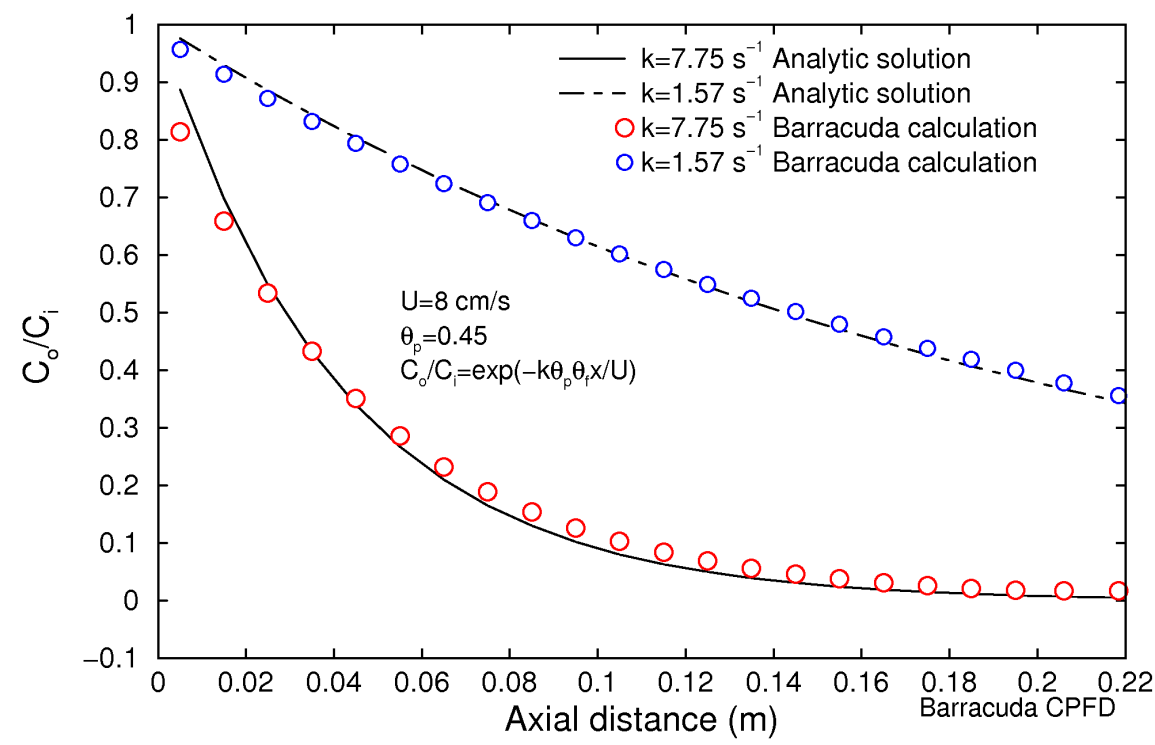

Figure 6. Barracuda calculation compared with analytic solution. Analytic solution uses $k=1.57 \mathrm{~s}^{-1}$ and $k=7.75 \mathrm{~s}^{-1}, \theta_{p}=0.45$, and $x=11.5 \mathrm{~cm}$.

2 The ozone production along a flow path of ozone can also be calculated from $\frac{d\left[O_{3}\right]}{d t}=\frac{d\left[O_{3}\right]}{d x} \frac{d x}{d t}=-\theta_{p} k\left[O_{3}\right] \quad$ which gives $\left[O_{3}\right]=\left[O_{3}\right]^{0} e^{\frac{-k \theta_{\theta} \theta_{f}}{U}}$. The ratio of new and old mole concentration is the same as the ratio for mass fractions 


\section{Fluidized bed ozone decomposition}

The ozone decomposition is calculated in a fluidized bed. The experiment by Fryer and Potter (1976) is modeled. The experiment vessel was $22.9 \mathrm{~cm}$ diameter and $200 \mathrm{~cm}$ tall. The packed bed contains solid catalyst of silica sand impregnated with $\mathrm{Fe}_{2} \mathrm{O}_{3}$. The bed is fluidized with dry air with $\mathrm{O}_{3}$ added. The parameters are listed in Table 2. All calculations were run for the full three-dimensional bed.

Table 2. Simulation conditions for a fluidized bed

\begin{tabular}{ll}
\hline Vessel diameter & $22.9 \mathrm{~cm}$ \\
Vessel height & $30 \mathrm{~cm}$ \\
Top pressure boundary for open vessel & $101 \mathrm{kPa}$ \\
Temperature & $300 \mathrm{~K}$ \\
Inlet mixture $\mathrm{N}_{2}$ & 0.702 mass fraction \\
Inlet mixture $\mathrm{O}_{2}$ & 0.198 mass fraction \\
Inlet mixture $\mathrm{O}_{3}$ & 0.1 mass fraction \\
Mixture flow rate & ranges from 2 to14 cm/s \\
Solid-catalyst & $\mathrm{Fe}_{2} \mathrm{O}_{3}$ with a silica base \\
Solid-catalyst density & $2655 \mathrm{~kg} / \mathrm{m}^{3}$ \\
Solid-catalyst radius & $60 \mu \mathrm{m}^{[1]}$ \\
Solid-catalyst sphericity & 1 \\
Reaction rate constant, $\mathrm{k}$ & 0.33 to $1.57 \mathrm{~s}^{-1}{ }^{[2]}$ \\
Initial solid-catalyst volume fraction & 0.6 \\
\hline
\end{tabular}

1. No information was given on the particle size distribution

2. Units from reaction rate equation, $\left(\mathrm{s}^{-1}\right)$.

Figure 7 shows the solids in the fluidized bed colored by volume fraction. The volume fraction spatial parameter is mapped to the discrete particle locations. The bed is churning, and like the experiment, the inner details of the bed are not distinct. Figure 8 shows the solid volume fraction by two other graphic methods in a cut section of the bed. Figure 8 a shows the volume fraction of solids on the Eulerian grid, which is similar to calculated data using an Eulerian representation of solids. The light areas are void structures or "bubbles", and the dark areas are more dense packed regions of solids. Figure $8 \mathrm{~b}$ shows the solid volume fraction greater than 0.3 . The holes are the void structures of gas rising through the bed.

Figure 9 shows the mass fraction of $\mathrm{O}_{3}$ next to the solids in the fluidized bed. The view is with the front half of the bed removed. The ozone enters the bed at 0.1 mass fraction and starts decomposing to oxygen in the presence of the catalyst. At the bottom of the bed, the catalyst is relatively uniformly mixed compared to higher in the bed where multiple "bubbles" have formed. This uniform catalyst-gas mixture gives a near uniform $\mathrm{O}_{3}$ decomposition for the first few centimeters. Further up in the bed, plumes of $\mathrm{O}_{3}$ rise in the bed in gas voids ("bubbles") while $\mathrm{O}_{3}$ in denser packed regions of catalyst decompose to oxygen. Above the bed, $\mathrm{O}_{3}$ which did not decompose to $\mathrm{O}_{2}$ drifts in the bulk flow and flows out of the bed.

In calculating fluidized beds, it is common to adjust the drag coefficient based on a measured fluidization velocity. This allows calculations which use a single particle size to adjust to a best-fit particle size for the calculation. This adjustment also allows a correlation to better represent a particular 
system. In this study, there were no adjustments in calculation parameters to fit or tune the calculation for the problem. The standard drag model used in this study is given in the Appendix.

The predicted pressure, as the inlet velocity is ramped with time, is shown in Fig. 10. The measured minimum fluidization velocity $\left(U_{m f}\right)$ was $1.7 \mathrm{~cm} / \mathrm{s}$ (Fryer and Potter, 1976), and from Fig. 10, the calculated $U_{m f}$ is approximately $1.6 \mathrm{~cm} / \mathrm{s}$. A solid size distribution was not available for this study, and possible inaccuracies in calculation parameters with respect to experimental conditions, including inaccuracy in the drag correlation are possible sources for the small discrepancy between measured and calculated $U_{m f}$.

The calculations were run sufficiently long at a fixed inlet flow rate to get a quasi steady rate of ozone decomposition. Figure 11 shows the ozone at the top of the vessel for an inlet flow rate of $7 \mathrm{~cm} / \mathrm{s}$ and a rate coefficient $k=1.57 \mathrm{~s}^{-1}$. At $24 \mathrm{~s}$, the inlet velocity is increased to $11 \mathrm{~cm} / \mathrm{s}$ and the calculation continues to run beyond the time period shown. Figure 12 shows the calculated and measured ozone decomposition as a function of inlet flow rate. The comparison is excellent. As the inlet flow rate increases, less fractional ozone decomposes to oxygen. In the bubbling fluidized bed, ozone moving in bubbles bypasses solid catalyst contact. Surprisingly, the prediction from the analytic solution for a uniform packed bed compares well with the measured ozone decomposition.

Figures 13 and 14 show the calculated ozone decomposition for $k=0886 \mathrm{~s}^{-1}$ and $k=0.33 \mathrm{~s}^{-1}$, respectively. The comparison between Barracuda and experiment is also good. The calculation is shifted a little above or a little below the measured decomposition data. The variation could be from slightly different calculation parameters from those used in the experiments. There was a range of measured rate coefficients that where combined to get the average coefficient which is used in the Barracuda calculation. For the average $k=7.75$, Fryer and Potter reported rate constants from 7.05 to 8.05. The reaction rate from this range of measured coefficients can produce a variation in decomposition of ozone from $-105 \%$ to $26 \%$ relative to the average reaction constant (analysis based on analytic solution). The ozone enters the bed at $1.5 \mathrm{~cm}$ from the bottom, while Barracuda calculations have ozone entering at the bottom. As noted by Fryer and Potter (1976) this gives an effectively shorter ozone decomposition zone. A $11.5 \mathrm{~cm}$ deep bed has a $13 \%$ smaller effective reaction zone. For a $24 \mathrm{~cm}$ deep bed, the effective reaction zone is $6 \%$ smaller. Again, the the analytic solution for a uniform packed bed compares well with the measured data. 


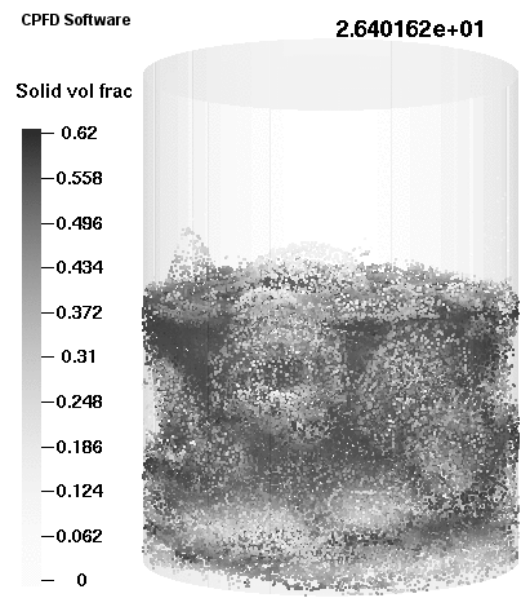

Figure 7. Calculated solids distribution. Discrete solids are shown colored by volume fraction mapped from the grid to particle locations.

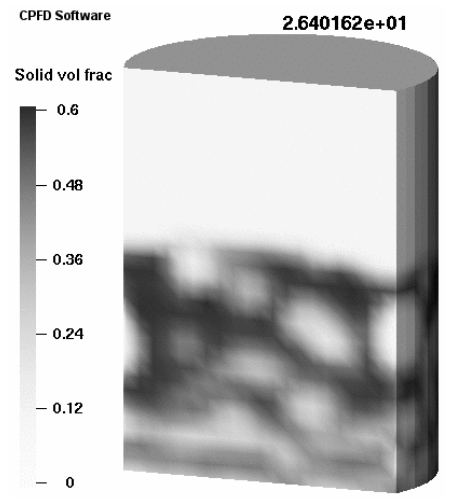

a

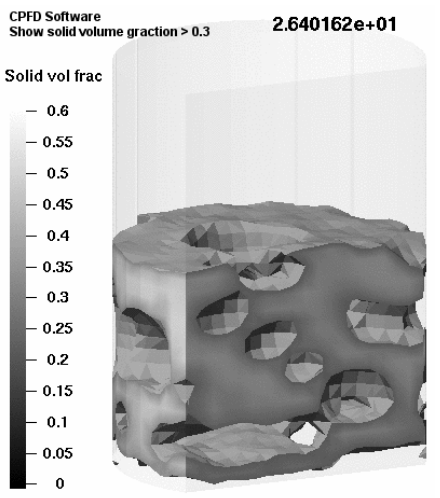

b

Figure 8. Calculated solids field, colored by volume fraction. $U_{\text {inlet }}=11 \mathrm{~cm} / \mathrm{s}$, static bed height is $11.5 \mathrm{~cm}$ and $k=1.57 \mathrm{~s}^{-1}$. Figure b shows volume fraction greater than 0.3. 


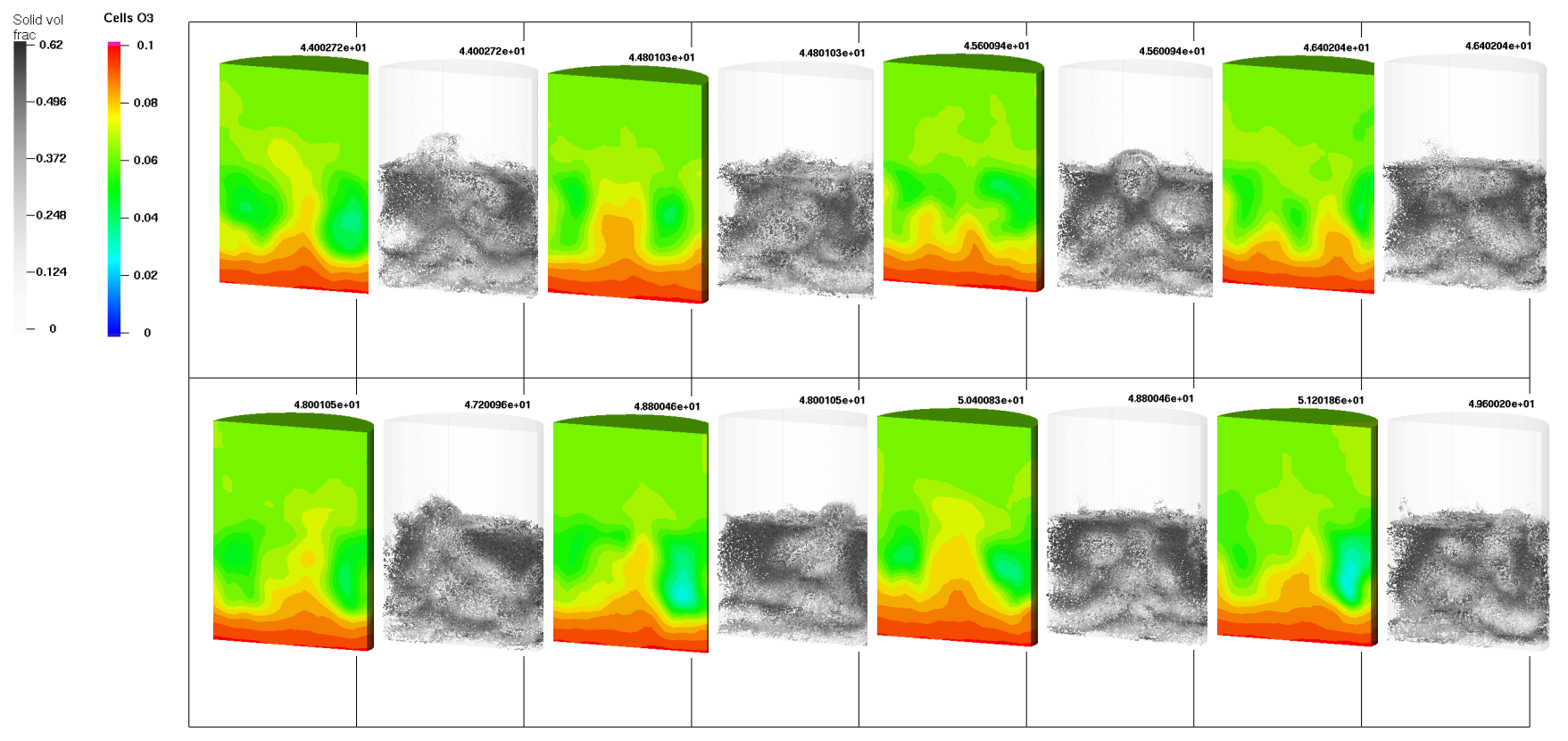

Figure 9. Calculated $\mathrm{O}_{3}$ mass fraction and catalyst-solids colored by volume fraction. $U_{\text {inlet }}=11 \mathrm{~cm} / \mathrm{s}$, static bed height is $11.5 \mathrm{~cm}$ and $k=1.57 \mathrm{~s}^{-1}$.
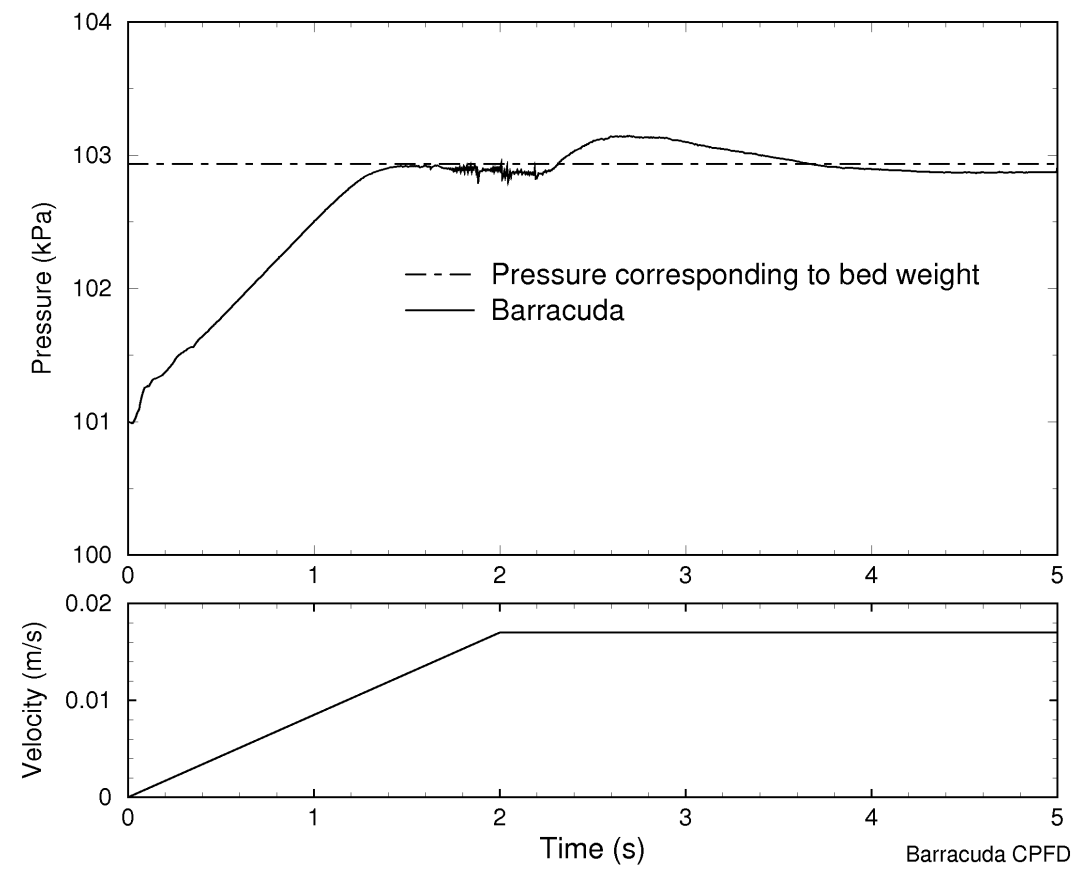

Figure 10. Calculated transient pressure and inlet gas-mixture velocity leading to minimum fluidization. Static bed height of $11.5 \mathrm{~cm}$ and reaction rate coefficient $k=1.57 \mathrm{~s}^{-1}$ 


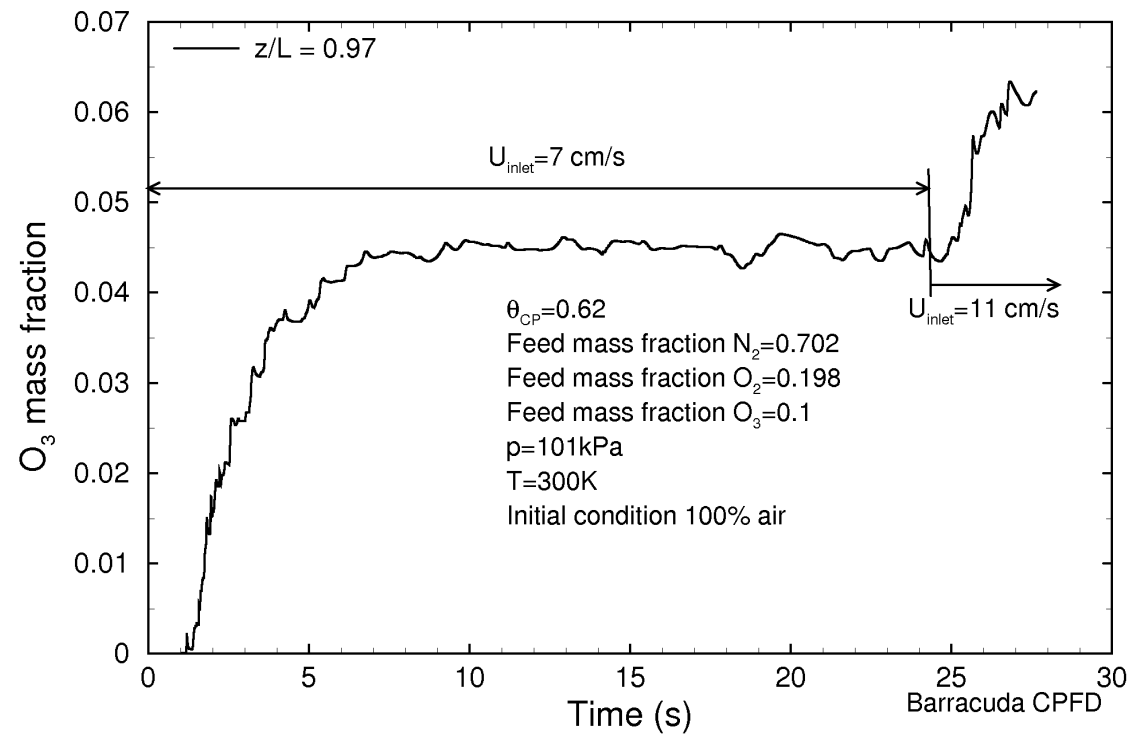

Figure 11. Calculated transient $\mathrm{O}_{3}$ mass fraction at inlet mixture velocity of $7 \mathrm{~cm} / \mathrm{s}$, static bed height of $11.5 \mathrm{~cm}$ and reaction rate coefficient $k=1.57 \mathrm{~s}^{-1}$

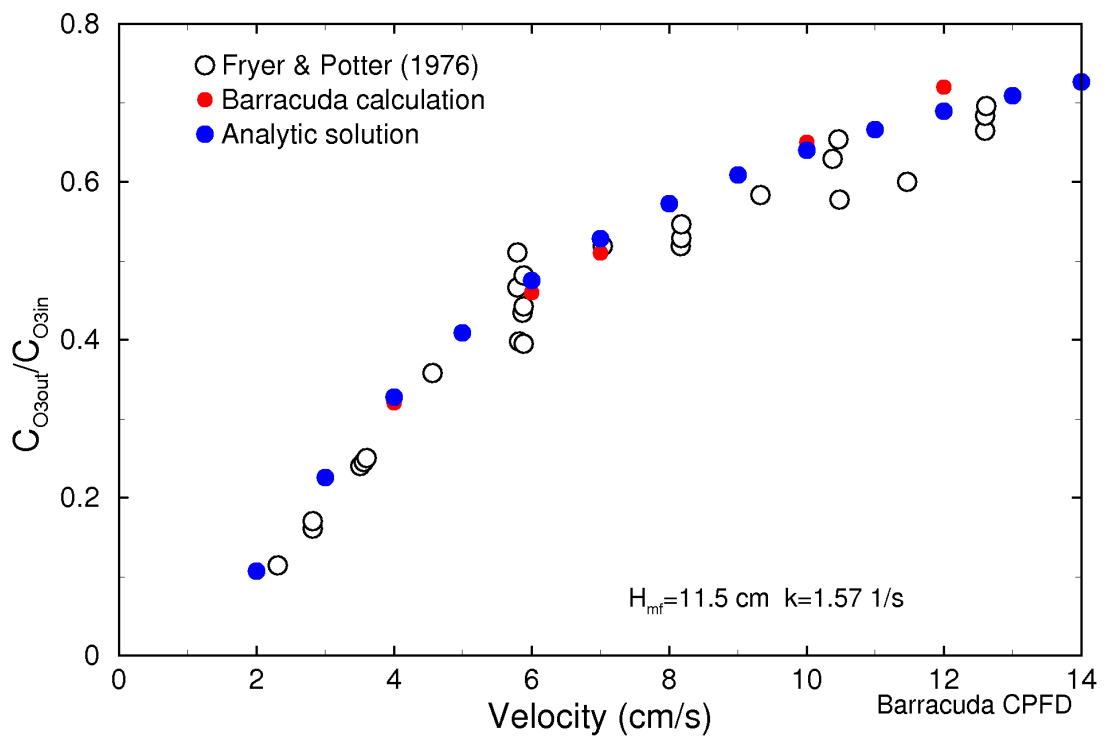

Figure 12. Measured and calculated $\mathrm{O}_{3}$ normalized mass fraction as function of inlet velocity. Static bed height is $11.5 \mathrm{~cm}$ and chemical rate constant $1.57 \mathrm{~s}^{-1}$. Analytic solution uses $k=1.57 \mathrm{~s}^{-1}, \rho_{f}=1.2 \mathrm{~kg} / \mathrm{m}^{3} \theta_{p}=0.45$, and $x=11.5 \mathrm{~cm}$. 


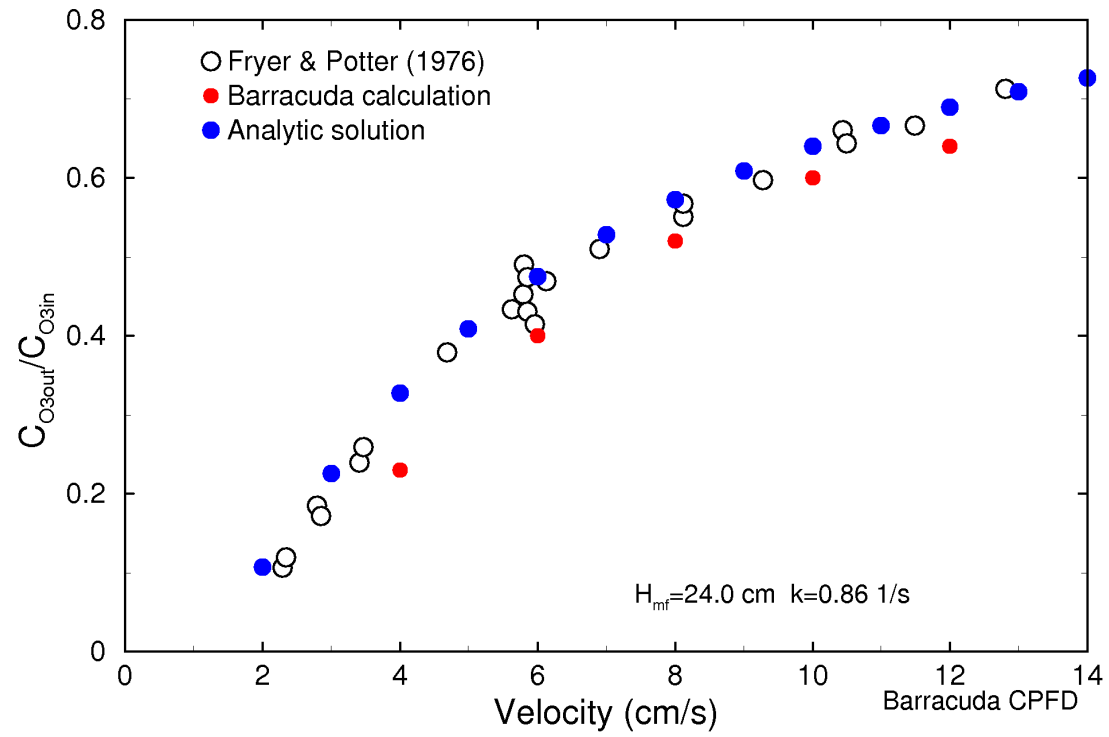

Figure 13. Measured and calculated $\mathrm{O}_{3}$ normalized mass fraction as function of inlet velocity. Static bed height is $24 \mathrm{~cm}$ and chemical rate constant $0.86 \mathrm{~s}^{-1}$. Analytic solution uses $k=0.86 \mathrm{~s}^{-1}, \rho_{f}=1.2 \mathrm{~kg} / \mathrm{m}^{3} \theta_{p}=0.45$, and $x=24 \mathrm{~cm}$.

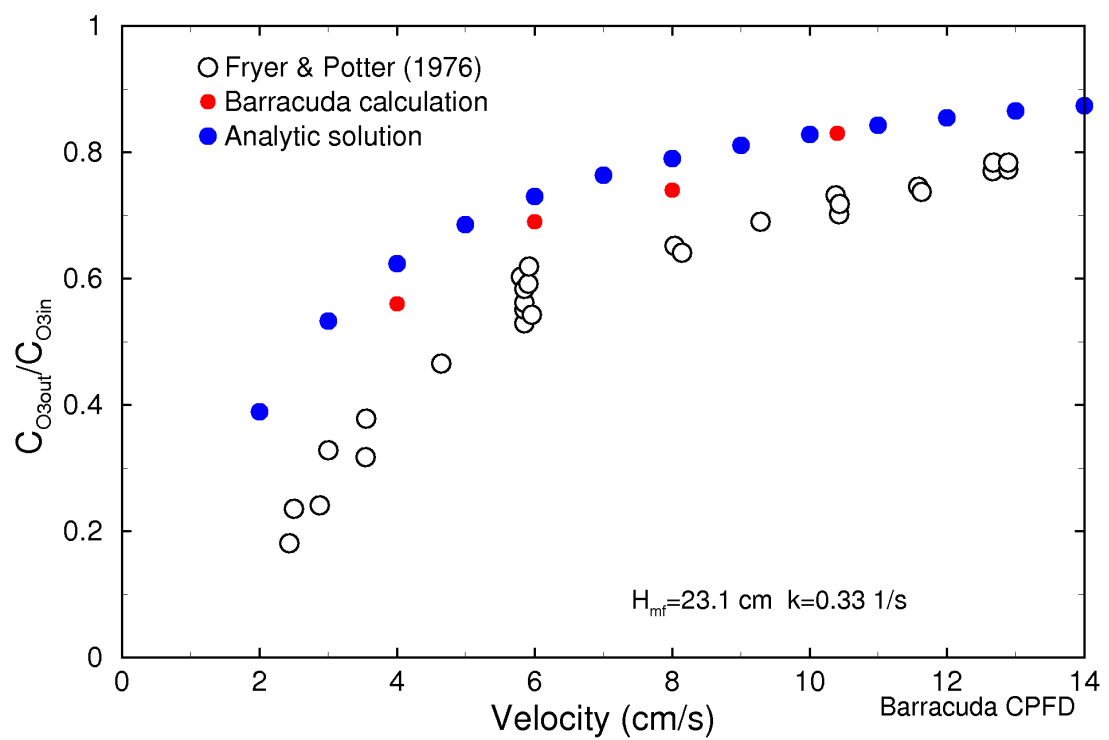

Figure 14. Measured and calculated $\mathrm{O}_{3}$ normalized mass fraction as function of inlet velocity. Static bed height is $23.1 \mathrm{~cm}$ and chemical rate constant $0.33 \mathrm{~s}^{-1}$. Analytic solution uses $k=0.33 \mathrm{~s}^{-1}, \rho_{f}=1.2 \mathrm{~kg} / \mathrm{m}^{3} \theta_{p}=0.45$, and $x=23.1 \mathrm{~cm}$. 


\section{Computer time}

The ozone decomposition in the closed cylinder was calculated in three-dimensions. However, the calculation did not require a fine grid or large number of solid particles for an accurate solution. The chemistry given by Eq.(2) was calculated by three methods and the computation times were compared. Eq. (2) was calculated by direct implicit solution, by direct explicit solution and and by using the Livermore National Laboratory CVODE library for solving sets of ordinary differential equations. The computation times for each are shown in Table 3. The timing of a process depends on the system processes running when a job is being timed, and times which vary within one second are, for practical purposes, the same time. The ozone has a moderately slow rate of decomposition and the chemistry solution is accurately calculated using the Barracuda ${ }^{\mathrm{TM}}$ explicit solver. For the first order, single chemistry equation, the direct implicit numerical solution and the explicit numerical solution have the same computation time (as expected).

Table 3. CPU time for $5 \mathrm{~s}$ physical time

\begin{tabular}{ll}
\hline Direct implicit numerical solution & $34.2 \mathrm{~s}$ \\
CVODE solution & $39.1 \mathrm{~s}$ \\
Explicit numerical solution & $34.4 \mathrm{~s}$ \\
\hline
\end{tabular}

\section{Concluding remarks}

The implicit solution of the ozone decomposition and explicit calculation of oxygen generation was calculated very well by Barracuda ${ }^{\mathrm{TM}}$. The ozone decomposition rate may be considered a simple reaction rate; however, the calculations included the three dimensional set of mass and momentum equations for gas phases, the three dimensional momentum and mass equations for the discrete particles, and solution of chemistry. The gas phase solution includes the implicit calculation of the transport equations of nitrogen, ozone and oxygen. The accuracy of the chemistry calculation is dependent on accurately calculating the "bubbles" in the bed. The bubbles transport gas with little contact with the catalyst and reduce the chemistry yield. From the good agreement for the cases chosen, it can be assumed that, if the measured rate coefficient is accurate, the bed dynamics were calculated well.

The two static bed solutions showed not only that the chemistry rate equation is accurately calculated, but that the coupled chemistry and solid-fluid physics equations are calculated well. The accurate prediction of pressure and density required proper solution of the fluid conservation equations for nitrogen, ozone and oxygen.

The Barracuda ${ }^{\mathrm{TM}}$ predicted ozone decomposition in the fluidized bed compared well to measured data. The fluidized bed calculation predicted the "usual" void structures or "bubbles"; however, there were instantaneous complex solids and gas flow patterns. All calculations were made in three dimensions and no parameters were tuned or adjusted to fit the experiment. 


\section{Reference}

Fryer, C. and Potter, O.E, "Experimental investigation of models for fluidized bed catalytic reactors," AIChE J., 22, 1976.

Hindermarsh, A. C., and Serban, R., User documentation for CVODE v2.5.0, Center for Applied Scientific Computing, Lawrence Livermore National Laboratory, UCRL-SM-208108, 2006.

\section{Appendix}

The drag model used in this study is shown below. There were no modifications in radius or parameters.

$$
\begin{gathered}
D_{p}=C_{d} \frac{3}{8} \frac{\rho_{g}}{\rho_{p}} \frac{\left|\boldsymbol{u}_{f}-\boldsymbol{u}_{p}\right|}{r}, \\
\operatorname{Re}<1000 \quad C_{d}=\frac{24}{\operatorname{Re}}\left(1+0.15 \operatorname{Re}^{0.687}\right) \theta_{f}^{-2.65} \\
\operatorname{Re} \geq 1000 \quad C_{d}=0.44 \theta_{f}^{-2.65} \\
\operatorname{Re}=\frac{2 \rho_{f}\left|\boldsymbol{u}_{f}-\boldsymbol{u}_{p}\right| r}{\mu_{f}},
\end{gathered}
$$

where $\boldsymbol{u}_{f}$ is fluid velocity, $\boldsymbol{u}_{p}$ is particle velocity, $\theta_{f}$ is fluid volume fraction, $\rho_{f}$ is fluid density, $\rho_{p}$ is particle density and $\mu_{f}$ is the gas viscosity and $r$ the particle radius. 

FLUIDIZED BEDS

Topical Report No. 2

Solid-Gas Chemistry

Dale Snider

CPFD Software LLC

October 2007

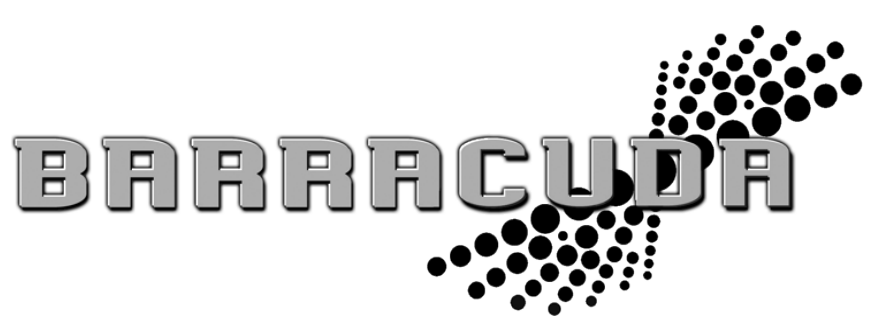

Performed as part of DOE Contract: DE-FC36-04G014153 


\title{
Solid-Gas Chemistry
}

\author{
Dale Snider \\ CPFD Software, LLC \\ October 2007
}

\section{Introduction}

Fluidized beds are used for non-catalytic reaction processes including chlorination, oxidation, roasting, calculations, combustion, incineration, heat treatment, coatings, and many others. However, understanding, control, and scale-up of these processes are limited by difficulties in measurement and modeling such dense multiphase flows. Millennium Inorganic Chemicals, Inc. (MIC) and ExxonMobil (EM) have formed a multidisciplinary team with CPFD Software, LLC (CPFD), and Sandia National Laboratories (SNL) to conduct a three-year research program to provide advanced methods of predicting solid-gas chemistry. The research and development of the math based models has been done by CPFD Software with industrial experience and experimental data provided from the industrial partners and National Laboratory.

This report gives the Barracuda ${ }^{\mathrm{TM}}$ test calculation of gas-solid chemistry. MIC produces 0.7 million tons/yr of $\mathrm{TiO}_{2}$ pigment. A large fraction of this pigment $(0.5$ million tons/yr $)$ is produced through the chloride process. Furthermore, roughly 3 million tons/yr of $\mathrm{TiO}_{2}$ are produced via the chloride process worldwide. The key feature of this process is the chlorination of ore (e.g., ilmenite, $\mathrm{FeTiO}_{3}$ ) in the presence of a reducing agent (coke) in a large fluidized bed. The main product of this process is titanium tetrachloride $\left(\mathrm{TiCl}_{4}\right)$, which is subsequently oxidized to pigmentary $\mathrm{TiO}_{2}$. $\mathrm{MIC}$ produces 1.2 million tons/yr of $\mathrm{TiCl}_{4}$. The byproducts of this process include the various metal chlorides and oxychlorides which arise from the impurities in the ore, sulfur dioxide, carbon dioxide, and carbon monoxide. Process improvements are needed to manage the production of these deleterious byproducts and improve overall process efficiency.

Substantial benefits in this unit operation, i.e., reduced energy use and lower emissions, can be achieved by the manipulation of concentrations and temperatures within the bed. This can be achieved only by understanding the chemistry occurring in the fluidized bed. Reaction chemistry is important because:

1) The chemical reactions provide the heat sources and sinks within the fluidized bed. The strength of these sources depends on the concentrations of the various species at that instant and contributes to the temperature gradients within the bed.

2) The chemical reactions cause a change in particle sizes (e.g., coke particles shrink in size), changing the particle size distribution in the bed and thereby causing the bed hydrodynamics to change.

3) The chemical reactions cause an undesirable buildup of inerts in the bed, thereby raising the bed height and pressure drop and modifying the local hydrodynamics, as well as contributing to "chlorine slip," all of which reduce efficiency.

4) Accurate quantification of the chemistry, and hence the process efficiency, is achievable only with accurate determination of particle size distributions (surface area) and coupled gas-particle dynamics, such as bubbling motion and blowover.

This paper presents calculation of $\mathrm{TiO}_{2}$ reduction to $\mathrm{TiCl}_{4}$. 


\section{Solid chemical test problem}

The solid chemistry test problem was supplied by S. Banerjee of Millennium Chemical Co. The reaction occurs in a thin rectangular fluidized bed which is $40 \mathrm{~cm}$ wide, $1.5 \mathrm{~cm}$ deep and $120 \mathrm{~cm}$ high. The bed initially contains $\mathrm{TiO}_{2}$ in a nitrogen gas. The inlet flow is $83.74 \%$ mole fraction Chlorine gas and $16.26 \%$ mole fraction carbon monoxide. The gas exits the top of the container at atmospheric pressure. The calculation parameters are given in Table 1.

Table 1. Calculation parameters.

\begin{tabular}{ll}
\hline Container size $(\mathrm{x}, \mathrm{y}, \mathrm{z})$ & $57 \times 1.5 \times 120 \mathrm{~cm}$ \\
Numerical cells $(\mathrm{x}, \mathrm{y}, \mathrm{z})$ & $40 \times 2 \times 80$ \\
Number numerical particles & 65,279 \\
Inlet gas & $0.21 \mathrm{~m} / \mathrm{s}$ \\
$\quad$ Pressure & $103 \mathrm{kPa}$ \\
$\quad$ Temperature & $1273 \mathrm{~K}$ \\
$\quad$ Gas species & 0.8374 mole fraction $\mathrm{CL}_{2}$ \\
& 0.1626 mole fraction $\mathrm{CO}$ \\
Outlet pressure & $103 \mathrm{kPa}$ \\
Initial condition & \\
$\quad$ Bed height & $51 \mathrm{~cm}$ \\
$\quad$ Gas species & $\mathrm{N}_{2}$ \\
$\quad$ Premperature & $1273 \mathrm{~K}$ (solids and gas) \\
Close pack & $103 \mathrm{kPa}$ \\
Solid density $\left(\mathrm{TiO}_{2}\right)$ & 0.61 \\
Solid radius & $4250 \mathrm{~kg} / \mathrm{m}^{3}$ \\
\hline
\end{tabular}

\section{Chemical reaction}

The simple solid reaction equation for $\mathrm{TiO} 2$ is

$$
\mathrm{TiO}_{2}+2 \mathrm{CO}+2 \mathrm{Cl}_{2} \rightarrow \mathrm{TiCl}_{4}+2 \mathrm{CO}_{2}
$$

The particle chemistry reaction rate is described by the rate equation

$$
\frac{d M_{\mathrm{TiO}_{2}(s)}}{d t}=-k\left[\mathrm{Cl}_{2}(\mathrm{~g})\right]_{p}^{m_{1}}[\mathrm{CO}(\mathrm{g})]_{p}^{m_{2}}
$$

where the [] denotes mole concentration and $\mathrm{M}$ is the solid mass (not mass concentration). The subscript $p$ specifies the gas phase mole concentration at a particle location. The reaction coefficient is

$$
k=c_{0} T_{\text {gas }}^{n_{1}} \rho_{p} d_{p}^{n_{2}} e^{-E / T}
$$

where $T_{\text {gas }}$ is the local gas temperature, $d_{p}$ is the solid diameter, $E$ is the activation energy, and $\rho_{p}$ is the solid density. The constants are given in Table 2. 
Table 2. Rate equation constants

\begin{tabular}{cc}
\hline $\mathrm{C}_{0}$ & $1.15470 \mathrm{e}-02$ \\
$\mathrm{E}$ & $2.10460 \mathrm{e}+04$ \\
$\mathrm{n}_{1}$ & $1.29000 \mathrm{e}+00$ \\
$\mathrm{n}_{2}$ & 2 \\
\hline
\end{tabular}

The total gas rate for reactants and products for a computation cell $\xi$ is

$$
\begin{gathered}
\frac{d\left[C l_{2}(g)\right]_{\xi}}{d t}=2 \frac{1}{\Omega_{\xi} M w_{T_{i O} 2}} \sum_{p}^{n_{p}} S_{p, \xi} N_{p} \frac{d M_{\mathrm{TiO}_{2}(s), p}}{d t} \\
\frac{d[C O(g)]_{\xi}}{d t}=2 \frac{1}{\Omega_{\xi} M w_{T i O_{2}}} \sum_{p}^{n_{p}} S_{p, \xi} N_{p} \frac{d M_{\mathrm{TiO}_{2}(s), p}}{d t} \\
\frac{d\left[C \mathrm{O}_{2}(g)\right]_{\xi}}{d t}=-2 \frac{1}{\Omega_{\xi} M w_{T i O_{2}}} \sum_{p}^{n_{p}} S_{p, \xi} N_{p} \frac{d M_{T i O_{2}(s), p}}{d t} \\
\frac{d\left[\mathrm{TiCl}_{4}(g)\right]_{\xi}}{d t}=-\frac{1}{\Omega_{\xi} M w_{T i O_{2}}} \sum_{p}^{n_{p}} S_{p, \xi} N_{p} \frac{d M_{\mathrm{TiO}_{2}(s), p}}{d t}
\end{gathered}
$$

where $S$ is the interpolation operator, $N_{p}$ is the number of solids in a numerical particle, $M w$ is the molecular weight, and $n_{p}$ is the number of numerical particles.

\section{Graphical user input}

The solid-chemistry is described in a general form through a graphical user interface (GUI). The GUI for the solid-chemistry is shown in Fig. 1.

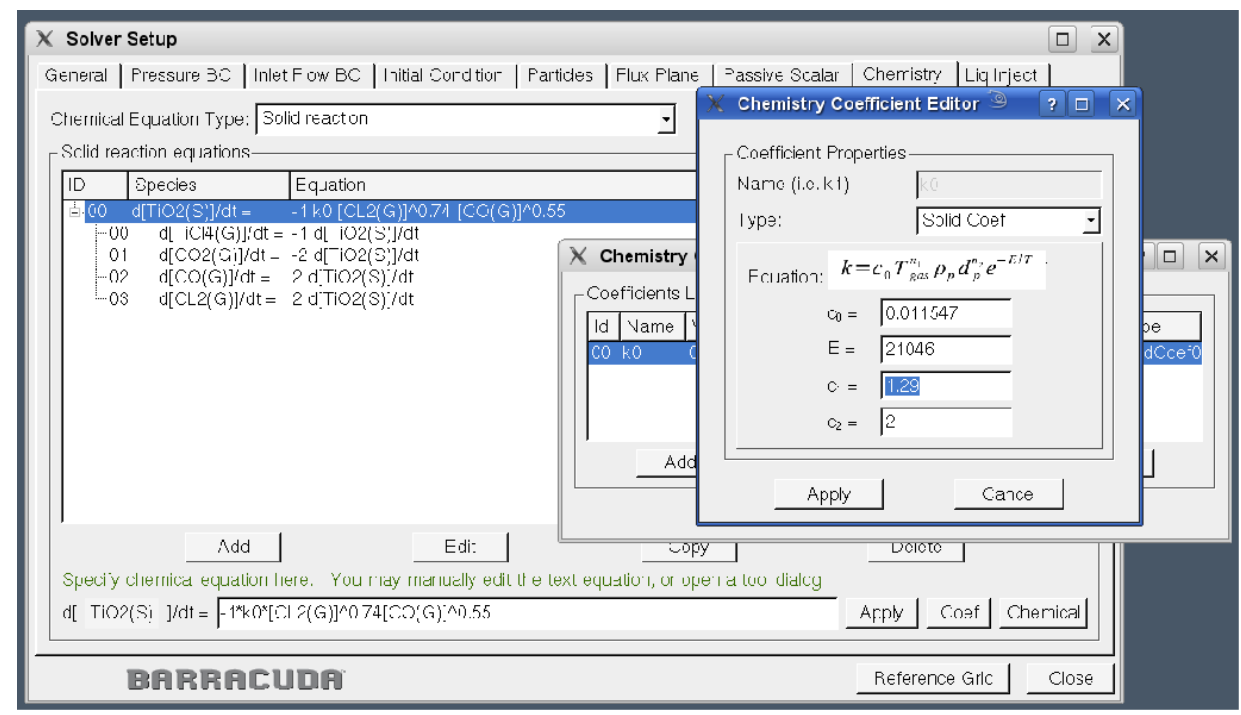

Figure 1. Graphical user interface for the solid-chemistry.

\section{Results}

The inlet gas, which is composed of chlorine and carbon monoxide, gives a bubbling fluidized bed. Figure 6 shows a snap-shot of the bed at $20 \mathrm{~s}$. For the given problem, the production of $\mathrm{TiCl}_{4}$ is limited by the $\mathrm{CO}$ feed. From Eq. (1), for each mole of $\mathrm{CO}$ supplied, $1 / 2$ mole of $\mathrm{TiCl}_{4}$ is produced. 
Because the $\mathrm{CO}$ is completely consumed in the bed, the mass and mole fractions at the vessel exit can be calculated. It is assumed that the problem has run long enough to clear-out the initial $\mathrm{N}_{2}$. The mole concentration for material $i$ is

$$
\left[X_{i}\right]=\frac{Y_{i}}{M_{i}} \rho
$$

where $Y_{i}$ is the mass fraction and $M_{i}$ is the molecular weight. The inlet mass flow rate of $C O$ is

$$
\dot{m}_{C O}=Y_{C O} \dot{m}
$$

The amount of product which can be produced for each material is

$$
\dot{m}_{i}=\frac{Y_{C O}}{M_{C O}} \dot{m} a_{i} M_{i}
$$

where $a_{i}$ is the coefficient in the chemical equation relative to CO. Because of mass production from solid chemistry, the mass flow rate increases at the top of the bed. Note that the chemical product $\left(\mathrm{TiCl}_{4}\right.$ and $\mathrm{CO}$ ) contains mass from the solid chemistry. The mass flow rates at the exit are

$$
\begin{gathered}
\dot{m}_{T_{i C l_{4}}}=\frac{0.07124}{28}(0.5) 189.8 \dot{m}=0.241 \dot{m} \\
\dot{m}_{C O_{2}}=0.112 \dot{m} \\
\dot{m}_{C L_{2}}=(0.929-0.1804) \dot{m}=0.748 \dot{m}
\end{gathered}
$$

At the exit the mass flow rate increases from solid chemistry and is

$$
\dot{m}_{\text {exit }}=1.101 \dot{m}
$$

The mass fraction at the exit is

$$
Y_{i}=\frac{\dot{m}_{i, e x i t}}{\dot{m}_{\text {exit }}}
$$

and the mass fractions at the exit are

\begin{tabular}{ll}
\hline $\mathrm{Y}_{\mathrm{TiCl} 4}$ & 0.22 \\
$\mathrm{Y}_{\mathrm{Cl} 2}$ & 0.68 \\
$\mathrm{Y}_{\mathrm{CO} 2}$ & 0.10 \\
$\mathrm{Y}_{\mathrm{CO}}$ & 0.00 \\
\hline
\end{tabular}

which compare well to the Barracuda calculations shown in Figs. 5 and 6.

The temperature rise in the system is difficult to analytically calculate because of the large thermal mass of solids. Over a calculation time of minutes, the bed temperature rises only moderately because of the solid temperature-inertia. If the heat transfer between gas and solids is set to zero and there is no inlet flow, the adiabatic temperature increase of a static bed can be estimated. The problem with the calculation of temperature for a static bed is that the bed is not static. The gas expansion from the reaction causes flow of gas and energy out of the bed, and the bed fluidizes. The calculated adiabatic gas temperature is $3404 \mathrm{~K}$, and from Fig. 3 the bed temperature reaches $2800 \mathrm{~K}$. Figure 3 shows the bed expansion from gas reaction. Unrealistic restrictions to force a static system could be applied; however, additional analysis beyond the given example is not warranted. 


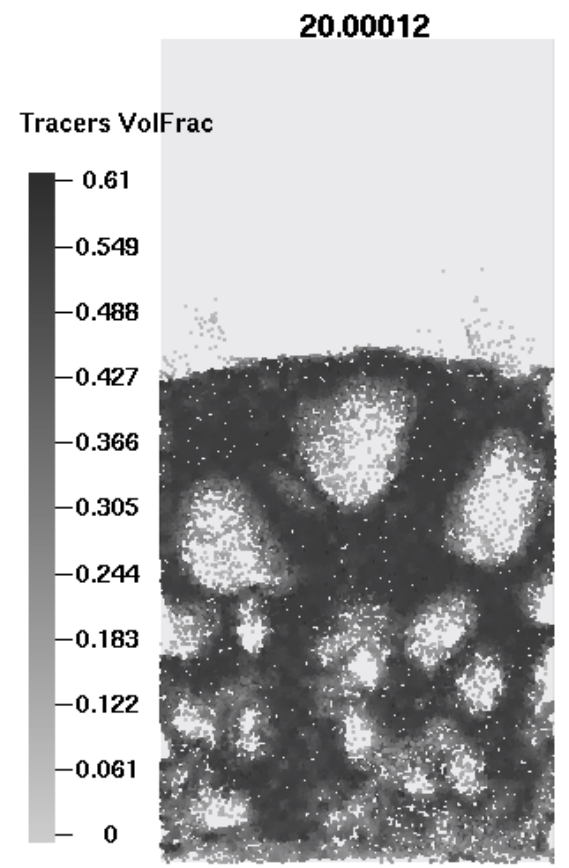

Figure 2 Fluidized bed at 20 s showing solid volume fraction.
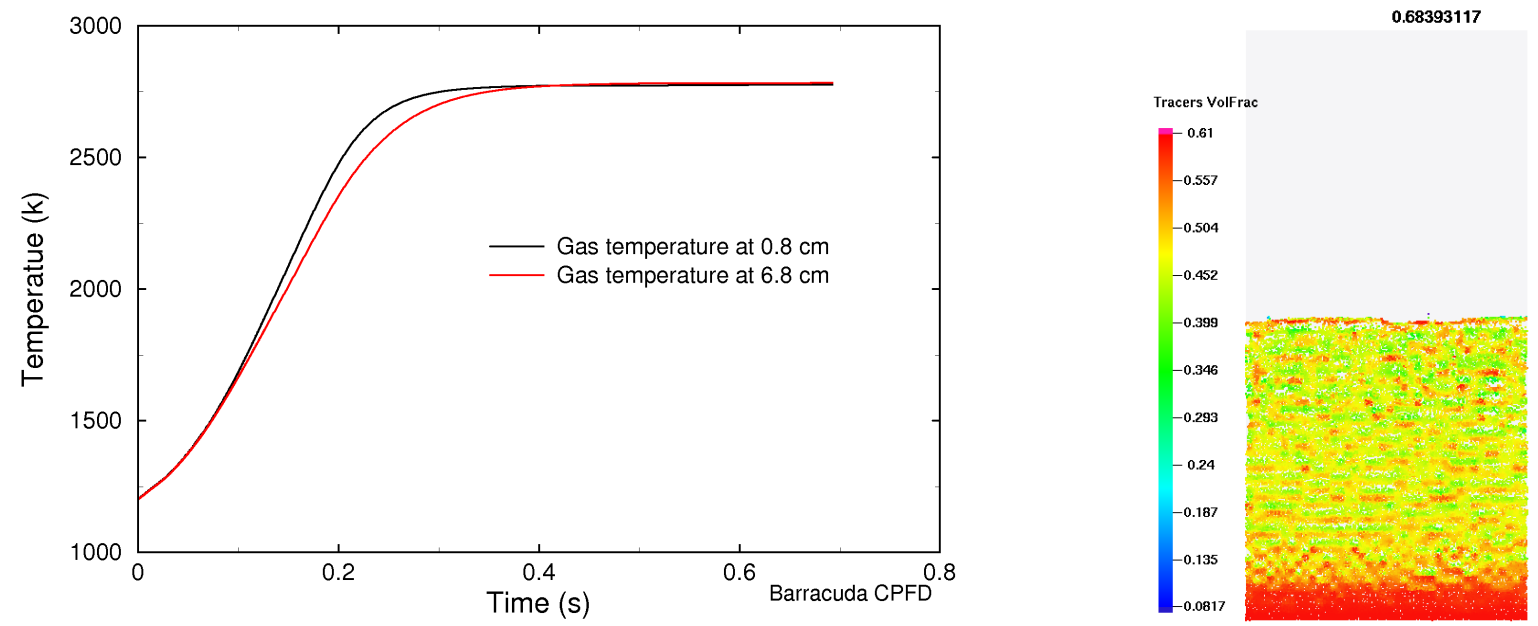

Figure 3. Bed temperature with no inlet flow and no gas-to-solid heat transfer.

Figure 4 shows the $\mathrm{TiCl}_{4}$ production along with other bed parameters at $20 \mathrm{~s}$. The reaction is exothermic; however, the bed temperature remains relatively constant. The near constant bed temperature results from 1) the reaction rate is limited by the $\mathrm{CO}$ feed rate (see Fig. 4c) and the reaction terminates in the bottom of the bed, 2) the large solid thermal mass tends to maintain a uniform temperature, and 3) the inlet gas is fed at the same temperature as the initial bed temperature. Figure 4 shows the solid $\mathrm{TiO}_{2}$ slightly decreases in size over the $20 \mathrm{~s}$ calculation period. 


\section{Inlet material fractions}

\begin{tabular}{ccc}
\hline Material & Mole fraction & Mass fraction \\
\hline $\mathrm{Cl}_{2}$ & 0.8374 & 0.9288 \\
$\mathrm{CO}$ & 0.1626 & 0.0712 \\
$\mathrm{CO} 2$ & 0 & 0 \\
$\mathrm{TiCl}_{4}$ & 0 & 0 \\
$\mathrm{~N}_{2}$ & 0 & 0 \\
\hline
\end{tabular}

\begin{tabular}{cc}
\multicolumn{2}{c}{ Exit material fractions } \\
\hline Material & Mass fraction \\
\hline $\mathrm{Cl}_{2}$ & 0.680 \\
$\mathrm{CO}$ & 0 \\
$\mathrm{CO} 2$ & 0.101 \\
$\mathrm{TiCl}_{4}$ & 0.220 \\
$\mathrm{~N}_{2}$ & 0 \\
\hline
\end{tabular}

Figure 5 shows the transient mass fraction of $\mathrm{TiCl}_{4}$ at the bottom of the bed and top of the vessel, and Fig. 6 shows the transient mass fraction of $\mathrm{Cl}_{2}$ and $\mathrm{CO}$ at the bottom of the bed and top of the vessel. After $10 \mathrm{~s}$ the process becomes steady with no appreciable bulk change in the gas species. Figure 7 shows the mass concentration of $\mathrm{TiCl}_{4}, \mathrm{Cl}_{2}$ and $\mathrm{CO}$ axially in the vessel. The $\mathrm{CO}$ feed is low and the $\mathrm{CO}$ is quickly consumed at the bottom of the vessel. After consumption of $\mathrm{CO}$, the reaction quits.

The reaction consumes $\mathrm{TiO}_{2}$, and Fig. 4d shows the $\mathrm{TiO}_{2}$ solid radius at $20 \mathrm{~s}$. All solids begin with a $64 \mu \mathrm{m}$ radius and the size decreases during the reaction. For the short calculation period of $20 \mathrm{~s}$, there is not significant reduction of $\mathrm{TiO}_{2}$ to be reflected in the figure's legend. The approximate loss in solid diameter is $1.44\left(10^{-5}\right) \mu \mathrm{m}$. 


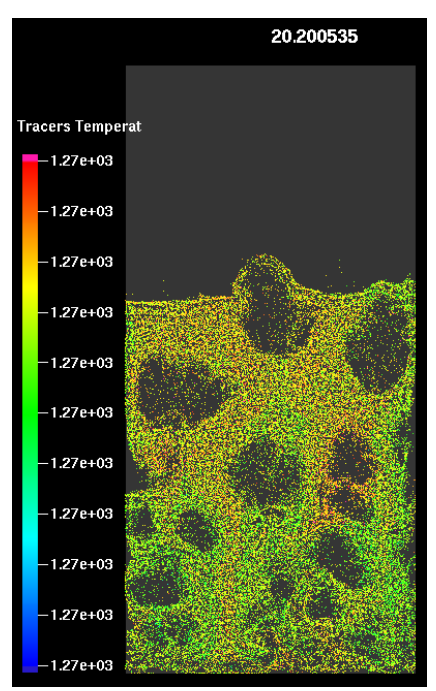

a

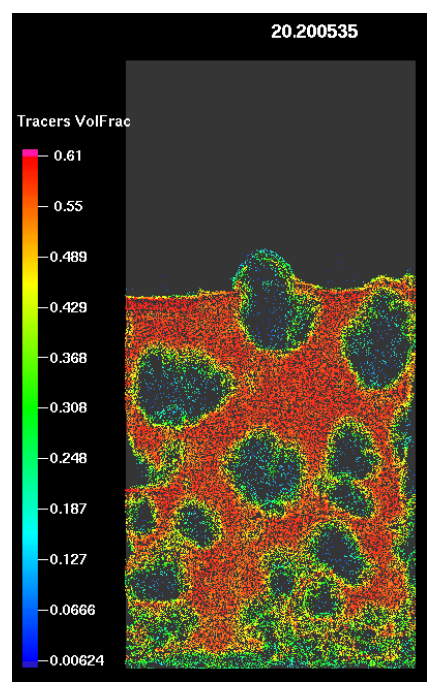

e

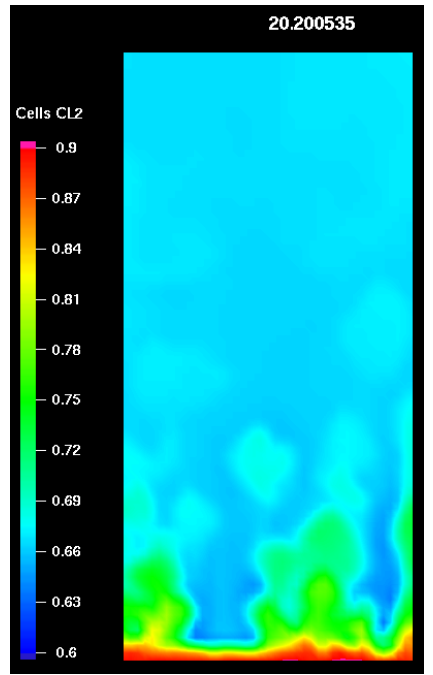

b

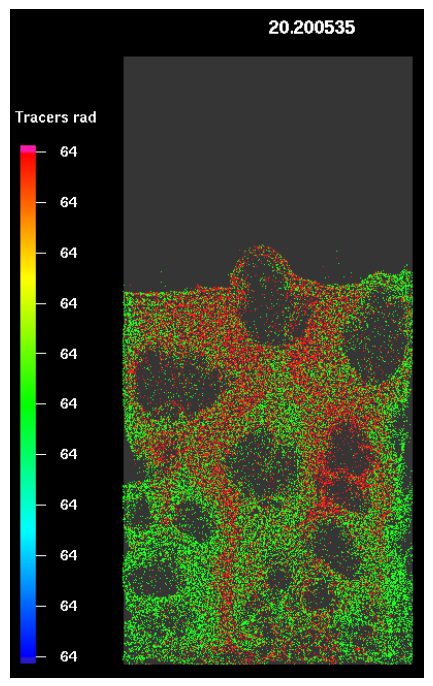

$\mathrm{f}$

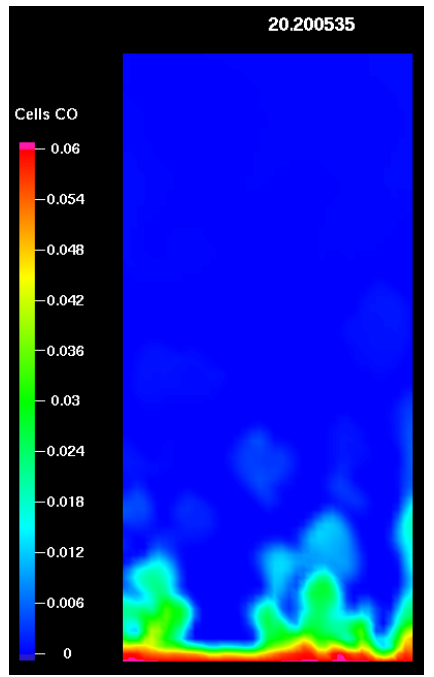

c

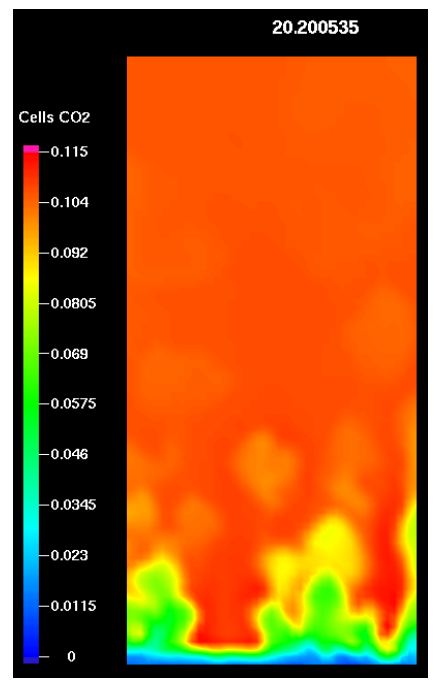

g

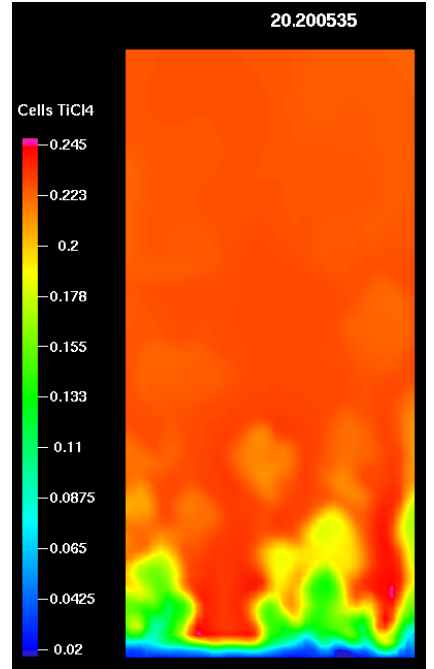

d

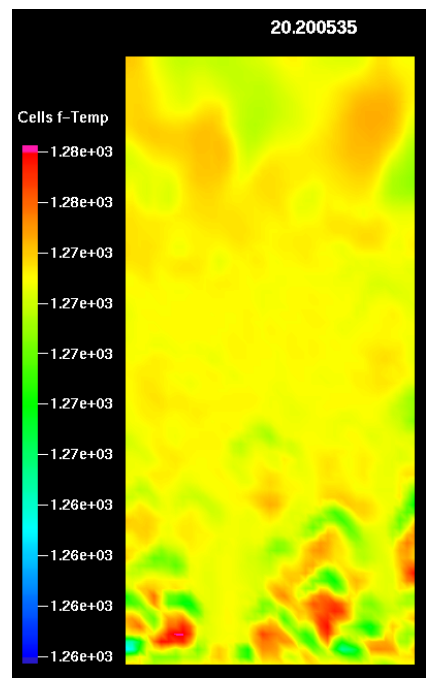

h

Figure 4. Fluidized bed at 20 s. a) solid colored by temperature, b) Cl2 mass fraction, c) CO mass fraction, d) TiCl4 mass fraction, e) solids colored by volume fraction, f) solids colored by size, g) CO2 mass fraction, and $h$ ) fluid temperature and a) solid temperature. 


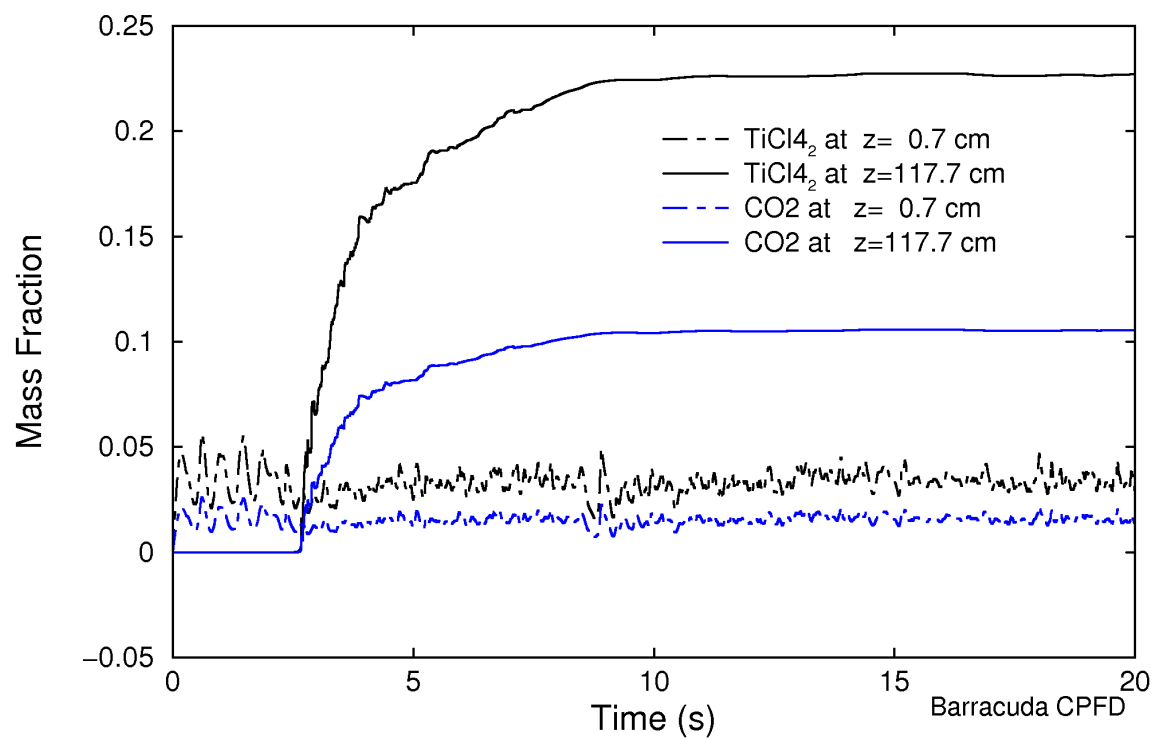

Figure 5. Transient products $\mathrm{TiCl}_{4}$ and $\mathrm{CO}_{2}$ at the bottom of the bed and top of the vessel.

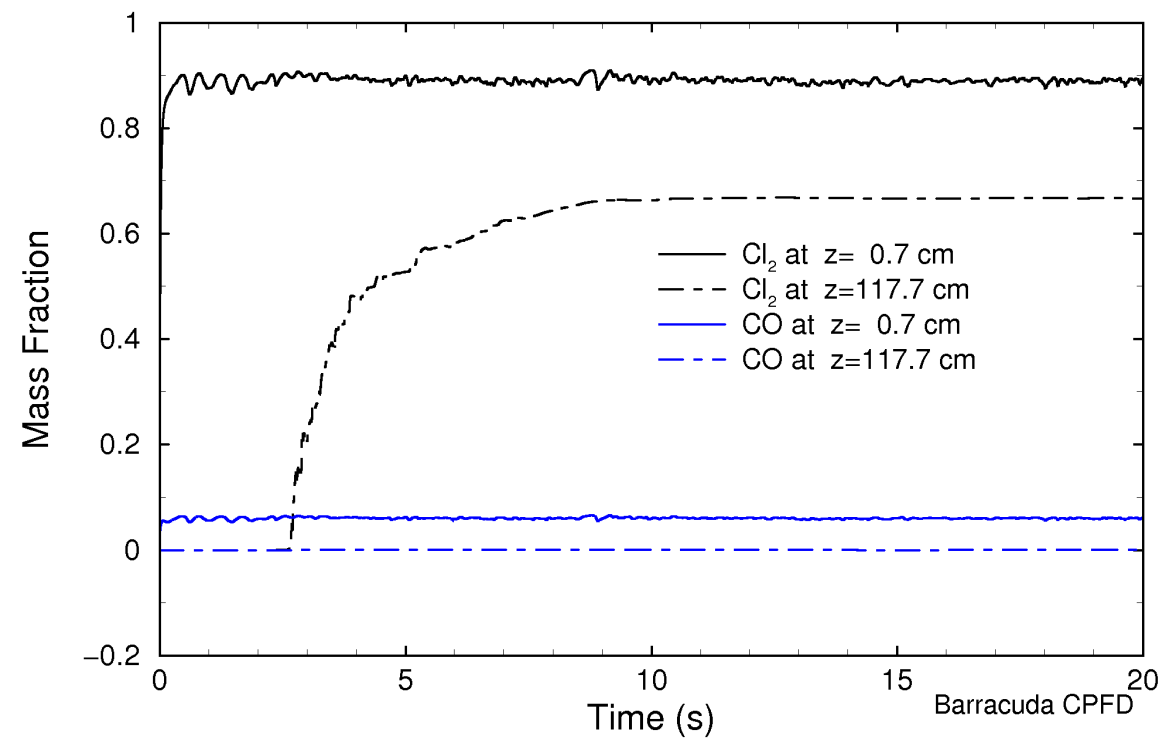

Figure 6. Transient reactants $\mathrm{Cl}_{2}$ and $\mathrm{CO}$ at the bottom of the bed and top of the vessel. 


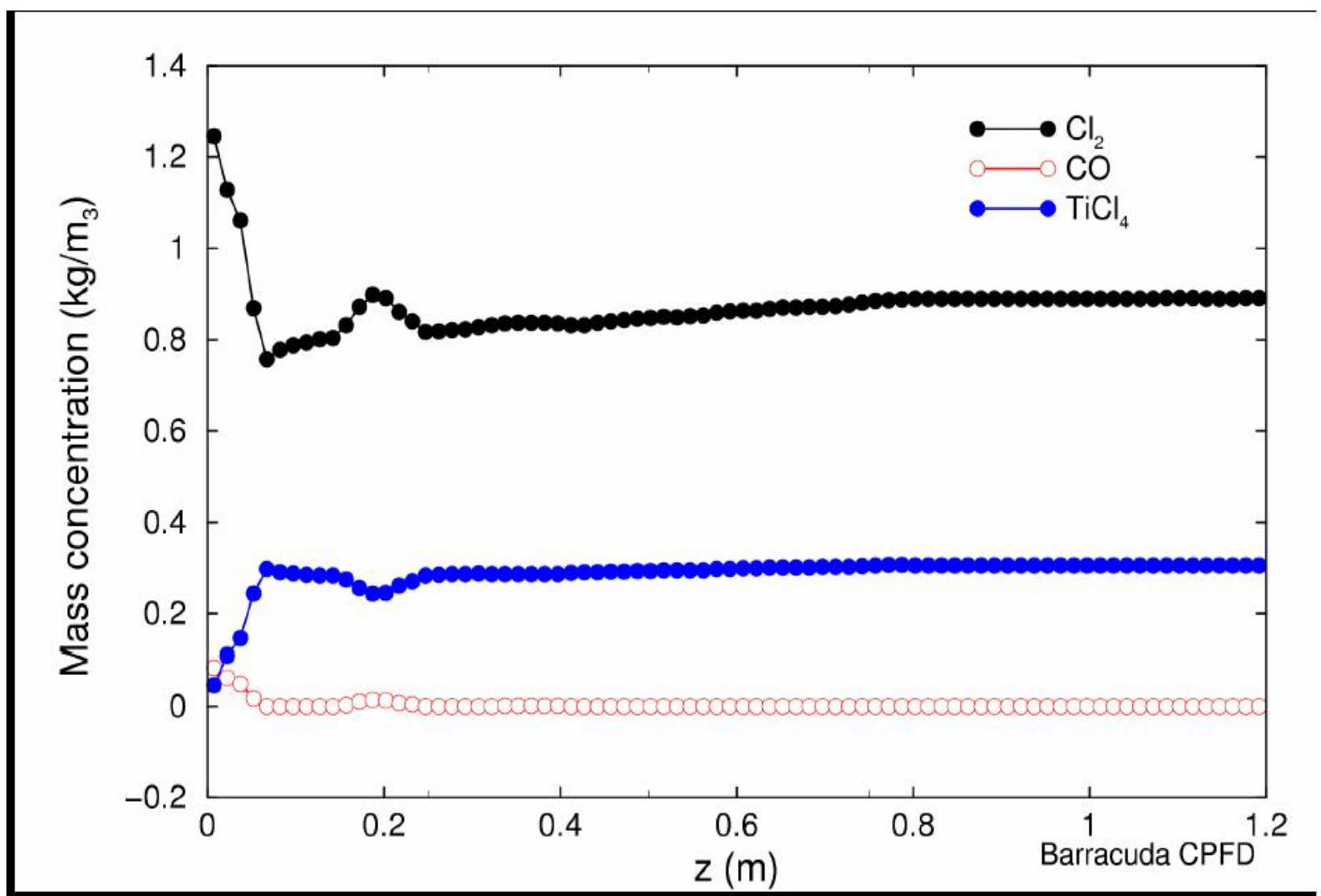

Figure 7. Gas species vertically in the vessel. Points are taken along the vessel center-line.

\section{Concluding remarks}

The Barracuda calculation predicts the solid chemistry production of $\mathrm{TiCl}_{4}$ from $\mathrm{TiO}_{2}$ solid. For the given conditions, the production of $\mathrm{TiCl}_{4}$ is limited by the fraction of $\mathrm{CO}$ feed. The reaction terminates in the bottom of the bed when all the $\mathrm{CO}$ is consumed. There is a high $\mathrm{Cl}_{2}$ excess flowing out the top of the vessel. The reaction is exothermic, but because of the quick consumption of $\mathrm{CO}$, a large thermal mass of solids, and the gas feed temperature being the same as the initial bed temperature, the bed temperature remains relatively constant at the initial solids temperature. 


\section{Appendix}

\section{Material properties}

The enthalpy contains sensible energy and chemical energy

$$
h=\int_{T_{r e f}}^{T} C_{p} d T+\Delta h_{f}=f(T)+h_{o}
$$

where

$$
h_{o}=-f\left(T_{r e f}\right)+\Delta h_{f}
$$

The material molecular weights are given in Table 2. The enthalpy for gas and solids is shown in Table 3 . Tables 4 and 5 give viscosity and thermal conductivity, respectively.

Table 2. Molecular weight.

\begin{tabular}{lc}
\hline & $\begin{array}{c}\text { Molecular } \\
\text { Weight }\end{array}$ \\
\hline $\mathrm{Cl}_{2}$ & 70.9 \\
$\mathrm{CO}$ & 28.0 \\
$\mathrm{TiO}_{2}$ & 80 \\
$\mathrm{CO}_{2}$ & 44 \\
$\mathrm{TiCl}_{4}$ & 189.8 \\
\hline
\end{tabular}

Table 3 Enthalpy

\begin{tabular}{lllllllll}
\multicolumn{7}{c}{$\mathrm{h}=\mathrm{a}_{0}+\mathrm{a}_{1} \mathrm{~T}+\mathrm{a}_{2} \mathrm{~T}^{2}+\mathrm{a}_{3} \mathrm{~T}^{3}+\mathrm{a}_{4} \mathrm{~T}^{4}+\mathrm{h}_{\mathrm{o}}(\mathrm{J} / \mathrm{kg})$} \\
\hline & State & $\mathrm{a}_{0}$ & $\mathrm{a}_{1}$ & $\mathrm{a}_{2}$ & $\mathrm{a}_{3}$ & $\mathrm{a}_{4}$ & $\mathrm{~h}_{\mathrm{o}}$ & $\Delta \mathrm{h}_{\mathrm{f}}$ \\
\hline $\mathrm{Cl}_{2}$ & $\mathrm{~g}$ & 563.7 & 0 & 0 & 0 & 0 & $-1.680\left(10^{5}\right)$ & 0 \\
$\mathrm{CO}$ & $\mathrm{g}$ & 1303.9 & 0 & 0 & 0 & 0 & $-4.335\left(10^{6}\right)$ & $-3.946\left(10^{6}\right)$ \\
$\mathrm{CO}_{2}$ & $\mathrm{~g}$ & 1401.2 & 0 & 0 & 0 & 0 & $-9.360\left(10^{6}\right)$ & $-8.942\left(10^{6}\right)$ \\
$\mathrm{TiCl}_{4}$ & $\mathrm{~g}$ & 570 & 0 & 0 & 0 & 0 & $-4.194\left(10^{6}\right)$ & $-4.024\left(10^{6}\right)$ \\
$\mathrm{N}_{2}$ & & 1310.3 & 0 & 0 & 0 & 0 & $-3.905\left(10^{5}\right)$ & 0 \\
$\mathrm{TiO}_{2}$ & $\mathrm{~s}$ & 711 & 0 & 0 & 0 & 0 & $-1.201\left(10^{7}\right)$ & $-1.18\left(10^{7}\right)$ \\
\hline
\end{tabular}

Table 4 Viscosity

$\mu=a_{0}+a_{1} T+a_{2} T^{2}+a_{3} T^{3}$

\begin{tabular}{lllll}
\hline & \multicolumn{5}{c}{$\mathrm{a}_{0}$} & $\mathrm{a}_{1}$ & $\mathrm{a}_{2}$ & $\mathrm{a}_{3}$ \\
\hline $\mathrm{Cl}_{2}$ & $-3.571\left(10^{-6}\right)$ & $4.870\left(10^{-8}\right)$ & $-8.530\left(10^{12}\right)$ & 0 \\
$\mathrm{CO}$ & $2.381\left(10^{-6}\right)$ & $5.394\left(10^{-8}\right)$ & $-1.541\left(10^{11}\right)$ & 0 \\
$\mathrm{CO}_{2}$ & $1.1811\left(10^{-6}\right)$ & $4.984\left(10^{-8}\right)$ & $-1.085\left(10^{11}\right)$ & 0 \\
$\mathrm{TiCl}_{4}$ & $-1.74\left(10^{-6}\right)$ & $3.86\left(10^{-8}\right)$ & $-5.930\left(10^{12}\right)$ & 0 \\
$\mathrm{~N}_{2}$ & $4.261\left(10^{-6}\right)$ & $4.753\left(10^{-8}\right)$ & $-9.883\left(10^{12}\right)$ & 0 \\
\hline
\end{tabular}


Table 5 Thermal conductivity

\begin{tabular}{lllll}
\multicolumn{5}{c}{$\mathrm{k}_{\mathrm{t}}=\mathrm{a}_{0}+\mathrm{a}_{1} \mathrm{~T}+\mathrm{a}_{2} \mathrm{~T}^{2}+\mathrm{a}_{3} \mathrm{~T}^{3}(\mathrm{~J} / \mathrm{s}-\mathrm{m}-\mathrm{K})$} \\
\hline & $\mathrm{a}_{0}$ & $\mathrm{a}_{1}$ & $\mathrm{a}_{2}$ & $\mathrm{a}_{3}$ \\
\hline $\mathrm{Cl}$ & $-1.940\left(10^{-3}\right)$ & $3.830\left(10^{-5}\right)$ & $-6.352\left(10^{-9}\right)$ & 0 \\
$\mathrm{CO}$ & $-1.580\left(10^{-3}\right)$ & $8.251\left(10^{-5}\right)$ & $-1.981\left(10^{-8}\right)$ & 0 \\
$\mathrm{CO}_{2}$ & $-1.200\left(10^{-2}\right)$ & $1.021\left(10^{-4}\right)$ & $-2.240\left(10^{-8}\right)$ & 0 \\
$\mathrm{TiCl}_{4}$ & $-2.31\left(10^{-3}\right)$ & $2.633\left(10^{-5}\right)$ & $-2.685\left(10^{-10}\right)$ & 0 \\
$\mathrm{~N}_{2}$ & $3.090\left(10^{-3}\right)$ & $7.593\left(10^{-5}\right)$ & $-1.101\left(10^{-8}\right)$ & \\
$\mathrm{TiO}_{2}$ & 1 & 0 & 0 & \\
\hline
\end{tabular}




\section{ENHANCED PRODUCTIVITY OF CHEMICAL PROCESSES USING DENSE}

FLUIDIZED BEDS

\section{Topical Report No. 3}

A Model for Collisional Exchange in Gas/Liquid/Solid Fluidized beds

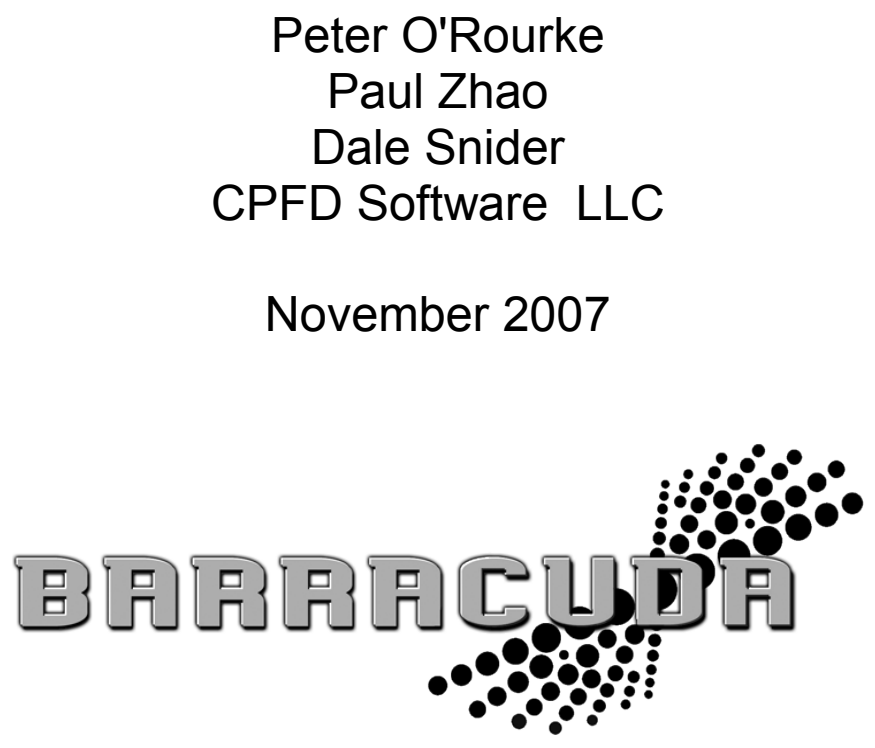

Performed as part of DOE Contract: DE-FC36-04G014153 


\title{
A Model for Collisional Exchange in Gas/Liquid/Solid Fluidized Beds
}

\author{
Peter O'Rourke \\ Paul Zhao \\ Dale Snider \\ CPFD Software, LLC \\ November 2007
}

\section{Introduction}

We have developed a unified model for collisional exchange of mass, momentum, and energy between particles in gas/liquid/solid fluidized beds. In such a fluidized bed, collisions between liquid spray droplets and bed particles, and between the wet bed particles themselves, are the mechanisms whereby the liquid spreads over the particles' surfaces. In addition to spreading the liquid over the particles' surfaces, collisional mass transfer results in mixing of liquid residing on different particles and to a tendency toward local uniformity of liquid chemical composition and liquid temperature on different particles. Collisional momentum transfer results in the damping of relative motion between particles, which, in turn, reduces the collision frequency.

\section{Model for collisional exchange in gas/liquid/solid fluidized beds}

The new model extends equations in the Multiphase Particle-in-Cell (MP-PIC) method [1-3] by including collision terms on the right-hand side of the transport equation for the single-particle distribution function for the bed particles. The form of the collision terms is the same as in the so-called BGK model for collisions in the Boltzmann equation of gas dynamics [4]. In the BGK model, the effect of collisions is represented by a simple relaxation term on the right-hand side of the Boltzmann equation that is the difference between the current value of the molecular distribution function and the equilibrium Boltzmann velocity distribution, divided by a molecular collision time. The situation in gas/liquid/solid fluidized beds is more complicated than in gas dynamics because, in addition to collisions causing particle velocities to relax to an equilibrium value, particle collisions result in equilibration of liquid film masses, chemical compositions, and film temperatures. To represent this situation, we assume that there are two BGK-like terms on the right-hand side of the particle distribution function, with different equilibrium distributions and different collisional time scales. One time scale is associated with achieving particle velocity equilibrium alone, and the other time scale is associated with achieving full equilibration of film masses, velocities, compositions, and temperatures.

Numerical integration of the collision terms is performed within the framework of the computational method in the Barracuda software. The continuous distribution function of particle properties is numerically approximated by a discrete distribution of Lagrangian computational parcels, each of which represents a number of physical particles with identical properties. In this work, we take the properties of physical particles to be their location, solid mass, the masses of the chemical species in their liquid film, particle velocity, solid temperature, and liquid film temperature. We assume that the temperature and chemical composition within each particle's film is uniform, but that the film temperature can differ from the solid particle temperature. The numerical calculation of collision effects is done on a cell-by-cell basis and is split from the calculation of other particle property changes. We determine the new parcel properties by using an implicit approximation to the BGK-like 
terms to obtain a provisional discrete distribution in which parcel numbers are increased. Because of computer memory limitations, we "numerically" agglomerate parcels in the provisional distribution into the new parcels in such a way that parcel numbers are conserved. Particle mass, momentum, and energy are also numerically conserved in the collision calculation.

Comparisons have been made of calculations using the new collision model with the experiments of Ariyapadi, et al [5]. The experiments measured liquid jet penetration into gas/solid fluidized beds using an x-ray imaging technique. The calculations reproduce trends in jet penetration when jet velocity and fluidization velocity are varied, but penetrations are somewhat over-predicted by the model.

A detailed paper documenting the new collision model and the experimental comparisons is being prepared for journal publication [6].

\section{Numerical implementation}

Liquid injection into a gas-solid fluidized bed is modeled by representing the injected liquid as spray droplets. The droplets motion is described by the same forces as those on solid particles. The liquid drops interact with solids through collisions and transfer liquid mass energy and momentum. Further, solids coated with the liquid collide with other solids and transfer liquid mass energy and momentum between solids. Liquid drops lose mass as they collide with solids and eventually a liquid drop disappears.

The Barracuda CPFD collisional model uses a unified representation for all particles in the bed, including liquid droplets, dry solids and wet solids. In this model, a liquid drop consists of a very small solid core $\left(10^{-10} \mathrm{~m}\right.$ radius) with liquid surrounding the solid core. The small solid core is sufficiently small as to have no effect on the behavior of the droplet. For a regular solid particle, the liquid is a film on the solid. The liquid may contain an arbitrary number of liquid species.

There may be an arbitrary number of liquid jets, and for each jet the boundary conditions include the jet nozzle location, injection direction, jet expansion angles, liquid droplet size distribution, liquid species and their mass fractions in the jet, total liquid mass flow rate, jet speed and temperature. The jet nozzle exit can be located anywhere in the computational domain. The liquid film can vaporize or chemically react producing gas species. Figure 1 shows the Barracuda GUI for liquid injection. 


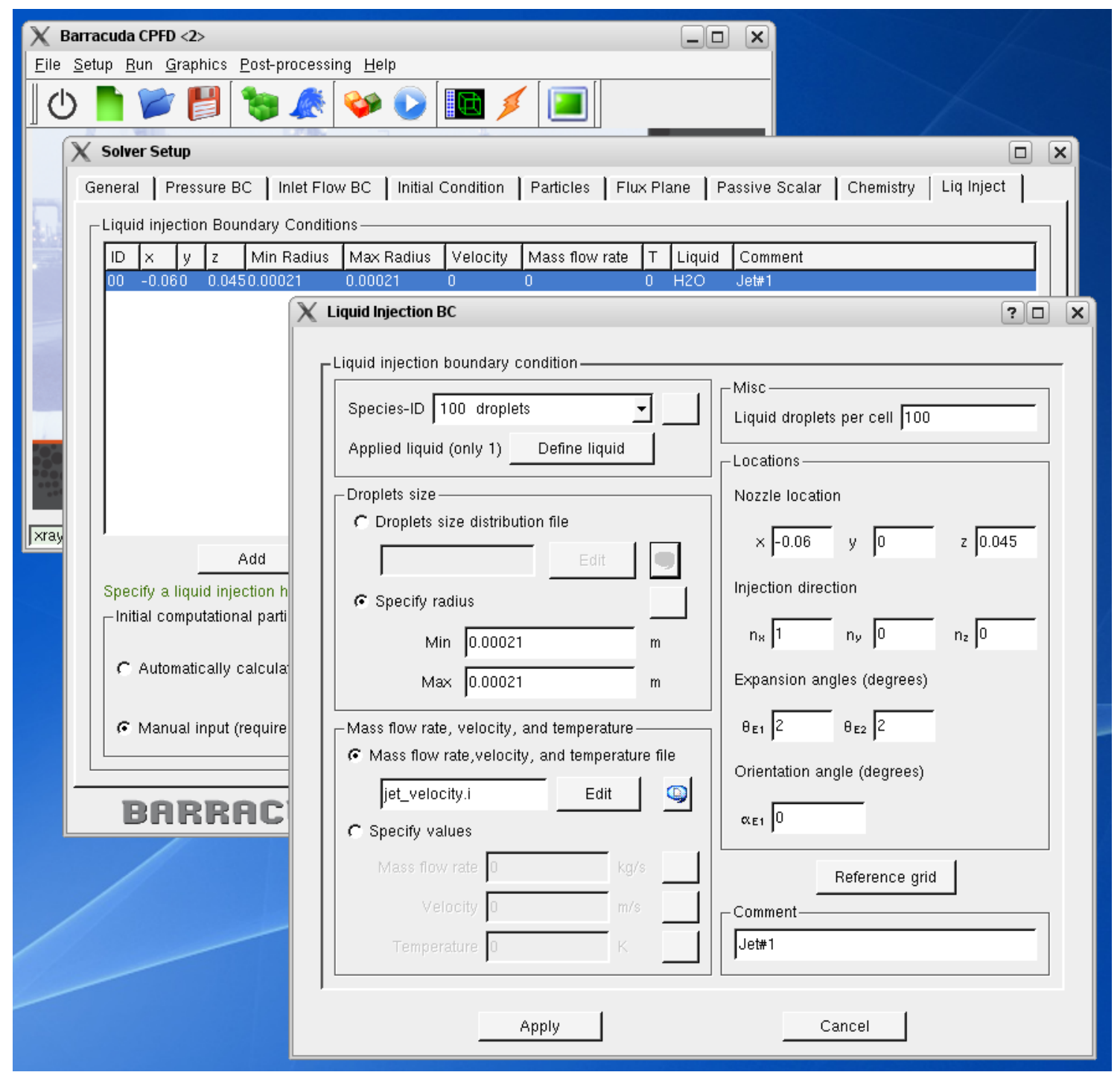

Figure 1. Barracuda GUI for liquid injection boundary conditions input. 


\section{Test problem}

The test problem is the liquid injection experiment reported by Ariyapadi et al [5] who used a non-intrusive X-ray imaging technique to visualize the horizontal injection of ethanol into a gas-solid fluidized bed. By examining the x-ray images of the fluidized bed, they obtained jet penetration lengths under varied injection conditions. X-ray movies were acquired to show the transient jet movement and the interaction between the liquid jet and the fluidized bed.

The experiment was carried out in a fluidized bed with a cross section of $20 \mathrm{~cm}$ by $20 \mathrm{~cm}$ and a height of $100 \mathrm{~cm}$. The solid particles were standard fluid catalytic cracking (FCC) catalyst with a Sauter mean diameter of $70 \mu \mathrm{m}$ and a minimum fluidization velocity of $0.3 \mathrm{~cm} / \mathrm{s}$. The bed was fluidized by air at ambient conditions. The expanded bed height was maintained around $40 \mathrm{~cm}$. A straight-tube injection nozzle was horizontally inserted into the bed and located about $4 \mathrm{~cm}$ above the air distributor plate. The nozzle diameter was $0.84 \mathrm{~mm}$. Prior to liquid injection, the bed was fully fluidized. The injection time was about $10 \mathrm{~s}$. Detailed experimental conditions are listed in Table1, together with calculation conditions. Because the particle size distribution (PSD) was not reported, a typical FCC PSD was used in the simulations.

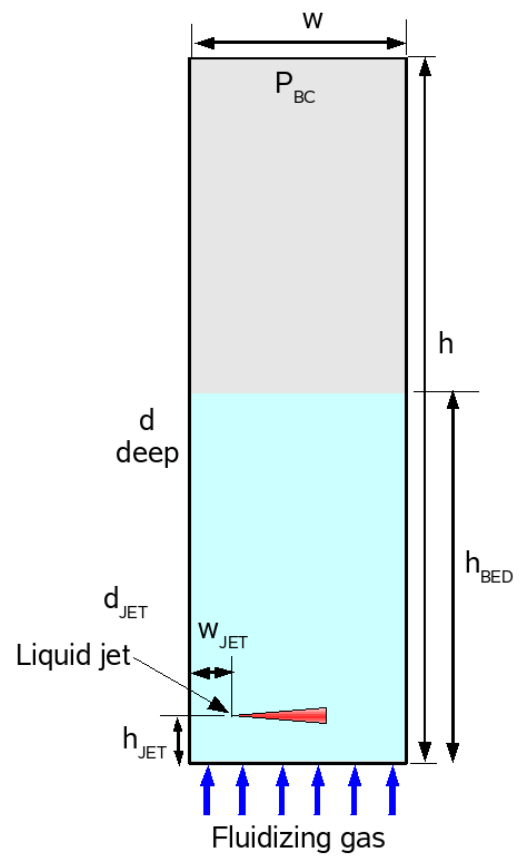

Figure 2. Computational domain and boundary conditions.

The simulations focus on jet penetration lengths under different injection and fluidization conditions and comparison between numerical predictions and experimental results. Two sets of injection and fluidization conditions were simulated, these conditions correspond to Tests L1 and Tests L3 in Ariyapadi et al [5] and are listed in Table 1. The liquid mass flow rate and jet velocity in Test L1 are much smaller than those in Test L3 while the fluidization gas velocity is larger in Test L1 than in Test L3. Each of these three parameters has a significant effect on the jet penetration.

Figure 2 shows the computational domain and boundary conditions. Fluidization gas enters the bed uniformly from the bottom of the bed. Ambient pressure is applied at the top. The geometry of the injection nozzle is not included in the model due to its small dimensions, but a jet source at a specified injection location corresponding to the nozzle exit in the experiment is used in the numerical solution. Injected liquid droplets enter the bed from the jet source with the specified mass flow rate, speed, 
direction and PSD. The calculation was started from a static bed with a solid inventory of close to 9.3 $\mathrm{kg}$ which matched the solid mass in the experiment. The number of numerical particles used in the calculation is close to $1,300,000$.

Table 1. Experimental and simulation conditions of liquid injection into a fluidized bed

\begin{tabular}{lll}
\hline & \multicolumn{1}{c}{ Ariyapadi et al [5] } & \multicolumn{1}{c}{ Simulation } \\
\hline Bed dimensions (w,d,h) & $20 \times 20 \times 100 \mathrm{~cm}$ & $20 \times 20 \times 65 \mathrm{~cm}$ \\
Solid particle density & (FCC) $1500 \mathrm{~kg} / \mathrm{m}^{3}$ & $1500 \mathrm{~kg} / \mathrm{m}^{3}$ \\
Solid particle size distribution & $\begin{array}{l}\text { Standard FCC } \\
\text { (Sauter mean diameter } \sim 70 \mu \mathrm{m})\end{array}$ & See Figure 1 \\
Bed inventory & $\sim 9 \mathrm{~kg}$ & $9.3 \mathrm{~kg}$ \\
Expanded bed height $\left(\mathrm{h}_{\mathrm{BED}}\right)$ & $\sim 40 \mathrm{~cm}$ & $\sim 40 \mathrm{~cm}$ \\
Injected liquid & Ethanol $(95 \% \mathrm{v} / \mathrm{v})$ & Ethanol \\
Density of injected liquid & $\sim 800 \mathrm{~kg} / \mathrm{m}^{3}$ & $800 \mathrm{~kg} / \mathrm{m}^{3}$ \\
Liquid droplet size & $($ Nozzle) Diameter $=0.84 \mathrm{~mm}$ & Diameter $=0.42 \mathrm{~mm}$ \\
Location of injection nozzle $\left(\mathrm{h}_{\mathrm{JET}}\right)$ & $4 \mathrm{~cm}$ from bottom of bed & See Figure 2 \\
Injection time & $10 \mathrm{~s}$ & $10 \mathrm{~s}$ \\
Fluidization gas/conditions & Air at ambient conditions & Air at ambient conditions \\
\hline
\end{tabular}

Table 2. Liquid injection and fluidization conditions in the experiment (Ariyapadi et al [5])

\begin{tabular}{lcc} 
& Test L1 & Test L3 \\
\hline Liquid mass flow rate $(\mathrm{g} / \mathrm{s})$ & 2.9 & 6.0 \\
Jet speed $(\mathrm{m} / \mathrm{s})$ & 6.6 & 13.9 \\
Fluidization gas velocity $(\mathrm{cm} / \mathrm{s})$ & 5.6 & 4.2 \\
\hline
\end{tabular}

\section{Calculation results}

A calculation with fluidizing gas velocity of $4.2 \mathrm{~cm} / \mathrm{s}$ was first run to $24 \mathrm{~s}$ without liquid injection. At this time the bed was fully fluidized and reached steady state. Figures 3.d and 3.e show the particle volume fraction distribution in the whole fluidized bed and in a thin center-cut slice at $24 \mathrm{~s}$ just before liquid injection (simulation time is displayed at the top of the snapshots). Liquid injection with conditions of Test L3 was turned on immediately after $24 \mathrm{~s}$ and lasted $10 \mathrm{~s}$. The calculation stopped at $34 \mathrm{~s}$. Figure $3 . f$ shows the liquid distribution at the end of the calculation. The blue color shows the liquid fraction defined as the ratio of the liquid mass to the total particle mass (liquid mass + solid mass). The liquid fraction is always 1 for liquid droplets and 0 for dry solid particles, independent of their size. For other wet particles, the liquid fraction falls between 0 and 1 .

The calculation for Test L1 was performed by restarting the previous calculation at $24 \mathrm{~s}$ with the fluidizing gas velocity changed to $5.6 \mathrm{~cm} / \mathrm{s}$ (from $4.2 \mathrm{~cm} / \mathrm{s}$ ). The calculation was run for 6 seconds for the fluidized bed to reach steady state at the new fluidization velocity. At $30 \mathrm{~s}$, liquid injection with conditions of Test L1 was turned on and lasted 10 s. Figures 3.a and 3.b show the pre-injection fluidized bed, and Figure 3.c shows the liquid fraction at the end of the calculation. 
The jet penetration was defined in Ariyapadi et al [5] as the maximum horizontal distance from the nozzle tip penetrated by the injected liquid. In the experiment, the jet penetration length was observed to fluctuate significantly with time. The penetration length for a particular test case was obtained by averaging the instantaneous penetration lengths from several images at different injection times. The jet penetration length is calculated from the simulation data in the same way the jet penetration is calculated from the experiment data. Figure 4 shows snapshots liquid drops only in the fluidized bed at different simulation times. Dry solids or solids with a liquid film in the bed are not shown. Note that the stream of liquid drops disappears as liquid is transferred from the liquid drops to solids. From these snapshots the instantaneous jet penetration lengths are measured. Similar to the experiment, the measurement of the jet penetration length is not a fixed length. The bubbling bed dynamics perturbs the jet motion with cross flows and bed gas eddies, giving a non-steady liquid stream.

The averaged jet penetration lengths for the two test cases are listed in Table 3 Both the experiment and simulation show that the jet penetration in Test L1 is much short than that in Test L3 because of smaller liquid flow rate and jet speed in Test L1. Furthermore, a higher fluidization velocity results in a stronger cross-flow effect and reduces the jet penetration as observed by the experiment. For both test cases, the jet penetration predicted by Barracuda is somewhat longer than measured in the experiment.

Table 3. Jet penetration length by experiment and Barracuda calculation

\begin{tabular}{lcc} 
Test & $\begin{array}{c}\text { Experiment by } \\
\text { Ariyapadi et al [5] }\end{array}$ & Simulation \\
\hline Test L1 & $3.3 \mathrm{~cm}$ & $5.1 \mathrm{~cm}$ \\
Test L3 & $7.3 \mathrm{~cm}$ & $9.7 \mathrm{~cm}$ \\
\hline
\end{tabular}

\section{Concluding remarks}

The experiment of liquid injection into a gas-solid fluidized bed reported by Ariyapadi et al [5] is numerically simulated by Barracuda CPFD. The jet penetration lengths for two test cases with different injection conditions and fluidization gas velocities are compared between the simulation and experiment. For the case with a lower jet liquid mass flow rate and jet velocity and higher fluidization gas, Barracuda predicts much longer penetration than the other case which is in agreement with the experiment. In both cases the predicted penetration length is slightly longer than the measured penetration length; however, considering the difficulty in defining and measuring penetration lengths in a bubbling bed, the comparison is considered good. 


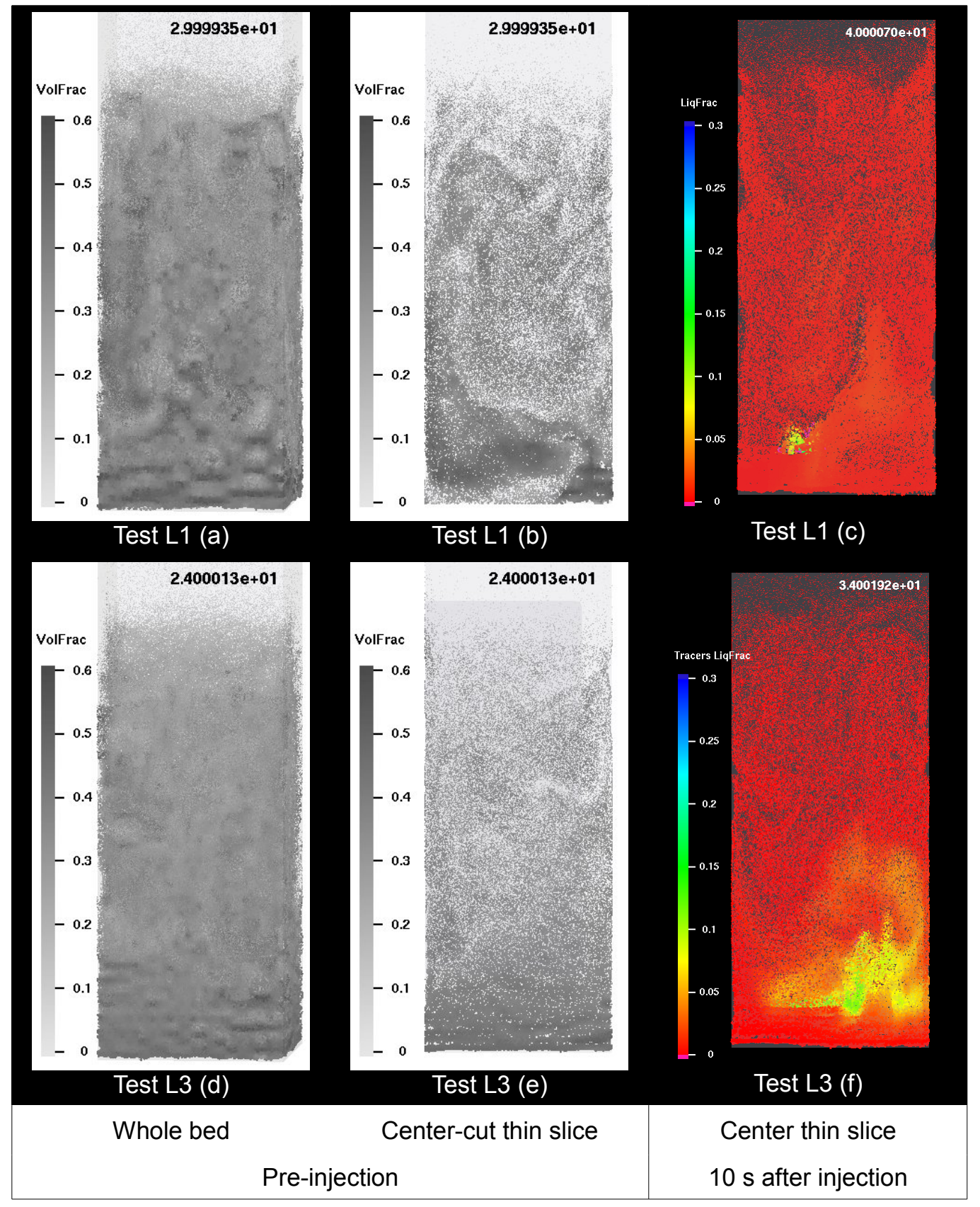

Figure 3. Snapshots of the fluidized bed before and after liquid injection.

Liquid injection starts at $30 \mathrm{~s}$ for Test L1 and $24 \mathrm{~s}$ for Test L3. In both cases injection lasts $10 \mathrm{~s}$. The first column to the left shows the whole fluidized bed with particle volume fraction distribution drawn in gray scales. The center column shows the particle volume fraction in the center-cut thin slice. The column on the right shows the liquid fraction at $10 \mathrm{~s}$ after the injection. 


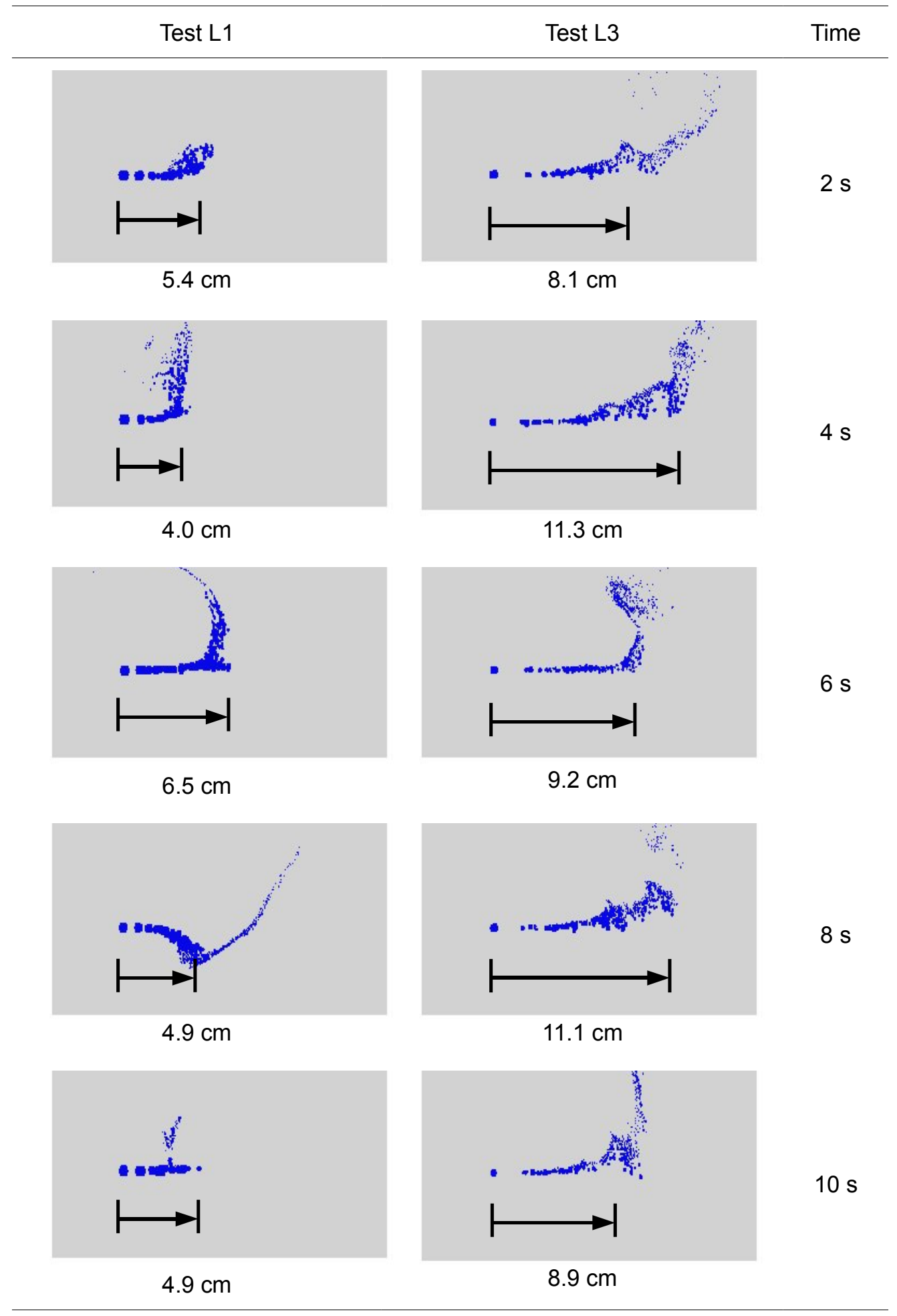

Figure 4. Injected liquid droplet distribution at different injection time showing the jet penetration for two sets of calculation conditions. The column to the right shows time after injection. The arrows show the penetration direction and lengths. The numbers denote the penetration lengths in $\mathrm{cm}$. 


\section{References}

1. M. J. Andrews and P. J. O'Rourke, "The Multiphase Particle-in-Cell Method (MP-PIC) Method for Dense Particle Flow," Int. J. Multiphase Flow 22, 379-402 (1996).

2. D. M. Snider, P. J. O'Rourke, and M. J. Andrews, "Sediment Flow in Inclined Vessels Calculated Using Multiphase Particle-in-Cell Model for Dense Particle Flows," Int. J. Multiphase Flow 24, 1359 (1998).

3. D. M. Snider, "An Incompressible Three-Dimensional Multiphase Particle-in-Cell Model for Dense Particle Flows," J. Comput. Phys. 170, 523-549 (2001).

4. W. G. Vincenti and C. H. Kruger, Jr., Introduction to Physical Gas Dynamics (Robert E. Krieger Publishing Company, Huntington, NY, 1975).

5. S. Ariyapadi, D. W. Holdsworth, C. J. D. Norley, F. Berruti, C. Briens, "Digital X-ray Imaging Technique to Study the Horizontal Injection of Gas-Liquid Jets into Fluidized Beds, " Int.. J. Chem. React. Engr. Vol 1, Article A56 (2003).

6. P. J. O'Rourke, P. Zhao, and D. M. Snider, "A Model for Collisional Exchange in Gas/Liquid/Solid Fluidized Beds" (in preparation). 


\section{ENHANCED PRODUCTIVITY OF CHEMICAL PROCESSES USING DENSE FLUIDIZED BEDS}

Topical Report No. 4

Bulk Liquid Film Chemistry

Dale Snider

CPFD Software LLC

November 2007

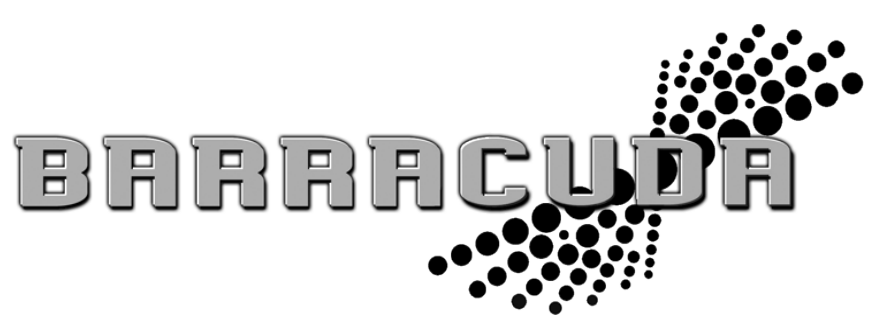

Performed as part of DOE Contract: DE-FC36-04G014153 


\title{
Bulk Liquid Film Chemistry
}

\author{
Dale Snider \\ CPFD Software, LLC \\ November 2007
}

\section{Introduction}

A liquid film on a solid and the gas in a system are two separate mass, energy and momentum systems which connect at their interface. The liquid system can have liquid chemistry separate from the gas phase, and there can be a film-surface chemistry where both liquid and gas phases react. As a first approximation, the complex liquid chemistry is modeled using a bulk liquid chemistry model. In the bulk chemistry model, the mass rate of change of the liquid film is calculated, and the liquid mass change produces gas species.

For a material description of solids (Lagrangian), the bulk liquid chemistry model provides a fast solution for liquid-film chemistry. The model has limitations. The liquid film generally contains numerous liquid species which react in the liquid film or vaporize from the film. Neither the liquid film chemistry or vaporization of different volatile liquids is directly calculated in the bulk liquid film model. The result of liquid chemistry and vaporization is transient mass fractions of the film's liquids. The bulk liquid film model assumes a fixed ratio of liquids in the liquid film.

The chemistry in a film of liquid on a solid particle is modeled by the liquid-film model. The liquid film chemistry model does not directly calculate the liquid chemistry. A chemistry "mechanism" is described where the liquid film produces gas and possibly a residue-solid. The production rate of gases and residue-solid are specified as rate equations

$$
\frac{d M_{i, G}}{d t}=a_{i} k_{i} M_{F, L}
$$

where $i$ is the $i^{\text {th }}$ gas, $a_{i}$ is a constant, $k_{i}$ is the rate coefficient and $M_{F, L}$ is the mass of the liquid film. The above equation is for a gas $(G)$ product. A similar equation describes the solid $(S)$ production rate. The rate equation for the liquid film is the negative of the production rates of gas and residue-solid,

$$
\frac{d M_{F, L}}{d t}=-\sum_{i}^{N_{\text {PRODUCT }}}\left(a_{i} k_{i}\right) M_{F, L}
$$

In solution of the production, it is best to calculate the liquid-film reaction rate and then calculate each of the products,

$$
\frac{d M_{i, G}}{d t}=\left[\frac{a_{i} k_{i}}{\sum_{i}^{N_{\text {PRODUCT }}}\left(a_{i} k_{i}\right)}\right] \frac{d M_{F, L}}{d t} .
$$

Consider the solid shown in Fig. 1 which has a liquid film of material $A(L)$ and chemically produces gases $B(G)$ and $C(G)$ and residue-solid $D(S)$. The $L, G$ and $S$ denote liquid, gas and solid respectively. In general, the composition of the liquid film would change with time as chemical products are produced at different rates; however, in this model the film composition remains fixed. For this lumped reaction model, a mass base is preferable. The mass production of products from liquid film chemistry is 


$$
\begin{aligned}
& \frac{d M_{B, G}}{d t}=\left[\frac{a_{0} k_{0}}{\left(a_{0} k_{0}+a_{1} k_{1}+a_{2} k_{2}\right)}\right] \frac{d M_{A, L}}{d t} \\
& \frac{d M_{C, G}}{d t}=\left[\frac{a_{1} k_{1}}{\left(a_{0} k_{0}+a_{1} k_{1}+a_{2} k_{2}\right)}\right] \frac{d M_{A, L}}{d t} \\
& \frac{d M_{D, S}}{d t}=\left[\frac{a_{2} k_{2}}{\left(a_{0} k_{0}+a_{1} k_{1}+a_{2} k_{2}\right)}\right] \frac{d M_{A, L}}{d t}
\end{aligned}
$$

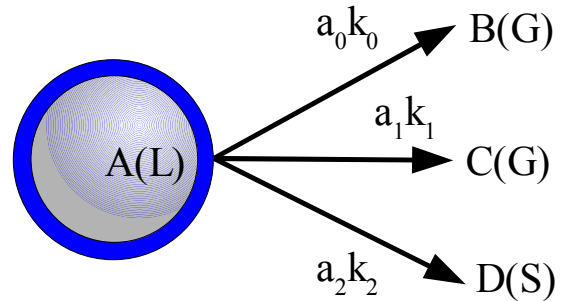

Figure 1. Model of a liquid film with a 3-lump chemistry model

The mass production rate of liquid in the liquid film is

$$
\frac{d M_{A, L}}{d t}=-\left(a_{0} k_{0}+a_{1} k_{1}+a_{2} k_{2}\right) M_{A, L}
$$

The coefficients can be an Arrhenius type reaction coefficient or a polynomial coefficient.

$$
\begin{gathered}
k=C_{0} e^{-E / T} \\
k=\alpha_{0}+\alpha_{1} T+\alpha_{2} T^{2}+\alpha_{3} T^{3}+\alpha_{4} T^{4}
\end{gathered}
$$

When other rate-coefficients are required, these coefficients can be added.

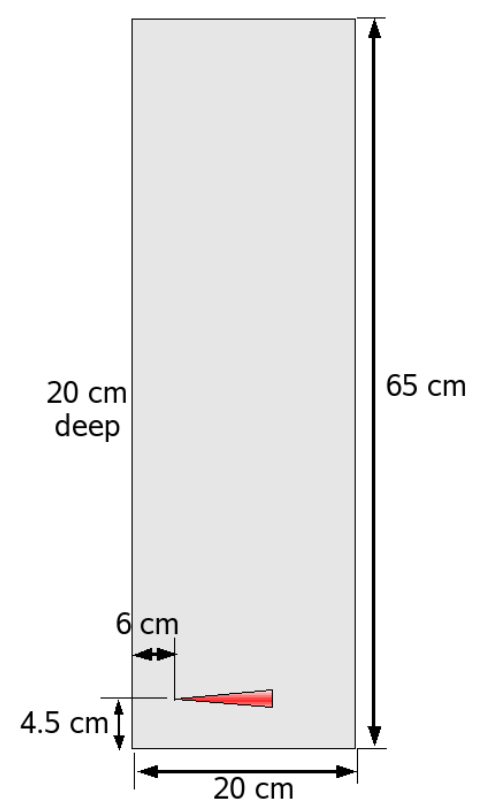

Figure 2. Description of geometry and jet location. 


\section{Chemistry of the test problem}

The example calculation is for a rectangular container shown in Fig. 2. The reaction example is from Alvin Chen at ExxonMobil Research and Engineering. The bed has heavy residue gas injected at the bottom, and side injection jet of liquid heavy residue. The example calculation conditions are given in Table 1. The example uses a 6-lump chemistry model illustrated in Fig. 3.

Table 1. Calculation parameters.

\begin{tabular}{cl}
\hline Inlet gas & $0.05 \mathrm{~m} / \mathrm{s}$ \\
Pressure & $300 \mathrm{kPa}$ \\
Temperature & $800 \mathrm{~K}$ \\
Gas species & Heavy resid $(\mathrm{G})$ \\
Outlet pressure & $300 \mathrm{kPa}$ \\
Liquid jet & \\
Temperature & $800 \mathrm{~K}$ \\
Flow rate & $0.1 \mathrm{~kg} / \mathrm{s}$ \\
Velocity & $100 \mathrm{~m} / \mathrm{s}$ \\
Liquid species & Heavy resid (L) \\
Initial condition & \\
Bed height & $39 \mathrm{~cm}$ at $40 \%$ volume fraction \\
Gas species & Heavy resid $(\mathrm{G})$ \\
Temperature & $800 \mathrm{~K}($ solids and gas) \\
Pressure & $301 \mathrm{kPa}$ \\
Close pack & 0.60 \\
Solid material & Coke \\
\hline
\end{tabular}

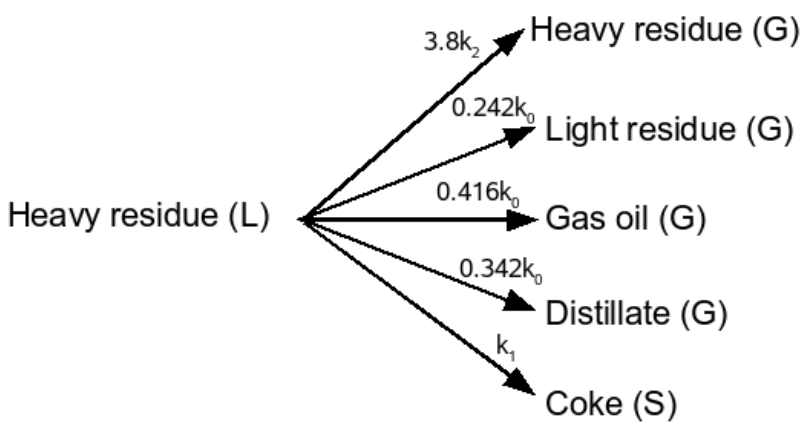

Figure 3. Illustration of 6-lump chemistry. 
The species are abbreviated as given below and gas, liquid and solid are denoted by $G, L$, and $S$ respectively.

\begin{tabular}{cc}
\hline Material & Abbreviation \\
\hline Heavy residue & HR \\
Light residue & LR \\
Gas oil & GO \\
Distillate & Dis \\
Coke & Coke \\
\hline
\end{tabular}

The liquid chemistry for the 6-lump model are described by

$$
\begin{gathered}
\frac{d M_{H R(L)}}{d t}=-\left(k_{0}+k_{1}+3.8 k_{2}\right) M_{H R(L)} \\
\frac{d M_{H R(G)}}{d t}=3.8 k_{2} M_{H R(L)} \\
\frac{d M_{L R(G)}}{d t}=0.242 k_{0} M_{H R(L)} \\
\frac{d M_{G O(G)}}{d t}=0.416 k_{0} M_{H R(L)} \\
\frac{d M_{\text {Dis }(G)}}{d t}=0.342 k_{0} M_{H R(L)} \\
\frac{d M_{\text {Coke }(S)}}{d t}=k_{1} M_{H R(L)}
\end{gathered}
$$

where $M$ is mass.

The three-dimensional conservation of mass, momentum and energy is solved for the fluid mixture, and an implicit solution for the transport of each gas species is calculated. Because there is a mass generation from vaporization of liquid to gas, the liquid-to-gas energy and mass are included within the solved conservation equations. The momentum from liquid to gas is not included within the conservation equation. The mass, momentum and energy equations are solved for each numerical-solid and liquid-film coated solid. From a kinetic theory collision approach, mass, energy and momentum of liquid is transfered (conserved) between solid's with liquid films. The momentum between solids and fluid are tightly coupled (two-way coupling) through momentum exchange (drag and pressure). The two-way heat transfer between solid and gas is calculated. The change in gas temperature associated with reaction bonds forming or breaking (chemistry) is naturally predicted using the enthalpy based energy equation and the gas thermal-physical properties (specific heat and heat of formation).

\section{Results}

The bed is fluidized from the bottom heavy-residue gas injection as shown in Fig. 4. There is a very high velocity, large mass flow jet into the side of the vessel. The jet velocity magnitude in the small test vessel $(20 \mathrm{~cm})$ is typical of a jet in a commercial Coker with diameter of meters. Even with the large injection rate, the chemistry from the single liquid injection jet is not sufficient to maintain a well fluidized bed.

The chemistry and distribution of gas species from thermal cracking of heavy residue liquid 
depends on the jet behavior. Figure 5 shows the liquid injection and solids which have a liquid coating greater than $0.1 \%$. Other solids are not shown. The jet nozzle is $6 \mathrm{~cm}$ into test section. The jet penetration can be affected by the bed fluidization gas. However in this example, the liquid jet penetrates across the test section and the majority of liquid transfers occur near the wall opposite the nozzle. Figure 5 shows the production of light residual at $0.75 \mathrm{~s}$. Light residual gas concentration less than $10^{-5} \mathrm{~kg} / \mathrm{m}^{3}$ is not shown. The jet produces a liquid mixing circulation pattern which spreads towards the front and back walls as seen in Fig. 6. As the liquid and liquid coated solids move, the liquid-film cracks producing gases. Figure 7 shows the particle flow pattern looking from the bottom up at $12 \mathrm{~s}$.

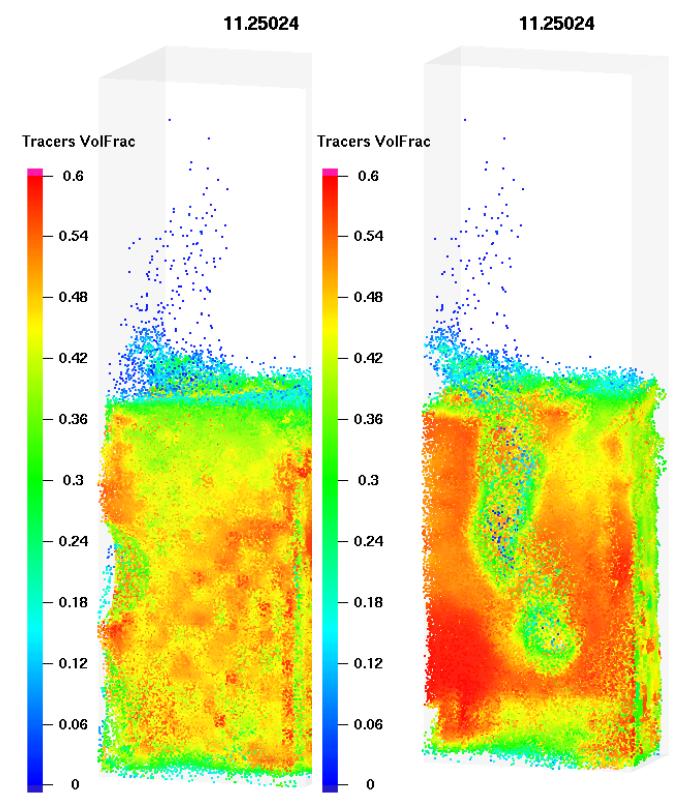

Figure 4. Particles in fluidized bed. Left: full view. Right: front half cut-away. 


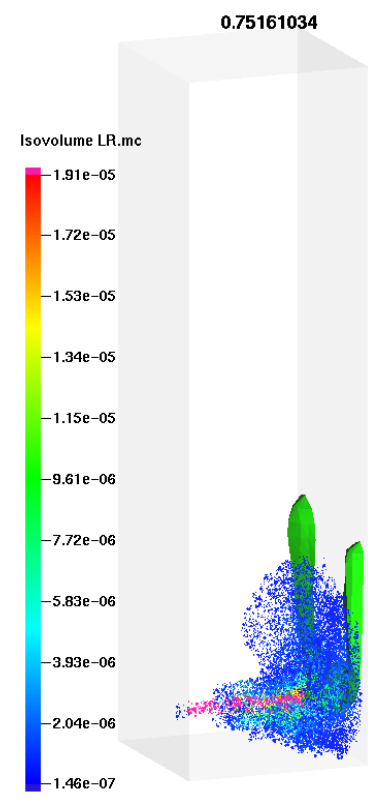

Figure 5. The liquid jet drops and solids which have a liquid coating with mass fraction greater than $0.1 \%$. The isovolume shows light residue production.

The gas in the gas mixture is primarily heavy residue gas because the bottom feed is residue gas. The mass fraction of gas oil, distillate and light residue gases vertically in the vessel is shown in Fig.8. The example does not include gas chemistry and the gases do not react to form other chemical species. Figure 9 shows light residue, gas oil and distillate.

The reaction is slightly endothermic. The solids temperature is shown in Fig. 10. The temperature difference is a fraction of a degree Kelvin. Because the solids have a large thermal-mass and gas is injected at $800 \mathrm{~K}$ at the bottom of the vessel, the bed stays near $800 \mathrm{~K}$.

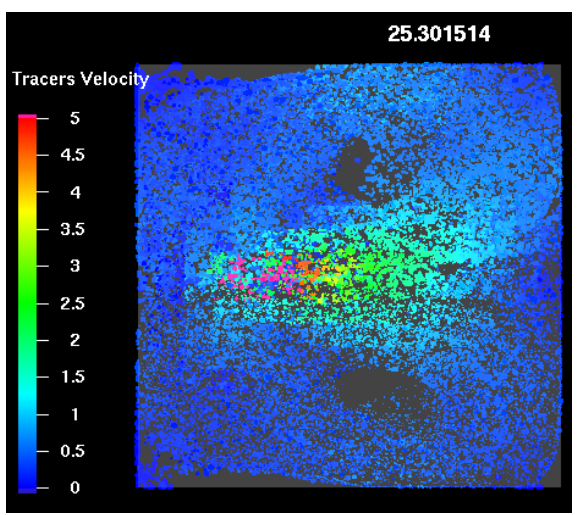

Figure 6. Particles shown colored by particle velocity. This is a top view showing both liquid drops and solids at the liquid injection elevation. Solids and the vessel above the jet are not shown (cut away). 


\subsection{1}

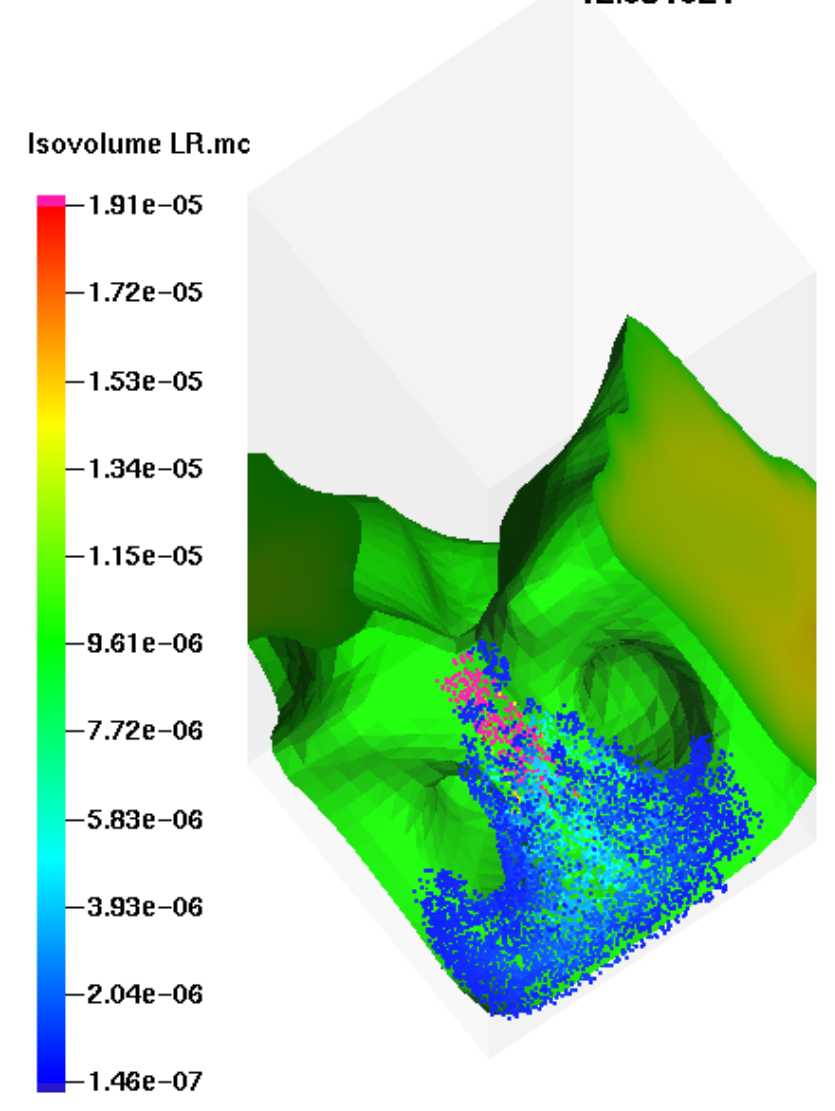

Figure 7. The liquid jet drops and liquid coated solids hitting wall opposite jet and flowing around to front and back walls. The liquid residue gas is forming from cracking of the heavy residue liquid. Light residue below $10^{-5}$ $\mathrm{kg} / \mathrm{m}^{3}$ is not shown. Solids which have a liquid coating with mass fraction less than $0.1 \%$ are not shown. Light residue partially hides particles. 


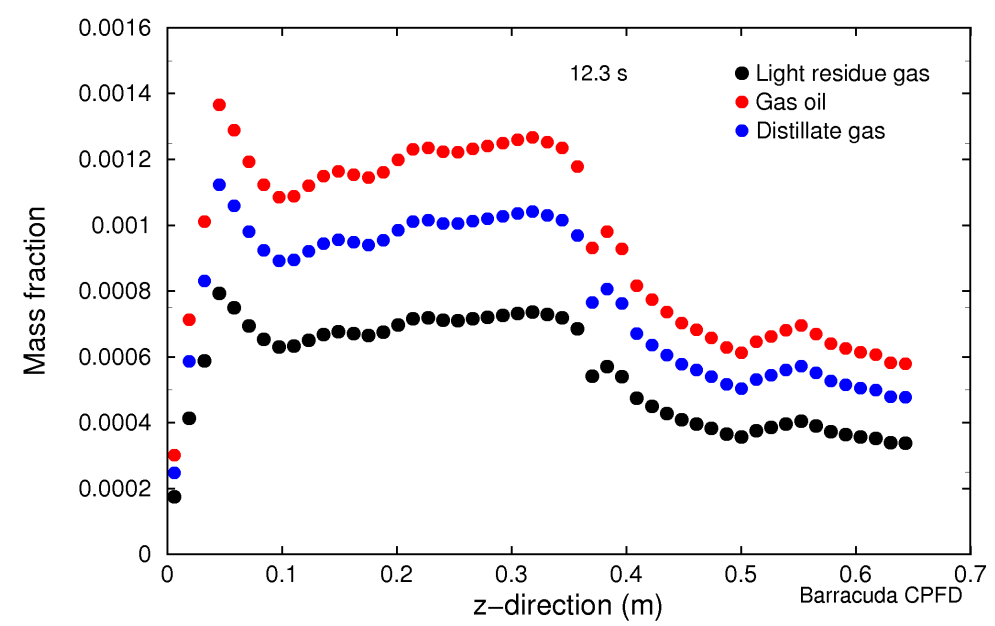

Figure 8. The mass fraction of gases in the vessel at $12.3 \mathrm{~s}$. The heavy residue gas mass fraction is approximately 1.

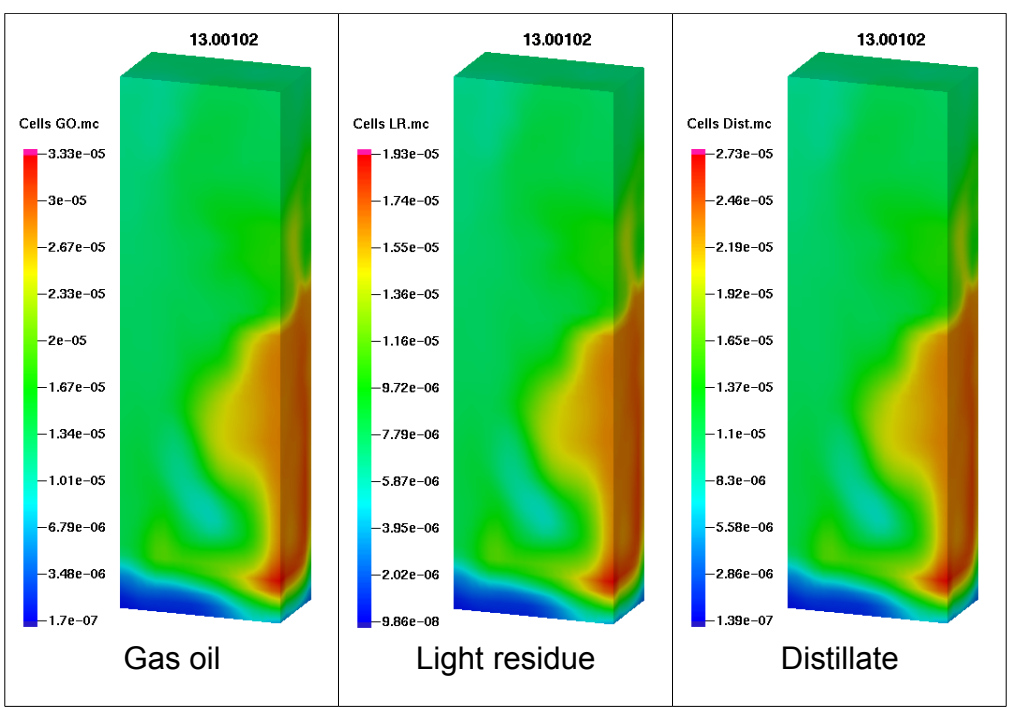

Figure 9. Gas products from liquid chemistry. Mass concentration shown. Because heavy residue gas is fed from the bottom, the mass fraction of heavy residue is about 1 . 


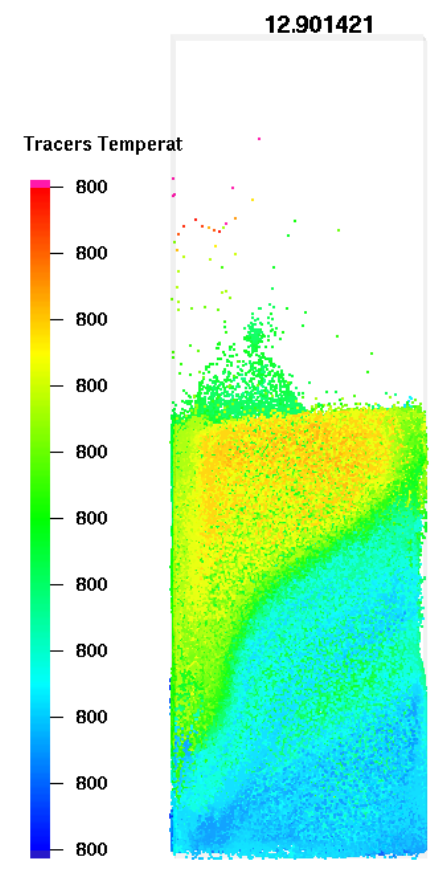

Figure 10. The solid temperature. Blue is lower temperature.

\section{Concluding remarks}

A six lumped chemistry model was used to predict cracking of heavy residue liquid to heavy residue gas, light residue gas, distillate, gas oil and solid coat which deposits on the solid. A liquid jet is injected into the bed, and the Barracuda collision model distributes liquid mass, momentum and energy from the liquid jet to solids and liquid from solid-to-solid. The reaction is endothermic, but because there is a large thermal mass of solids, and the gas feed temperature is the same as the initial bed temperature, the bed temperature remains relatively constant at the initial solids temperature. 


\section{Appendix A}

\section{Material properties}

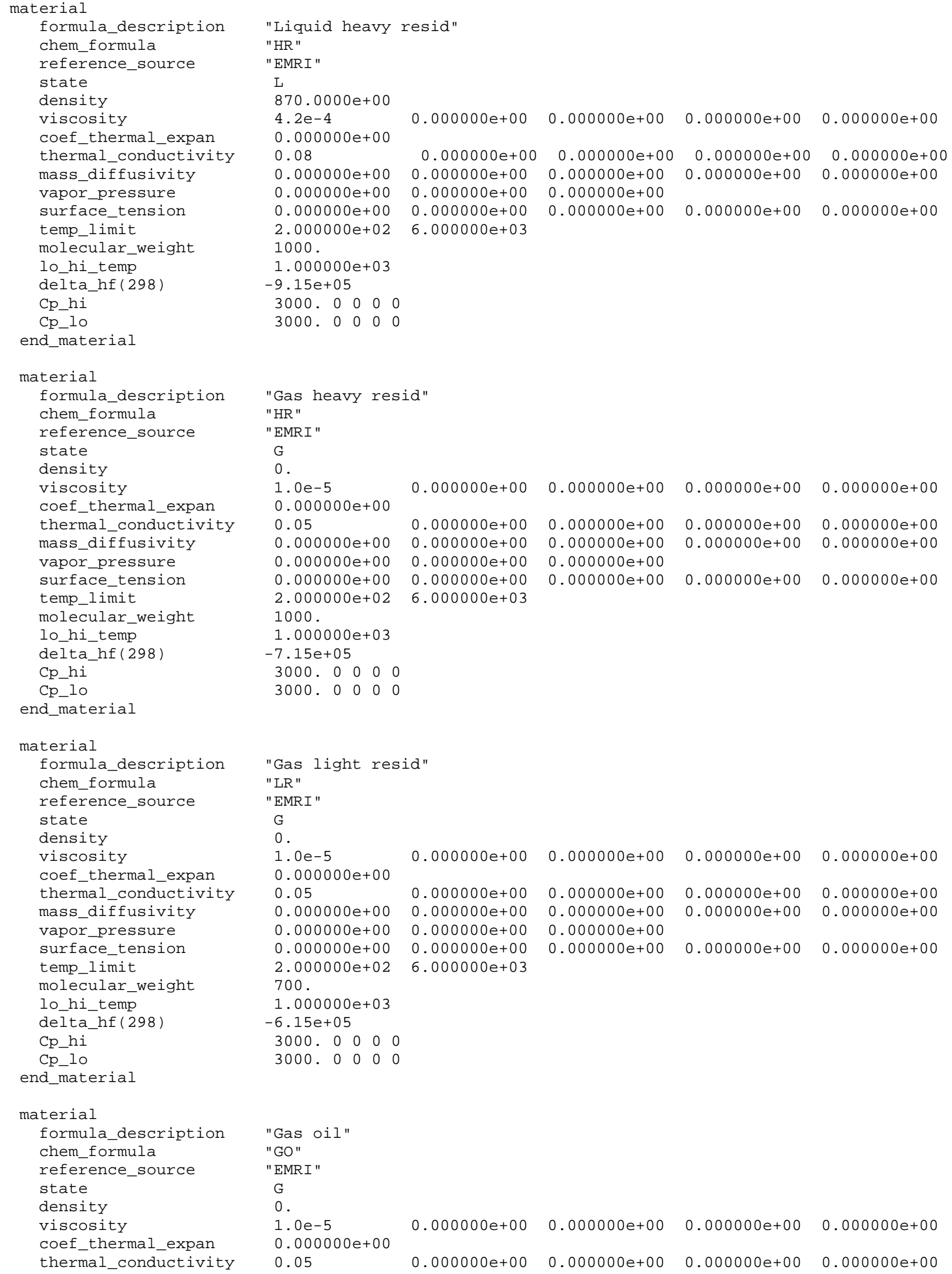




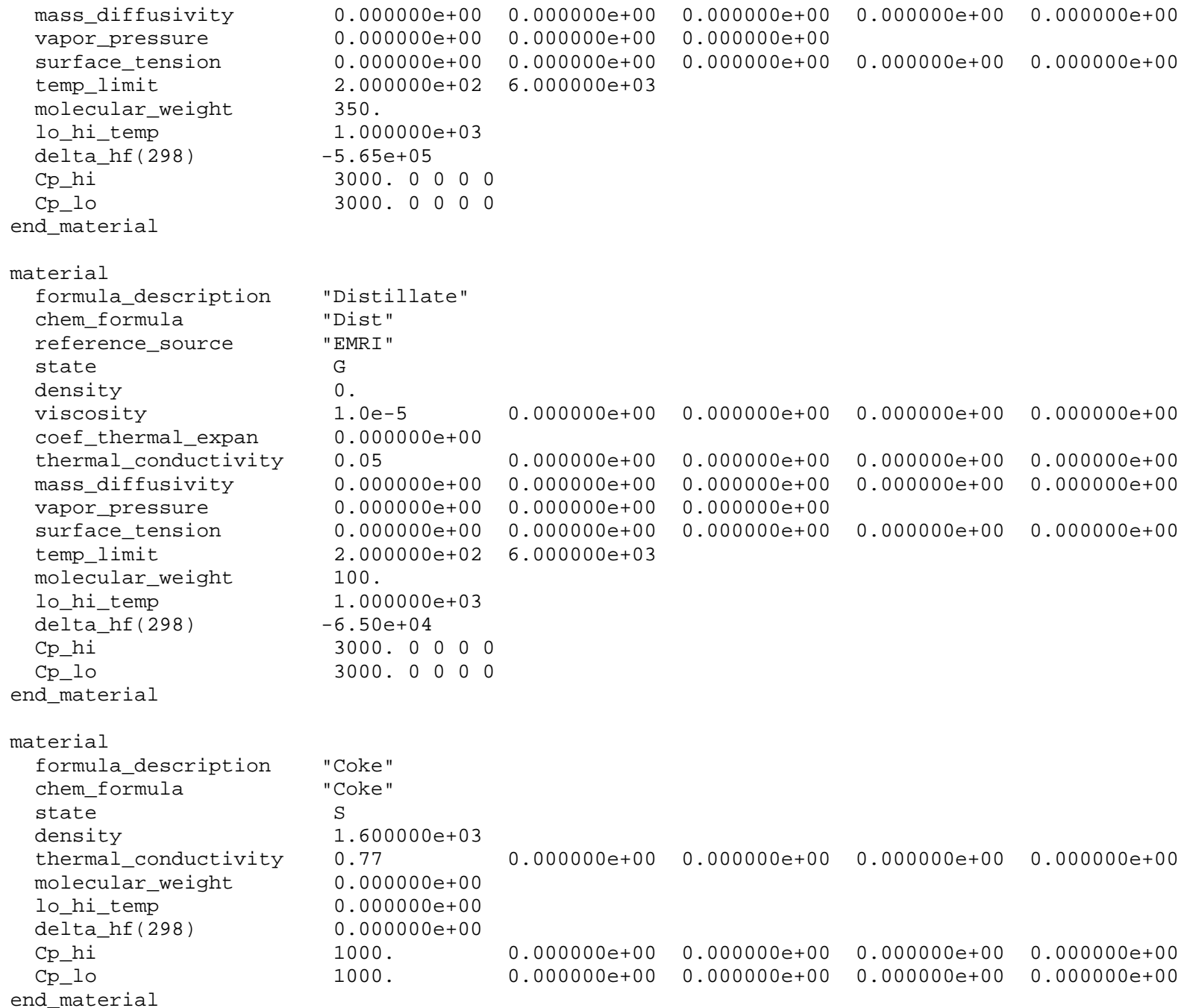

\section{Particle size distribution.}

\begin{tabular}{cc}
\hline $\begin{array}{c}\text { Summation } \\
\text { fraction }\end{array}$ & $\begin{array}{c}\text { Radius } \\
(\mu \mathrm{m})\end{array}$ \\
\hline 0.0 & 9 \\
2.5 & 14 \\
5.8 & 18 \\
7.8 & 20 \\
19.8 & 26 \\
44.9 & 33 \\
65.0 & 40 \\
73.8 & 44 \\
86.7 & 52 \\
93.8 & 62 \\
100.0 & 96
\end{tabular}




\title{
ENHANCED PRODUCTIVITY OF CHEMICAL PROCESSES USING DENSE FLUIDIZED BEDS
}

Topical Report No. 5

Experiments and Design of Experiments

\author{
Tim O'Hern \\ Paul Tortora \\ CPFD Software LLC
}

Performed as part of DOE Contract: DE-FC36-04G014153 


\title{
Experiments and Design of Experiments
}

\author{
Tim O'Hern and Paul Tortora \\ Sandia National Laboratories
}

\section{Introduction}

The primary role of Sandia National Laboratories in this project was to provide and evaluate highquality data sets for validation of new models implemented in Barracuda ${ }^{\mathrm{TM}}$. The original intent was to build a large fluidized bed but the project team decided to suspend that effort when funding was delayed in the first two project years. However, several sets of small-scale experiments were still performed. These, along with literature data reviews, are included below. The outline of this section is: 1) present experimental facilities and some experiments performed in them and 2) present proposed experiments and studies of available data pertaining to topics where validation data was not readily available in the literature. Some of the proposed experiments had to be deferred when funding was slowed and diverted. Key literature findings will be mentioned.

Other aspects of the Sandia work included evaluation of data available in the open literature to determine their suitability for validation. Also, Sandia personnel have been applying image processing routines to help understand some propriety EMRE data. Finally, several Barracuda ${ }^{\mathrm{TM}}$ validation simulations were run at Sandia over the course of the program.

\section{Two-Dimensional Fluidized Bed}

Two-dimensional (2D) fluidized beds are often used to study flow phenomena in gas-solid flows. Experiments have been performed on 2D fluidized beds for many years, and it is well known that the flow in a 2D bed is more strongly influenced by wall effects and has other differences from three-dimensional (3D) beds (Wu et al., 1996). However, this simpler flow can provide insight into the more complicated dynamics in industrial-scale 3D beds. 2D beds are typically rectangular and narrow (on the order of $1 \mathrm{~cm}$ thick), so that flow phenomena (such as bubbles) span the depth and may be observed visually. The intent is to examine a flow that resembles a slice from the interior of a visually opaque 3D fluidized bed. Since the simulations can be run with the exact geometry of a 2D bed the question of how precisely the $2 \mathrm{D}$ flow represents the 3D flow becomes less important. In fact, the 2D bed allows fairly simple setup, operation, and especially visualization not available in 3D beds.

Researchers have examined flow phenomena in 2D fluidized beds such as pressure fluctuations, bubble size, bubble velocity, particle velocity, and particle segregation. Measurements have also been compared to theoretical relations and computational simulations. Kuipers et al. (1991) filmed the growth of a bubble in a 2D fluidized bed and compared the results with theoretical predictions and computational simulations. Fluidizing air flowed into the bed through a porous distributor at its base, and bubbles were formed with air flowing through a central orifice. Similarly, Bokkers et al. (2004) filmed bubbles in a 2D fluidized bed with a central orifice and compared the results to computational simulations. They also performed PIV and segregation experiments with different-colored particles, comparing the results to computational simulations. Daw et al. (2000) used pressure measurements in a $2 \mathrm{D}$ fluidized bed to characterize bubble behavior. Cross-correlations of the pressure data were used to estimate bubble rise velocities, and slow oscillations (on the order of 100 seconds) were also observed in the pressure data. Kage et al. (2004) measured bubble diameters and velocities in a 2D fluidized bed with digital cameras. 
They also examined a vibrating fluidized bed and compared bubble diameters and velocities with theoretical relations.

Other investigators describe automated image analysis techniques for measurements in 2D fluidized beds. Shen et al. (2004) describe automated techniques to determine bubble diameter, bubble velocity, bubble density, and gas throughflow, and compare measurements to theoretical predictions. Goldschmidt et al. (2003) used color photography and image analysis to distinguish different-colored particles from each other and from a colored background. They were able to describe the expansion dynamics (frequency and height of oscillations) for each particle species and measure segregation.

A 2D fluidized bed $1.35 \mathrm{~cm}$ deep, $50 \mathrm{~cm}$ wide, and $1 \mathrm{~m}$ high was designed and fabricated for this work and is shown schematically in Figures 1 and 2. The bed typically contained an initially quiescent 60-cmhigh bed of Potters Industries Model P-0070 glass beads (Figure 3). The density of the beads is approximately $2500 \mathrm{~kg} / \mathrm{m}^{3}$ and their diameter ranges from 120 to 180 microns (Geldart Group B). Humidified air is fed into a pressurized plenum at the base of the bed and is introduced into the bed through a porous distributor (approximately 10 micron pore size). The $2 \mathrm{D}$ bed was used for determining fluidization characteristics (minimum fluidization velocity, minimum bubbling velocity, etc.) for different particle types under consideration for the large-scale bed and provided a capability for visualization and detailed flow measurement not achievable in the large bed. Figure 4 shows photographs of the 2D bed in operation. Figures 5 and 6 show examples of pressure data acquired while running the 2D bed under various conditions.

Particle image velocimetry (PIV) was implemented in this bed with the P-0070 glass beads (120 to $180 \mu \mathrm{m}$ diameter range) for which the minimum bubbling velocity is approximately equal to the minimum fluidization velocity. Example images and corresponding velocity fields are shown in Figure 7. Matlab scripts were written to calculate turbulent statistics (mean and fluctuating horizontal and vertical velocities, Reynolds stresses, turbulent kinetic energy) from the large number of individual velocity fields $\left(\mathrm{O}\left(10^{4}\right)\right)$ for each flow condition.

Barracuda $^{\mathrm{TM}}$ simulations were performed in parallel with experiments and compare favorably (Figure 8). A large amount of effort went into insuring that the parameters of the experiments and simulations (pressures, particle properties, air velocity and density) were matched as closely as possible.

The 2D bed was also instrumented with a side port to allow air injection into the fluidized bed. These experiments were the first step towards experiments aimed at understanding liquid sprays into fluidized beds (Appendix C). Figure 8 shows comparison of experiments and Barracuda ${ }^{\mathrm{TM}}$ simulations of a low speed jet injected into the 2D bed. Qualitative agreement is very good.

A series of experiments involving pressure measurements in the $2 \mathrm{D}$ fluidized bed was performed. The goal was to assess the time response and sensitivity of pressure measurements and compare the results to the literature. Pressure ports were fitted with either a porous metal "frit" or a metal screen to keep particles from entering the transducers. The frits have been used extensively in the past (e.g., in the MFDRC riser (O'Hern et al., 2006)). Metal screens were tested here because it was inferred that they would cause less damping of the pressure signals than the frits. The superficial gas velocity was approximately $0.8 \mathrm{~m} / \mathrm{s}$ and gauge pressure was measured at axial locations of $2 \mathrm{~cm}$ and $12 \mathrm{~cm}$ above the distributor. Pressures were sampled at $100 \mathrm{~Hz}$. Figure 9 shows a comparison of experimental results and Barracuda $^{\mathrm{TM}}$ simulations.

The measured pressures were divided into seven 8192-sample segments and a periodogram was taken for each. The periodograms were then averaged and the results are shown in Figure 10, which shows the 
reduction in damping caused by the metal screen as compared to the porous frits. The power spectra are comparable to those obtained by Brown and Brue (2001). The method of averaging periodograms was also obtained from that paper. However, the peaks seen the in spectra of Brown and Brue are not seen here. This may be because the particle bed used here was too light (resulting in low pressure readings) or the experimental conditions differed in some other significant way.

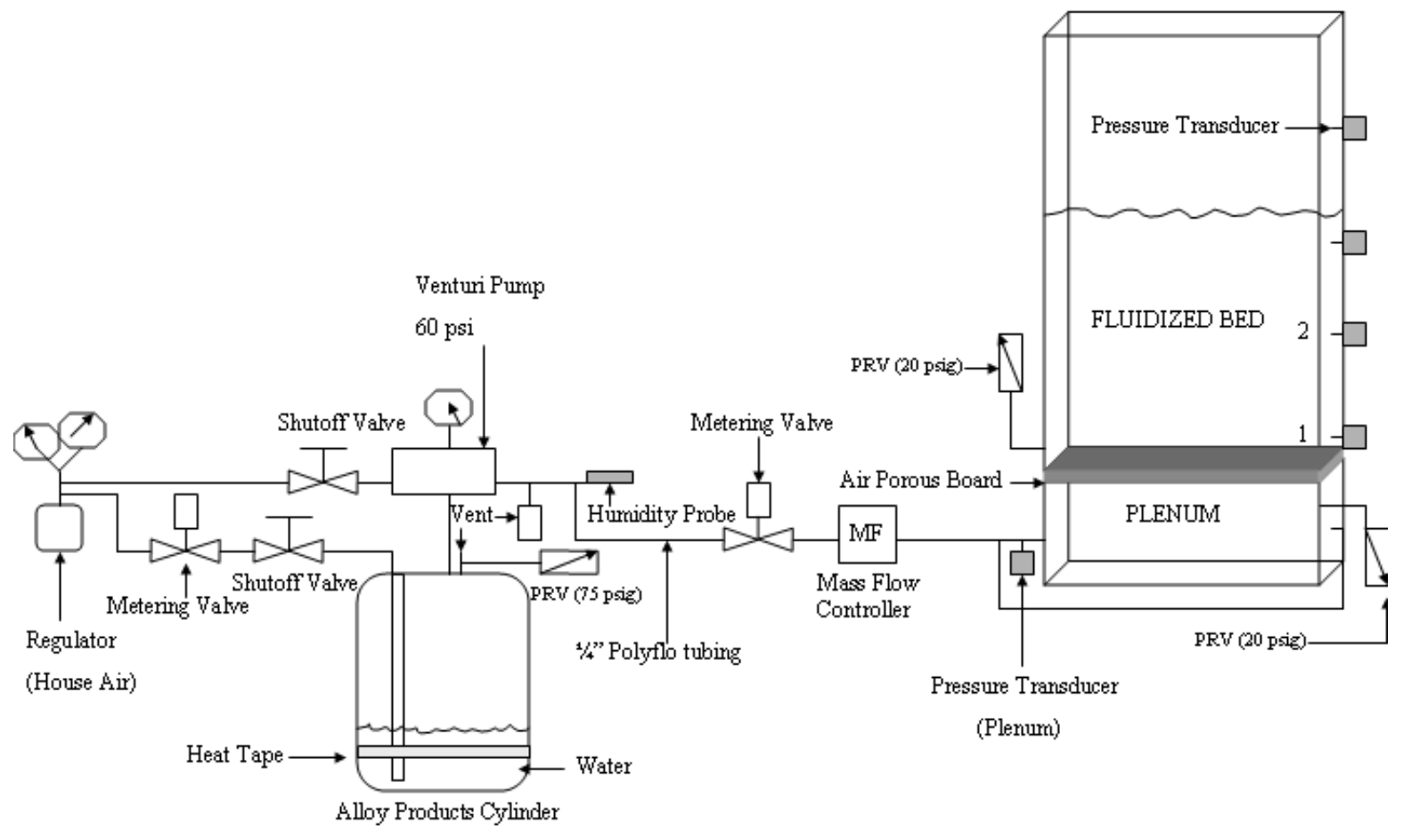

Figure 1. Overall layout of two-dimensional fluidized bed setup. 


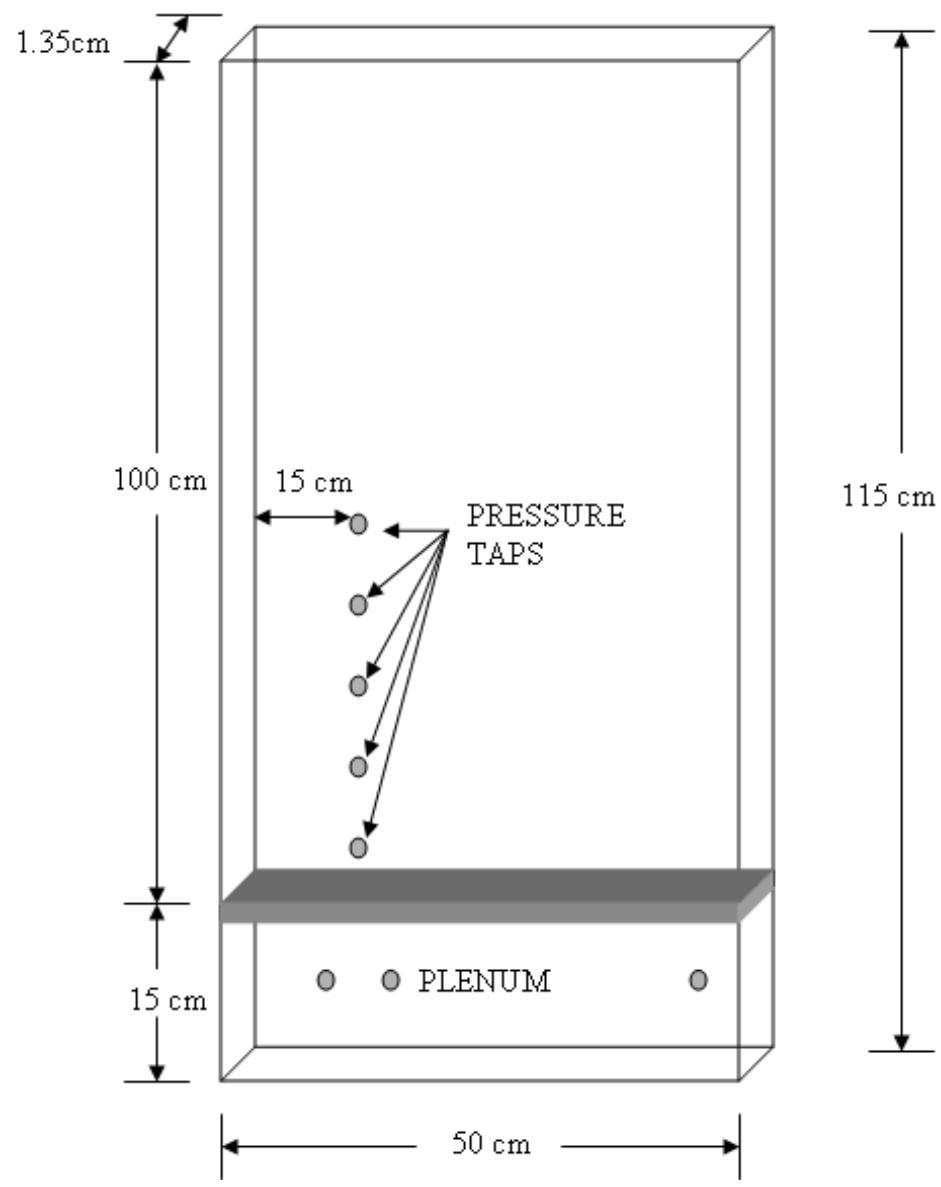

Figure 2. Details of 2D bed
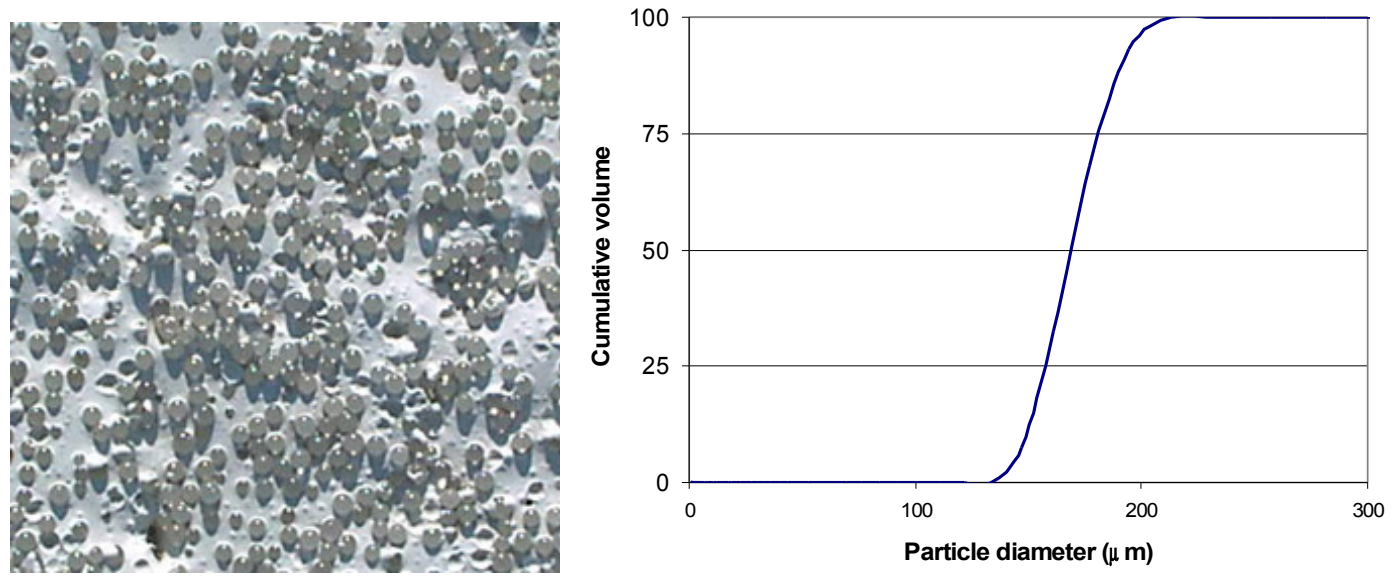

Figure 3. Potters Industries Model P-0070 glass beads. Nominal diameter range 120-180 $\mu \mathrm{m}$ 

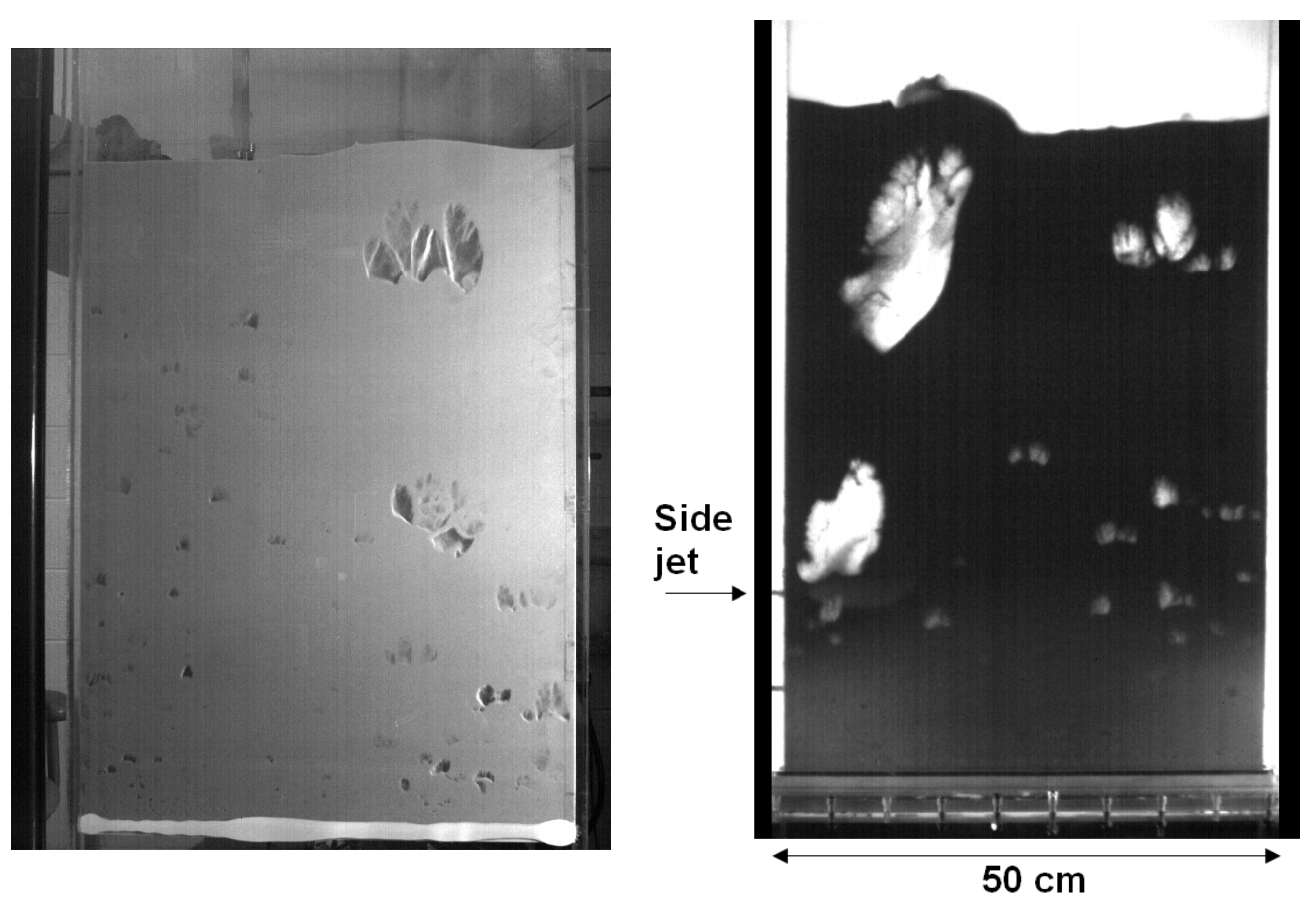

Figure 4. Photographs of two-dimensional fluidized bed in operation with 120-180 $\mu \mathrm{m}$ diameter P-0070 glass beads. Left, front illuminated. Right, back illuminated, with side air jet in operation

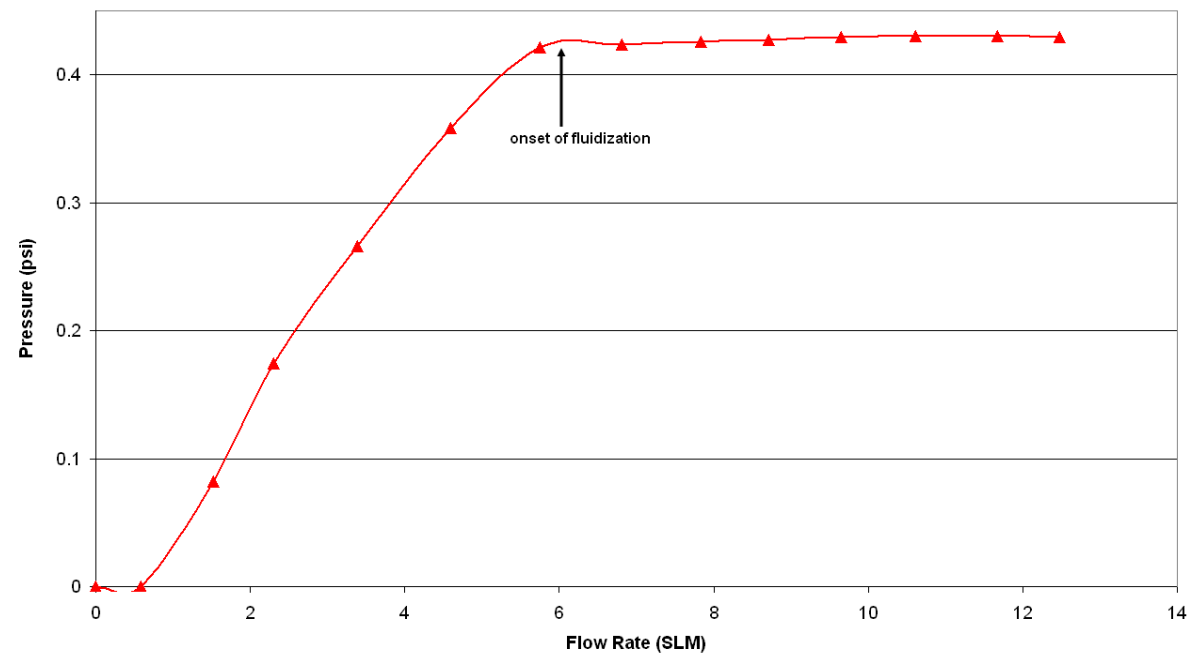

Figure 5. Data trace showing bed pressure as a function of flow rate (superficial gas velocity) for the two-dimensional fluidized bed 


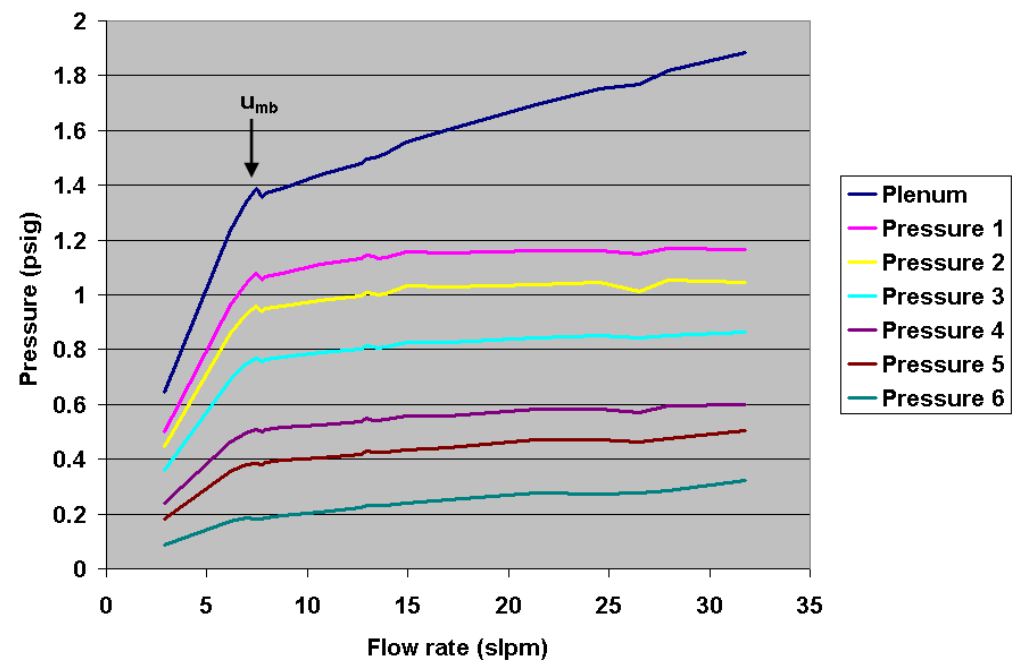

Figure 6. Data showing bed pressure as a function of superficial gas velocity for the two-

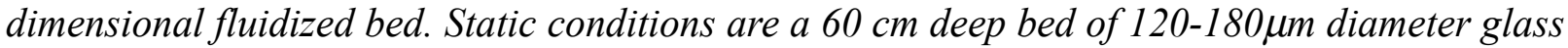
beads (Potters P-0070). Pressure measurements start $2 \mathrm{~cm}$ above the distributor (Pressure 1) and are thereafter every $10 \mathrm{~cm}$ up the bed
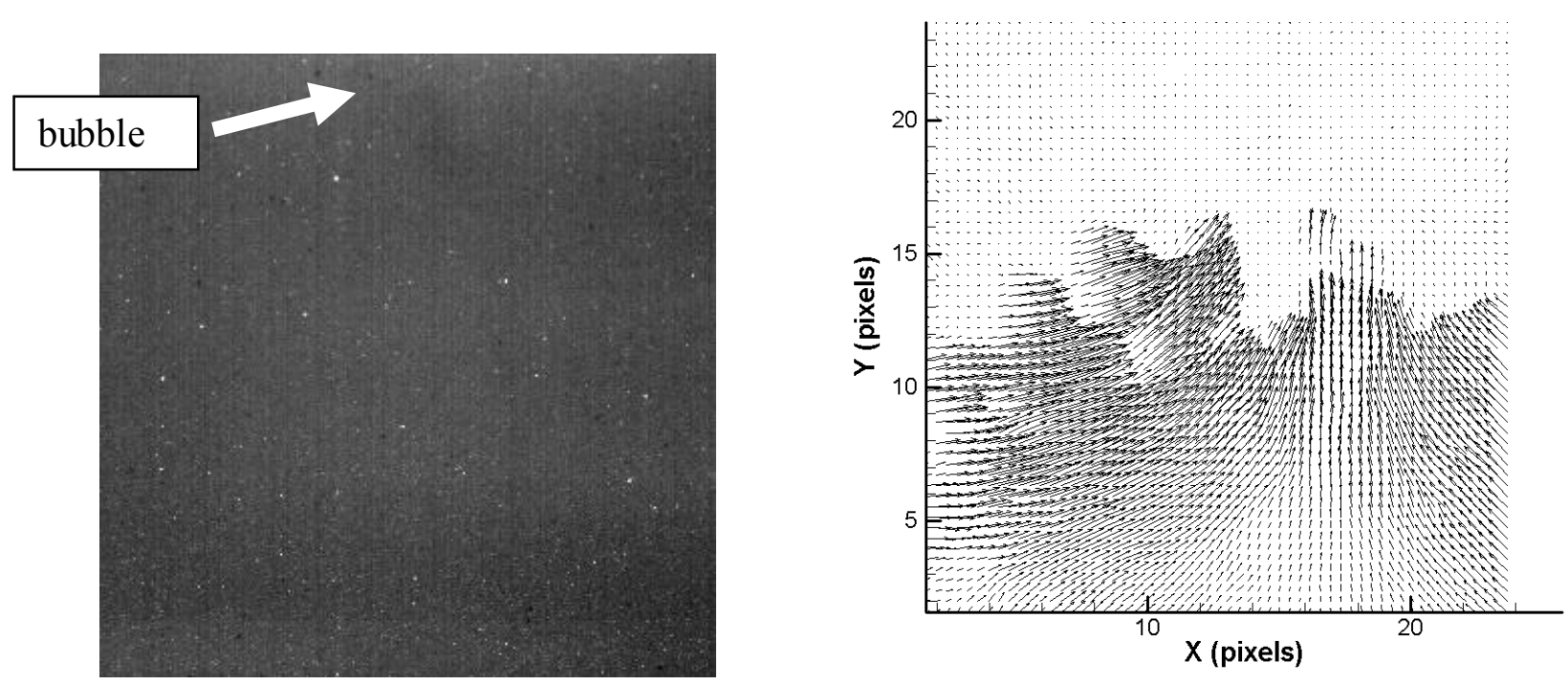

Figure 7. PIV image and corresponding velocity field for $150 \mu \mathrm{m}$ glass beads in $2 D$ fluidized bed at superficial gas velocity of approximately $0.03 \mathrm{~m} / \mathrm{s}$ (air flow rate of 10.9 liters/min) 


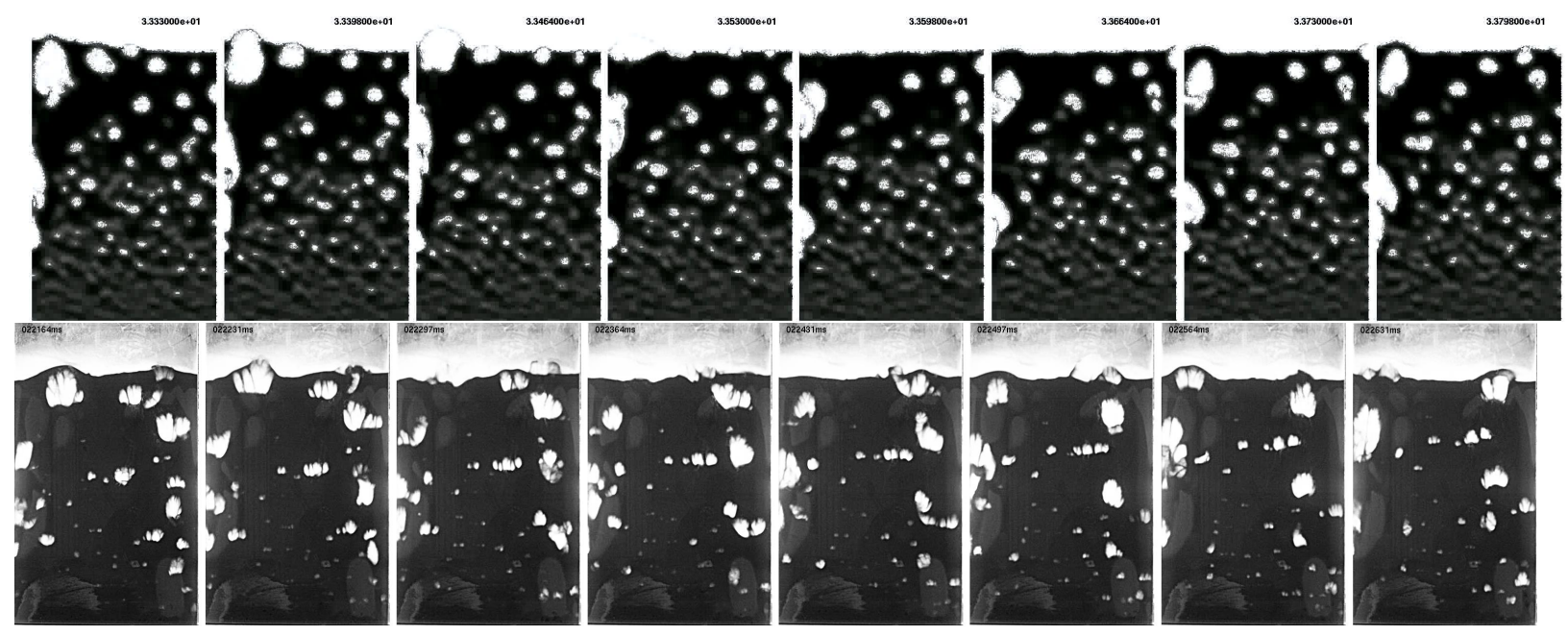

Figure 8. Arena-flow simulations (top) and experiments (bottom) showing low speed air jet injected into 2-dimensional fluidized bed $(50 \times 60 \times 1.35 \mathrm{~cm})$ operating under bubbling conditions with 150 um glass beads

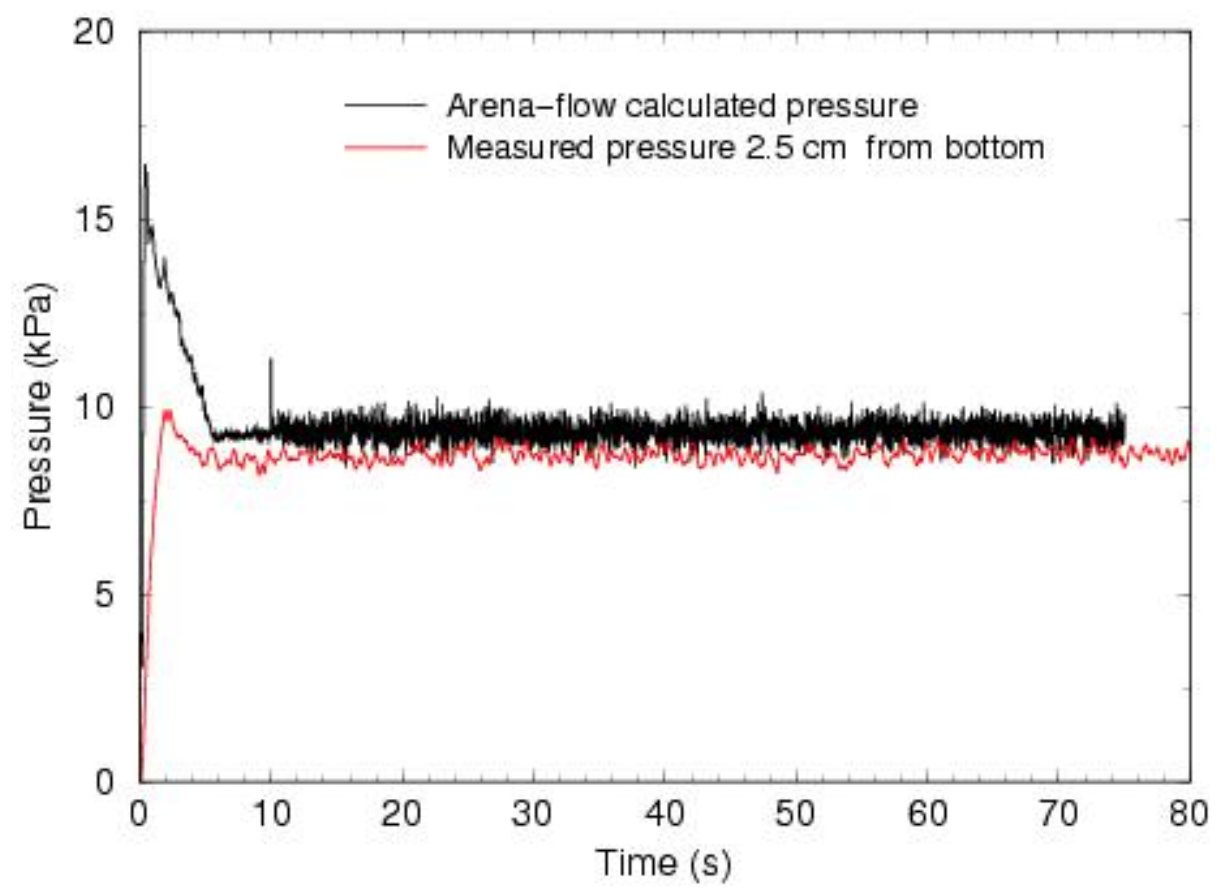

Figure 9. Data showing bed pressure as a function of time in the two-dimensional fluidized bed. Static conditions are a $60 \mathrm{~cm}$ deep bed of $150 \mu \mathrm{m}$ diameter glass beads (Potters P-0070, Figure 3). Pressure measurements are at $2.5 \mathrm{~cm}$ above the distributor. Experimental (red), Arena-flow simulations (black). Agreement is good after initial start up 


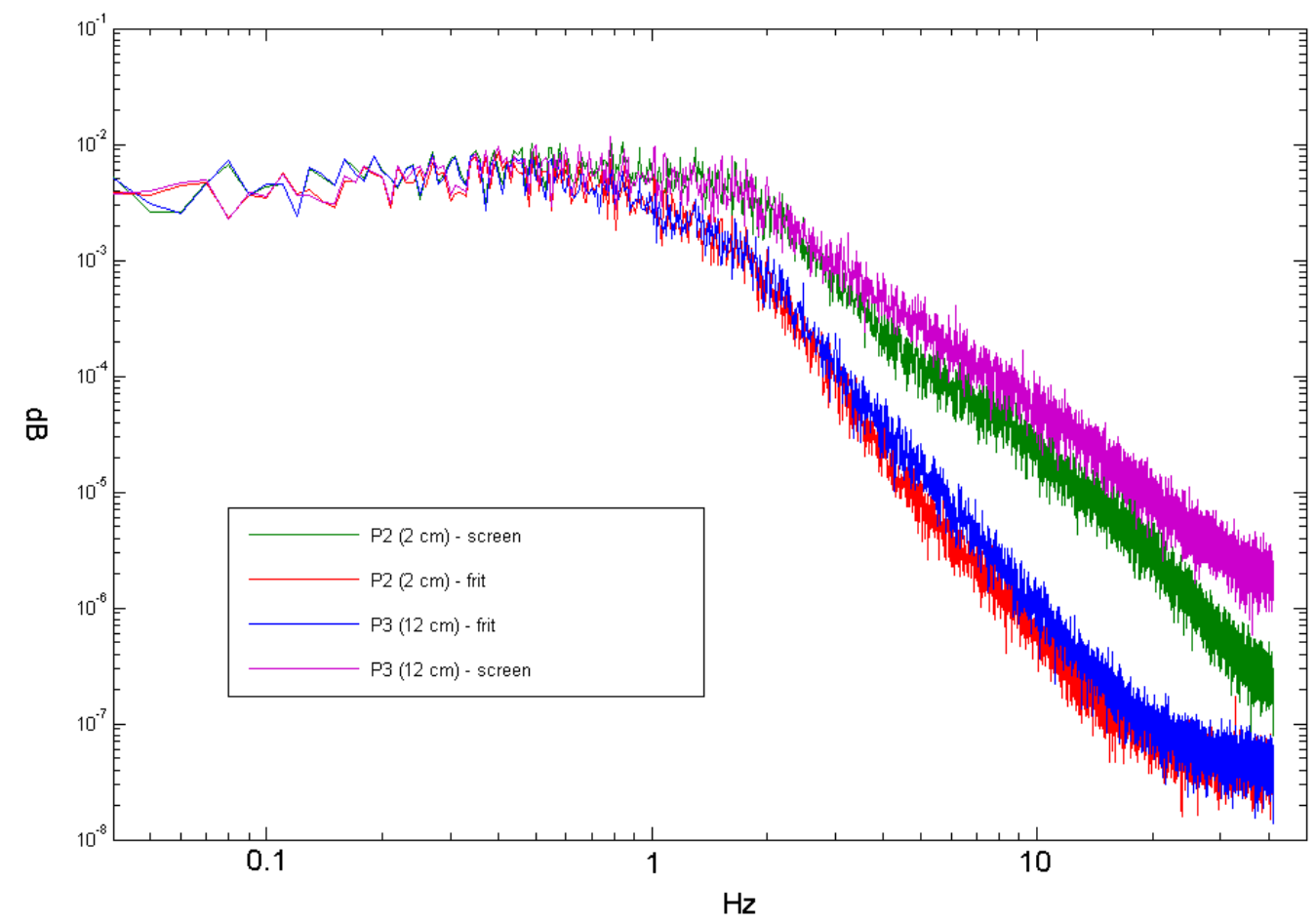

Figure 10. Spectral content of pressure measurements in $2 D$ bed. Note that the signals from pressure transducers with screens are stronger (in terms of spectral content) than those with frits

Further experiments were performed with both $30 \mathrm{~cm}$ high and $60 \mathrm{~cm}$ high beds of the $120-180 \mu \mathrm{m}$ diameter Potters Model P-0070 glass beads. Figures 11 and 12 are representative of all of pressure and flow measurements taken during these experiments. The velocities listed are superficial gas velocities, i.e., those in the freeboard above the fluidized bed. The locations of pressure taps above the distributor are given in $\mathrm{cm}$.

Transient data were also recorded for $2 \mathrm{D}$ bed experiments, and example of which is shown in Figure 13. In this experiment with a $60 \mathrm{~cm}$ high bed of glass beads, the fluidizing air was first turned on suddenly, followed by the sudden activation of a side jet of air, and then each was suddenly stopped in reverse order. The superficial gas velocity was $0.063 \mathrm{~m} / \mathrm{s}$ without the jet and $0.16 \mathrm{~m} / \mathrm{s}$ with the jet. As can be seen, the presence of the jet increases the magnitude of the pressure fluctuations, but does not increase the average pressure appreciably.

Additionally, a large series of experiments were performed in the 2D bed to explore the usefulness of particle image velocimetry (PIV) for solids velocity measurements. For the Redlake MotionPro cameras used, the largest field of view possible was approximately $5 \mathrm{~cm}$ wide, without losing resolution of individual glass particles. Figure 7 shows an example of a PIV-measured velocity field taken near the center of the bed. Since the passage of bubbles is sporadic, it was expected that more images than usual for PIV would be needed to acquire meaningful statistics. Therefore up to 40,000 images were taken and running averages of statistics for individual vectors were calculated. An example is shown in Figure 14. Images were processed in batches of 2000. The statistic presented is $\mathrm{V}^{\prime 2}$ (the square of the difference between instantaneous vertical velocity and average vertical velocity). As can be seen, this statistic seems to converge after approximately 30,000 images. This is somewhat larger than the approximately 10,000 uncorrelated velocity measurements typically needed to assure 
converged statistics in typical turbulent flows. This is thought to be due to the dominance of bubbles in driving the flow field, causing some of the velocity fields to be correlated. Each bubble passage causes a characteristic sequence of nearby velocity values (upward above the bubble, outward near the bubble, and inward and upward in the bubble wake (as shown in Figure 7). Neighboring images acquired at 30 frames/sec are not totally uncorrelated because the bubble passages involve several sequential frames. This number of images can be acquired quickly but processing takes 1-2 days. Added to the fact the 5 $\mathrm{cm}$ is a relatively small portion of the $2 \mathrm{D}$ bed, the conclusion is that, with currently available cameras, PIV requires too much time to map out the entire flow field.

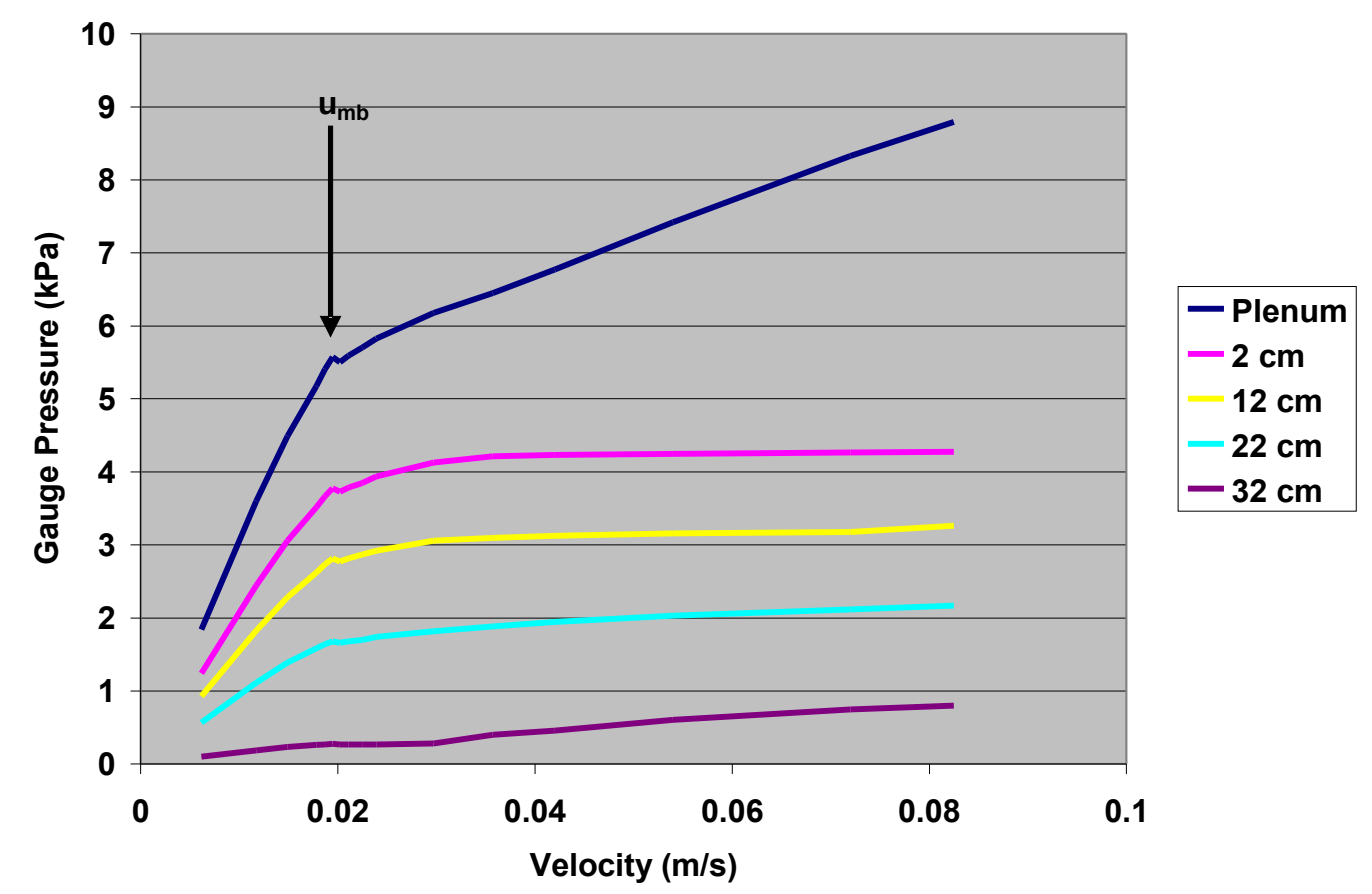

Figure 11. Bed pressures vs. freeboard velocity for $30 \mathrm{~cm}$ high 2D bed of glass beads

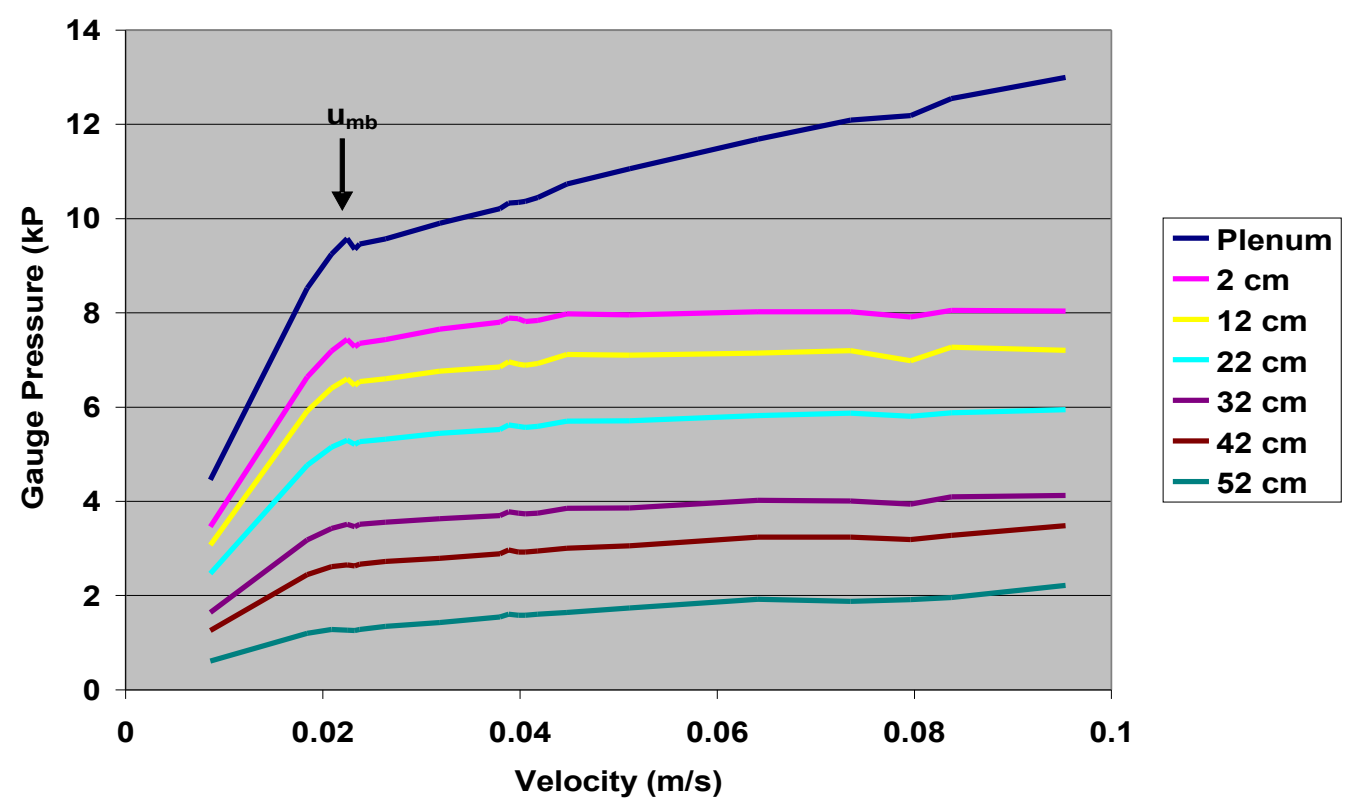

Figure 12. Bed pressures vs. freeboard velocity for $60 \mathrm{~cm}$ high 2D bed of glass beads 


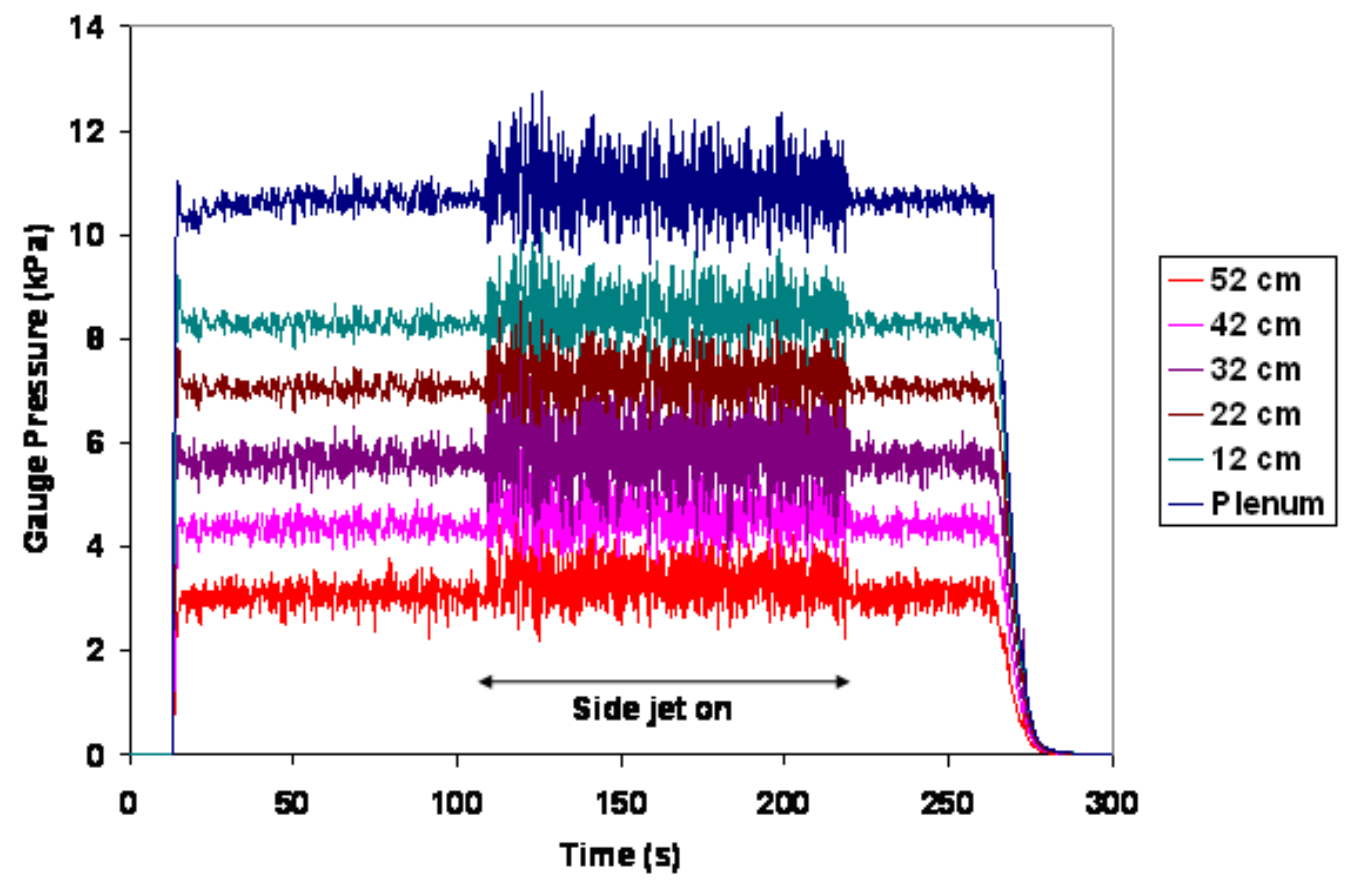

Figure 13. Pressure traces from 2D bed experiment with a $60 \mathrm{~cm}$ high bed of glass beads. The fluidizing air was first turned on suddenly, followed by the sudden activation of a side jet of air, and then each was suddenly stopped in reverse order. The superficial gas velocity was 0.063 $\mathrm{m} / \mathrm{s}$ without the jet and 0.16 with the jet

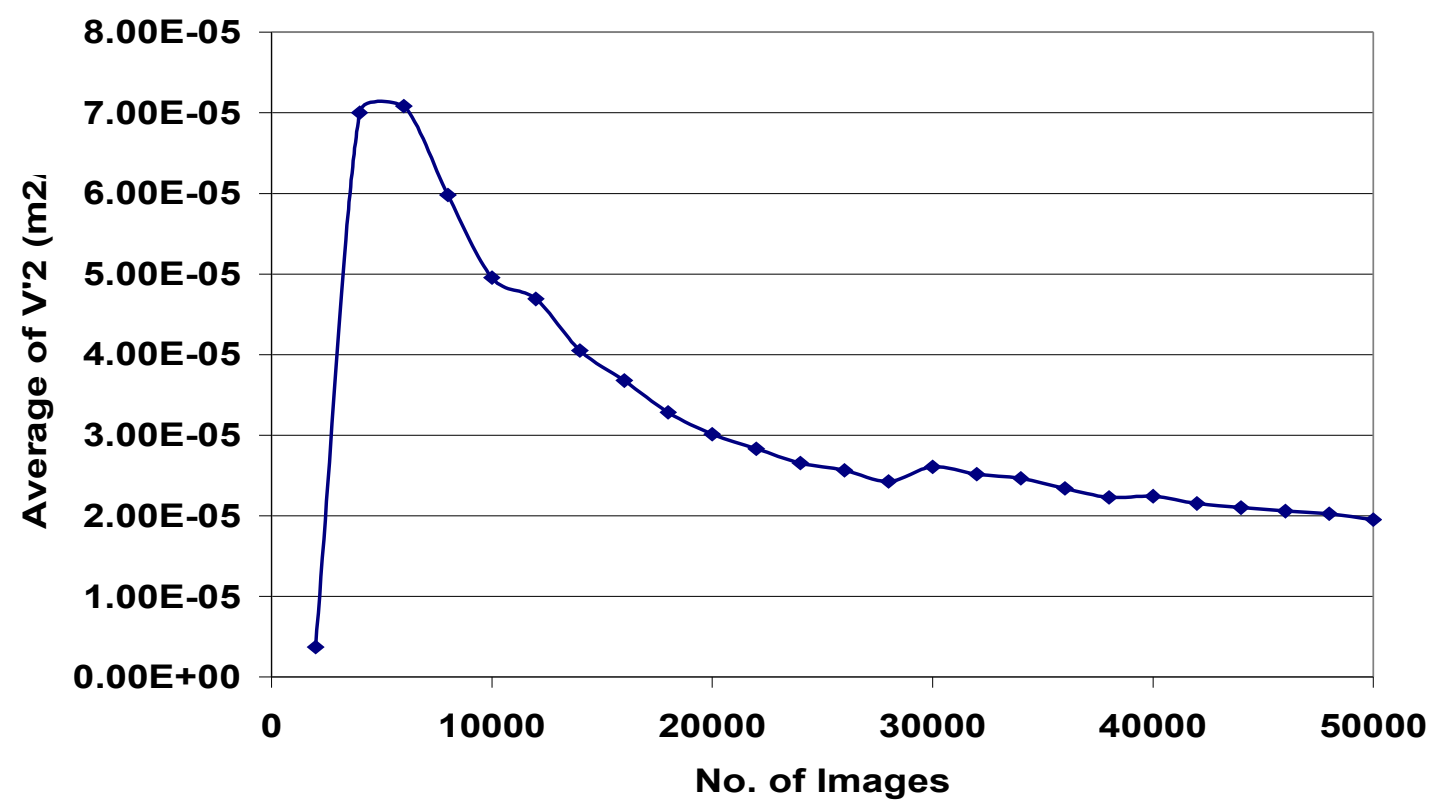

Figure 14. Running average of $V^{2}$ for location near center of $2 D$ bed, conditions same as those presented in Figure 13 without jet operating 


\section{Small Fluidized Bed}

A 10.2-cm ID, 244-cm high fluidized bed (also called the "narrow bed") was also constructed, initially to measure the pressure drop across a narrow portion of the porous distributor and particle bed planned for use in the large-scale 3D bed. The small bed was fully instrumented with pressure transducers in the air feed plenum and axially along the bed, an air humidification system and humidity meter, and a gas flow meter. The setup is shown in Figure 15.

Experiments in this bed were designed to examine particle drag and segregation behavior. Experimental test plans on particle drag models and particle segregation (literature review and proposed experiments) were developed for this bed, and will be discussed below (see also Appendix A and B).

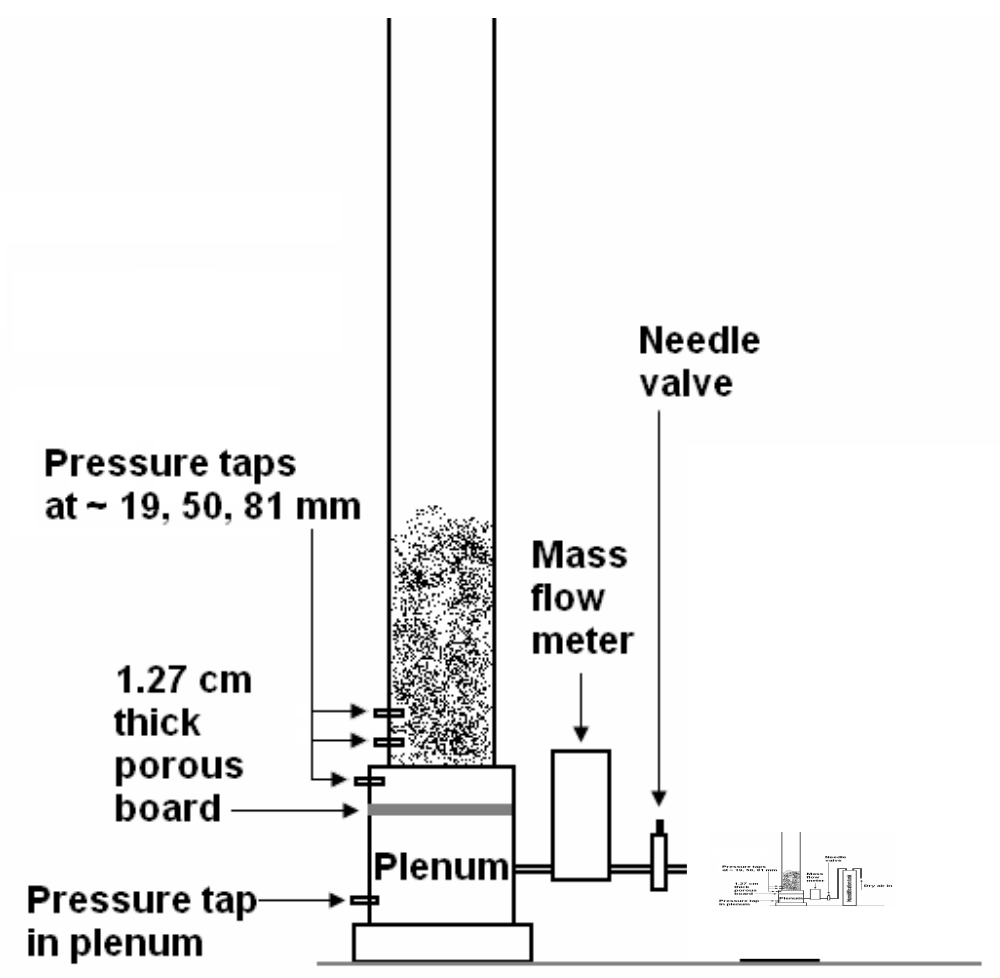

Figure 15. Setup of small fluidized bed experiment

\section{Drag (pressure drop) experiments in the small fluidized bed}

Drag models are typically written in terms of a single particle diameter, and their applicability to particles with a range of diameters, as typically used in industrial processes, is uncertain. In other words, if a model can accurately predict the drag on a single particle, can it also predict the drag on a particle size distribution? Experiments were aimed at assessing the accuracy of particle drag models implemented in Barracuda ${ }^{\mathrm{TM}}$. See Appendix A for further details of the experimental plan.

Drag experiments were performed in the narrow fluidized bed using beds of glass beads with diameter ranges of $120-180 \mu \mathrm{m}, 300-430 \mu \mathrm{m}$, and $600-710 \mu \mathrm{m}$. All three size ranges were used in experiments with a bed height/diameter ratio of 1 , and an additional experiment was performed with the120-180 $\mu \mathrm{m}$ beads with a bed height/diameter ratio of 2 . Starting with a quiescent bed, superficial gas velocity was increased to a maximum, then decreased, while differential pressures at several bed heights and videos were recorded. The bed height and pressure drop were measured, from which the drag per unit volume in the fluidized bed was calculated. Bed height and pressure drop were calculated 
from pressure measurements at three axial locations along the bed. Initial comparison of experimental data with Barracuda ${ }^{\mathrm{TM}}$ simulations showed that the mass and volume of particles present in the static bed prior to initiating air flow are key measurements needed in order to accurately model the flow (because the Ergun relation is sensitive to these values). These measurements were carefully made and reported for all subsequent experiments.

Figure 16 and Table 1 show the results of one such experiment with a $10.2 \mathrm{~cm}$ high bed of glass beads (120-180 micron) fluidized with dry air at various velocities. The uncertainty bars are identical for each data point and are very small, but are only shown on a few to improve the figure's readability. The uncertainties for superficial gas velocity are derived from the flowmeter uncertainty and are \pm 0.3 $\mathrm{m} / \mathrm{s}$ for velocities less than $12 \mathrm{~m} / \mathrm{s}$ and $\pm 3 \mathrm{~m} / \mathrm{s}$ for velocities greater than $12 \mathrm{~m} / \mathrm{s}$.

The gauge pressure at the bottom of the bed is equal to the differential pressure across the bed because the bed is open to the atmosphere. The pressure at the base of the bed was obtained by linearly extrapolating the pressure vs. height data (obtaining the y-intercept in Figure 16). Similarly, the bed height was obtained by linearly extrapolating the data to the x-axis. Figure 17 shows differential pressures vs. superficial gas velocity for this experiment at the three axial locations of pressure taps.

The results from the first experiment (120-180 $\mu \mathrm{m}$ glass beads with a height/diameter ratio of 1) are presented here, and the results from the other three experiments are qualitatively similar. These results are summarized in Figure 18. Plenum pressures (right axis) and pressures at three bed heights (left axis) are plotted against superficial gas velocity. In a number of successive runs, superficial gas velocity was first increased then decreased, as denoted in the legend.

A noticeable feature in Figure 18 is the hysteresis in the first three runs: as superficial gas velocity is repeatedly increased and decreased, the recorded pressures within the bed rise. After observing this behavior, the bed was operated for several hours at the maximum superficial gas velocity (between runs 3 and 4). After this, pressures no longer increased with successive runs (run 4 encompassed several successive runs). Thus, after this "break-in" period (operating the bed at a high superficial gas velocity for several hours), the bed behaved in a repeatable fashion with no clear hysteresis. The reason for this appears to be the elutriation of fine particles (on the order of $10 \mu \mathrm{m}$ ) out of the bed, which are completely removed after several hours. These fines accumulated on a fine screen capping the bed, which were collected and amounted to a volume only on the order of $1 \mathrm{~mL}$, compared to a bed volume of 825 to $1650 \mathrm{~mL}$.

Fines were not observed collecting on the screen when operating the bed with larger-size-range particles. They appear only to be present in the $120-180 \mu \mathrm{m}$ particles.

Finally, some noise is noticed in the data in Figure 18 when the superficial gas velocity is less than $0.05 \mathrm{~m} / \mathrm{s}$. This is the region in which bubbling fluidization first takes place when increasing gas velocity (and where it stops when decreasing velocity). This process tends to occur unevenly, with certain regions bubbling and others not during either transition. The locations of the regions vary sometimes near the pressure taps, sometimes not - which explains the noise in the recorded pressure signals.

The differential pressure across the entire bed and the bed height were also used to straightforwardly calculate the drag per unit volume. Since the intention of the experiments was to verify drag models, these values are plotted against three drag models in Figure 19. The drag models using for comparison were, first, two versions of the Ergun equation. The Ergun equation is intended to predict the drag across a packed bed of particles. The first version is presented by Syamlal and O'Brien (1987) and is used in the multiphase computational fluid dynamics code MFIX. The second is presented by Gidaspow (1994) and is the more common version (the versions are identical in form and 
differ only by constants). Finally, a model presented by Gidaspow (1994) for void fractions greater than 0.8 is included. These models are plotted for all superficial gas velocities for completeness and are not expected to match the data in most cases. Rather, the purpose is to observe the general trends of each model with increasing superficial gas velocity.

The Ergun equation should be capable of predicting the pressure drop across a packed bed (the three lowest velocities, before bubbling begins). The second version (Gidaspow, 1994) predicts the pressure drop corresponding to the lowest velocity $\left(0.0084 \mathrm{~m} / \mathrm{s}\right.$ ) reasonably well (data: $5200 \mathrm{~N} / \mathrm{m}^{3}$; model: $\left.4900 \mathrm{~N} / \mathrm{m}^{3}\right)$. However, for the next velocity $(0.016 \mathrm{~m} / \mathrm{s})$ the model predicts double the experimental value, and for the following velocity $(0.021 \mathrm{~m} / \mathrm{s})$ the model predicts triple the experimental value. Also note that the other version of the Ergun equation (Syamlal and O'Brien, 1987) is significantly offset from the Gidaspow version.

Pressure and flow data, and videos, were collected for a variety of particle types and bed aspect ratios. An experimental test matrix including 4 particle types and 1 or 2 bed aspect ratios was completed. Examples of these data are shown in Figure 20.

\section{Particle segregation experiments in the small fluidized bed}

Appendix B presents the particle segregation test plan. Segregation is relevant in industrial processes for a number of reasons, including effects on reaction rates and wear. The literature contains many studies of binary particle mixtures (i.e., non-overlapping size distributions) with gas velocities very close to the minimum fluidization velocities of the individual components. However, the industrial processes of concern here involve much higher gas velocities (well in excess of minimum fluidization velocity) and segregation under such conditions has not been extensively studied in the past. A typical assumption is that fluidized beds operated at high gas velocities are well-mixed. This was tested in a preliminary set of experiments performed in the narrow bed. A mixture of polystyrene particles $(0.99-1.68 \mathrm{~mm})$ and colored sand $(\sim 0.4 \mathrm{~mm})$ was fluidized with gas velocities up to 10 times the minimum fluidization velocity. Pressures and flow rates were measured and video was recorded. Figure 21 shows another segregation setup with glass beads of two distinct density and diameter ranges (blue is glass $120-180 \mu \mathrm{m}, 2.5 \mathrm{~g} / \mathrm{cc}$ and white is polystyrene $1000-1670 \mu \mathrm{m}, 1 \mathrm{~g} / \mathrm{cc}$ ).

An initial segregation experiment was performed to investigate the feasibility of measuring size segregation when particles of distinct size ranges are mixed during fluidization. Equal masses of $300-430 \mu \mathrm{m}$ and 600-710 $\mu \mathrm{m}$ diameter glass beads were measured out so that the total volume equaled that of a bed with an aspect ratio of 1 . The particles were initially well mixed by running the bed at a high superficial gas velocity. Then the superficial gas velocity was lowered to a value of $0.21 \mathrm{~m} / \mathrm{s}$ where some obvious segregation took place (some mixing, but a visible layer of larger particles on the bottom) as shown in Figure 22. The bed was operated at this velocity for over an hour, then stopped suddenly by venting the plenum with a valve. Layers of particles were then vacuumed off into a container specially designed to prevent the loss of particles in filters, seams, etc. Each sample was sieved and weighed. Three layers approximately $2 \mathrm{~cm}$ deep were first removed, and the final $4 \mathrm{~cm}$ was removed all at once. The results are shown in Figure 23. The total weight of the sieved samples was compared to the weight of the initial batch of particles, and it was found that only approximately $2 \mathrm{~g}$ (out of a total of approximately $1200 \mathrm{~g}$ ) was lost during vacuuming, sieving, and transferring particles. As Figure 23 shows, the segregation, which was obvious visually, could be quantified by the method of vacuuming, sieving, and weighing. 


\section{Other Experiments in Small Fluidized Bed}

The deaeration properties of a fluidized bed are often used to characterize the bed properties. Deaeration involves the rapid loss of the fluidizing gas, converting the fluidized gas-solid system back to a packed bed. Deaeration occurs in two stages, a rapid disengagement as gas bubbles leave the system and then a gradual settling of the fluidized solids as gas escapes from the void spaces. By carefully monitoring the bed height during deaeration using pressure and video measurements, these rates can be measured.

Several deaeration experiments were performed with Group A particles (Group B particle defluidize rapidly, so such experiments are not useful). FCC particles were used, with mean diameter $65 \mu \mathrm{m}$ and density $1275 \mathrm{~kg} / \mathrm{m}^{3}$. An example of these data is shown in Figure 24.

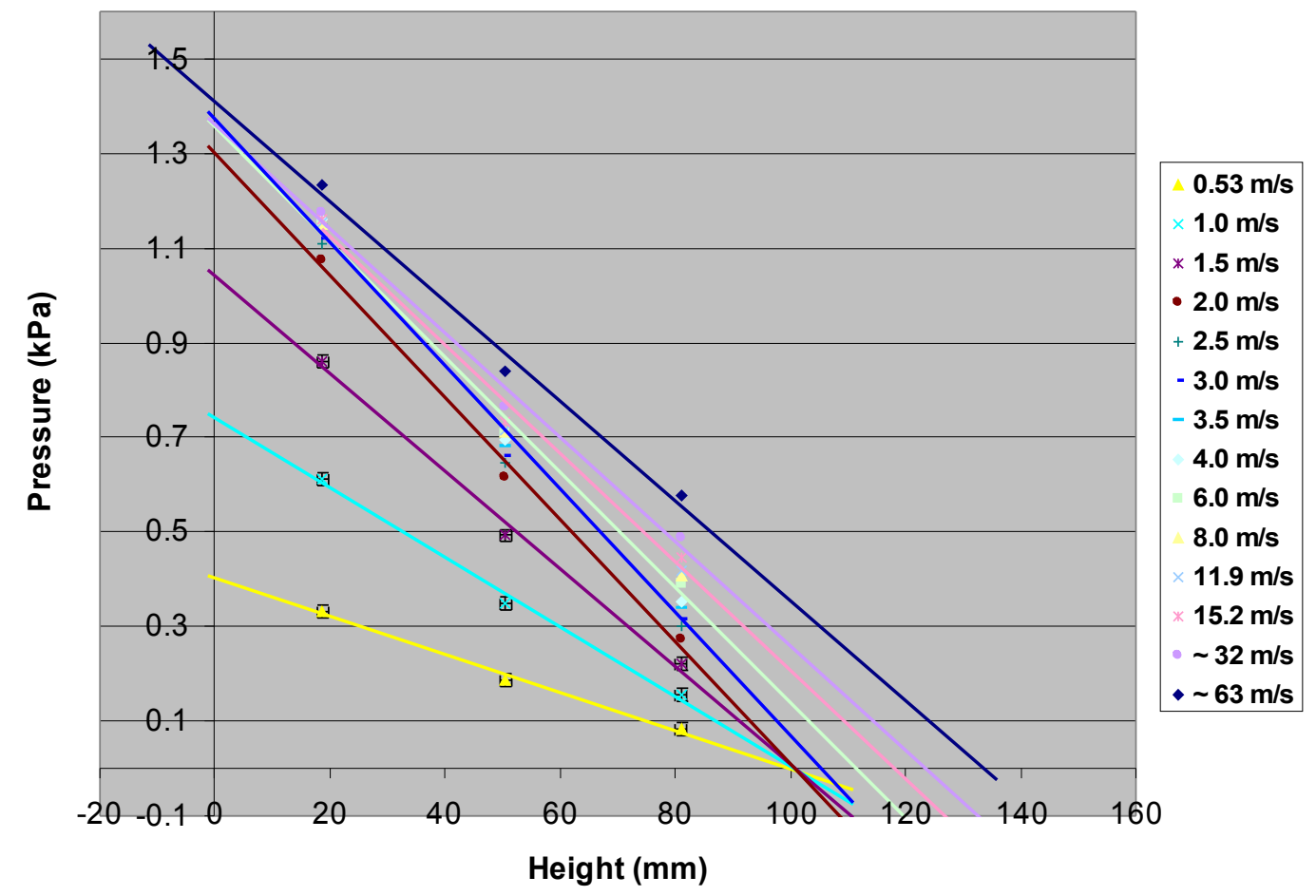

Figure 16. Pressure vs. Height in $10.2 \mathrm{~cm}$ ID Fluidized Bed using Potters P-0070 glass beads fluidized with air at the fluidization velocity values shown in the legend 


\begin{tabular}{c|cc}
$\begin{array}{c}\text { Superficial } \\
\text { gas velocity }\end{array}$ & $\begin{array}{c}\text { Pressure } \\
\text { @ bottom } \\
(\mathrm{kPa})\end{array}$ & $\begin{array}{c}\text { Bed height } \\
(\mathrm{mm})\end{array}$ \\
\hline $0.53 \mathrm{~m} / \mathrm{s}$ & 0.402 & 99.9 \\
$1.0 \mathrm{~m} / \mathrm{s}$ & 0.7401 & 100.6 \\
$1.5 \mathrm{~m} / \mathrm{s}$ & 1.04 & 100.7 \\
$2.0 \mathrm{~m} / \mathrm{s}$ & 1.299 & 100.4 \\
$2.5 \mathrm{~m} / \mathrm{s}$ & 1.335 & 102.6 \\
$3.0 \mathrm{~m} / \mathrm{s}$ & 1.347 & 103.7 \\
$3.5 \mathrm{~m} / \mathrm{s}$ & 1.371 & 105.2 \\
$4.0 \mathrm{~m} / \mathrm{s}$ & 1.384 & 106.5 \\
$6.0 \mathrm{~m} / \mathrm{s}$ & 1.356 & 111.1 \\
$8.0 \mathrm{~m} / \mathrm{s}$ & 1.354 & 112.9 \\
$11.9 \mathrm{~m} / \mathrm{s}$ & 1.355 & 113.8 \\
$15.2 \mathrm{~m} / \mathrm{s}$ & 1.354 & 117.4 \\
$\sim 32 \mathrm{~m} / \mathrm{s}$ & 1.36 & 122.8 \\
$\sim 63 \mathrm{~m} / \mathrm{s}$ & 1.412 & 132.7
\end{tabular}

Table 1. Extrapolated Pressure at Bottom of Fluidized Bed

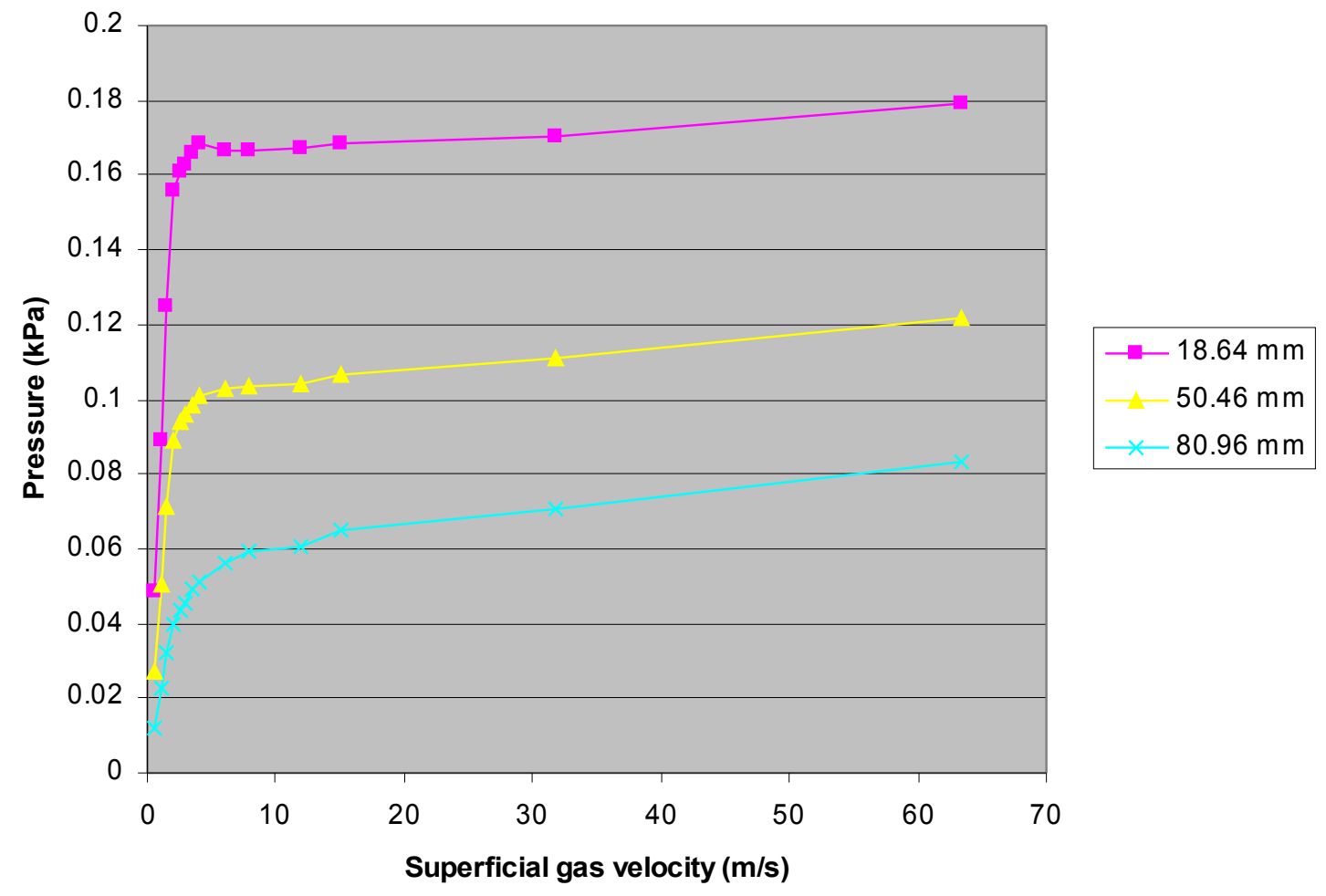

Figure 17. Pressure vs. Superficial Velocity 


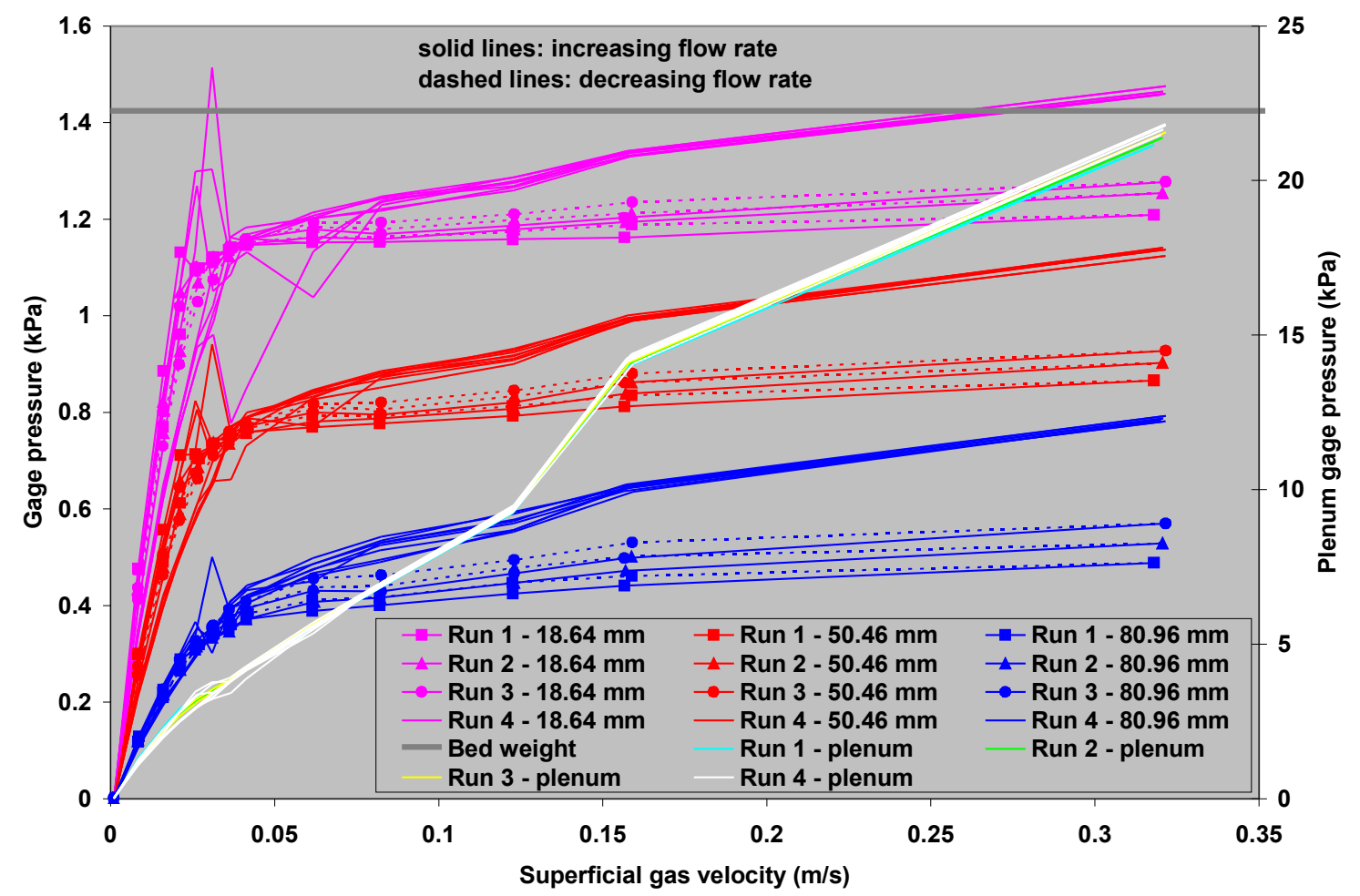

Figure 18. Pressure vs. superficial gas velocity for $10.2 \mathrm{~cm}$ high fluidized bed using air and glass beads (120-180 $\mu \mathrm{m}$ diameter range)

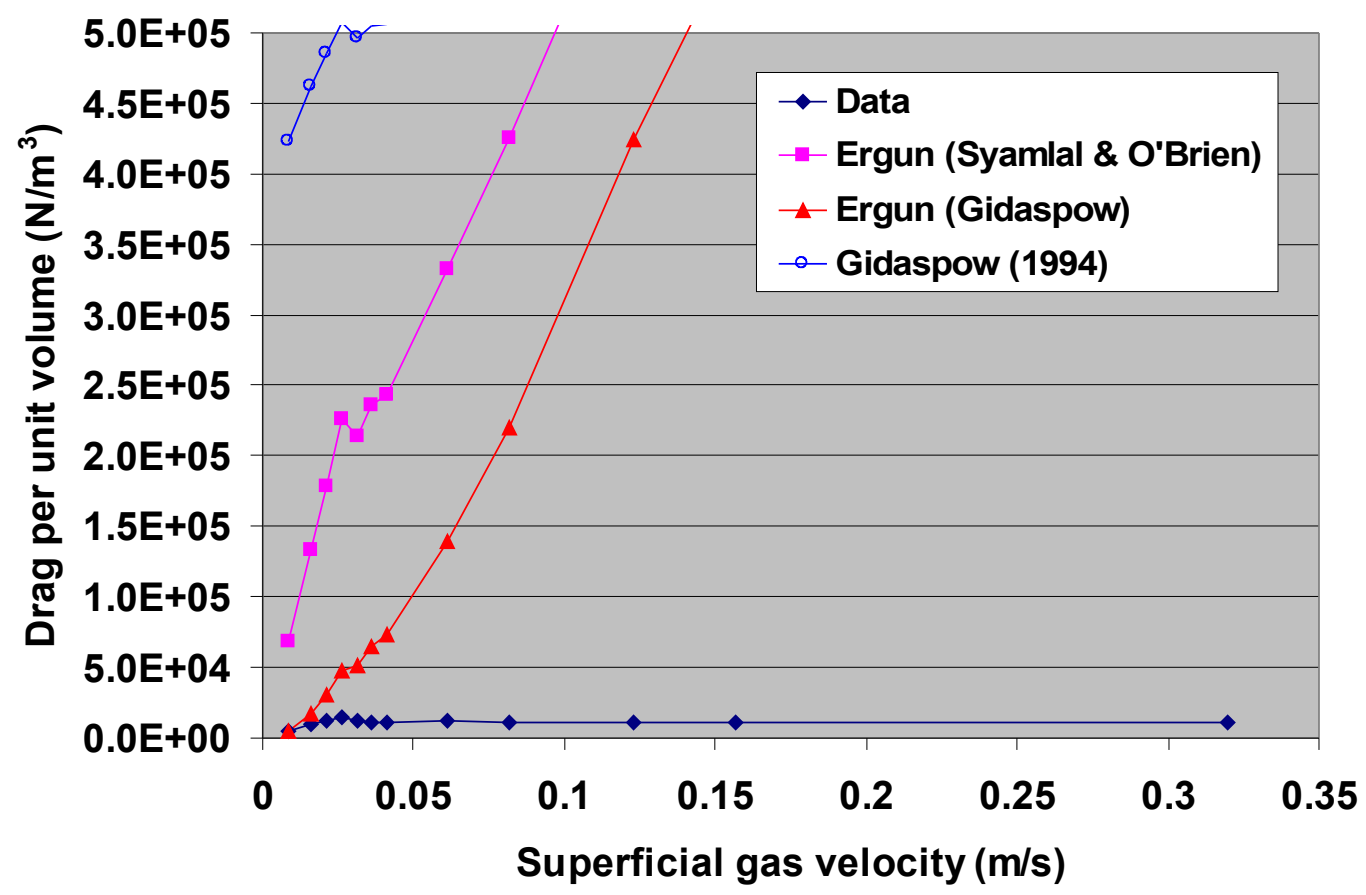

Figure 19. Drag per unit volume vs. superficial gas velocity for experimental data and models. Because bubbling fluidization starts at approximately $0.025 \mathrm{~m} / \mathrm{s}$, only the first three data points are expected to agree with the Ergun equation 


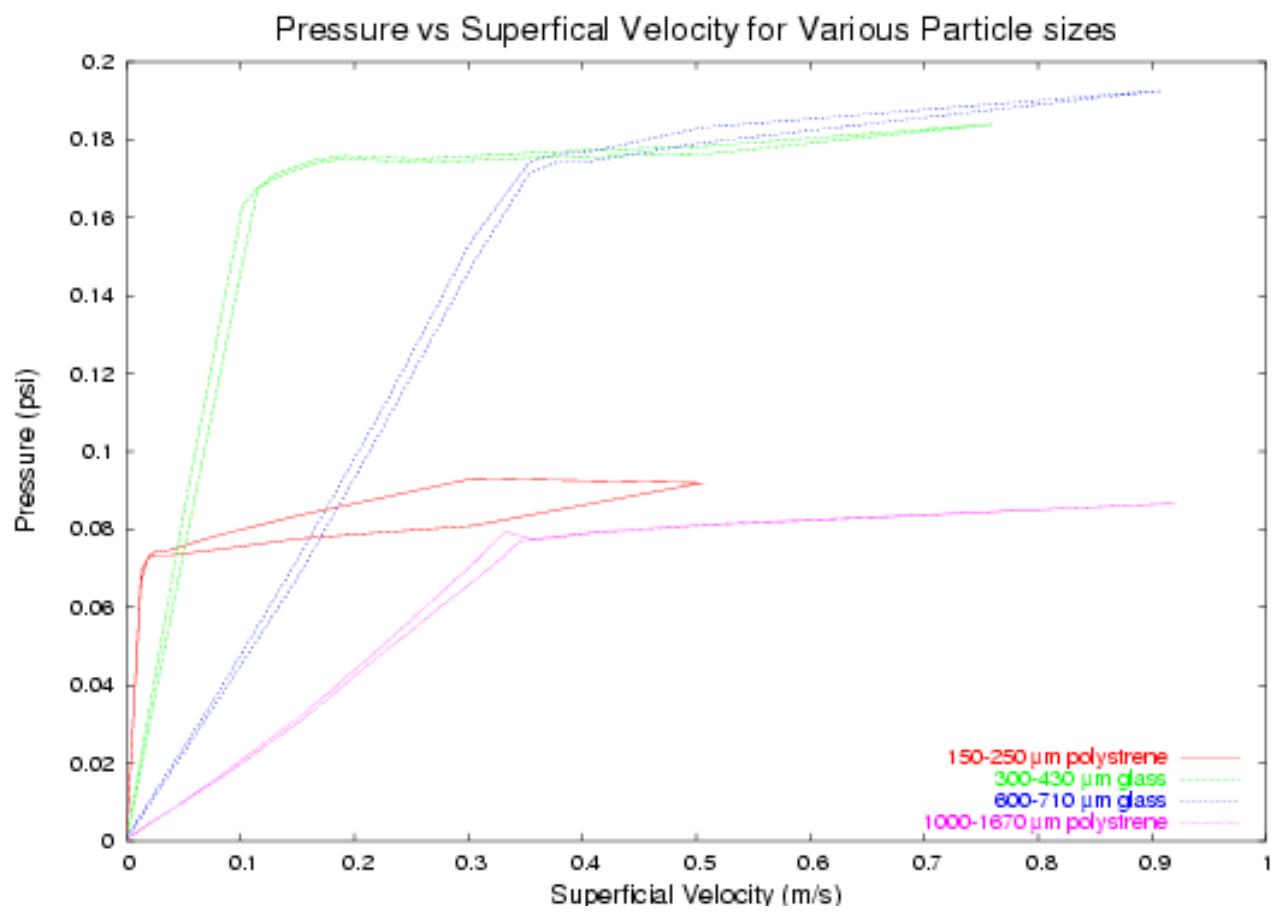

Figure 20. Pressure vs. superficial gas velocity for four particle types (particle diameter ranges indicated in legend), from 0 to many times minimum fluidization. Some hysteresis is seen as gas flow is increased (lower curve of each color) then decreased (upper curves for each color), and is typical. The glass has a density of $2500 \mathrm{~kg} / \mathrm{m}^{3}$ and the polystyrene has a density of $1050 \mathrm{~kg} / \mathrm{m}^{3}$. Pressures were recorded $16.64 \mathrm{~mm}$ above the distributor
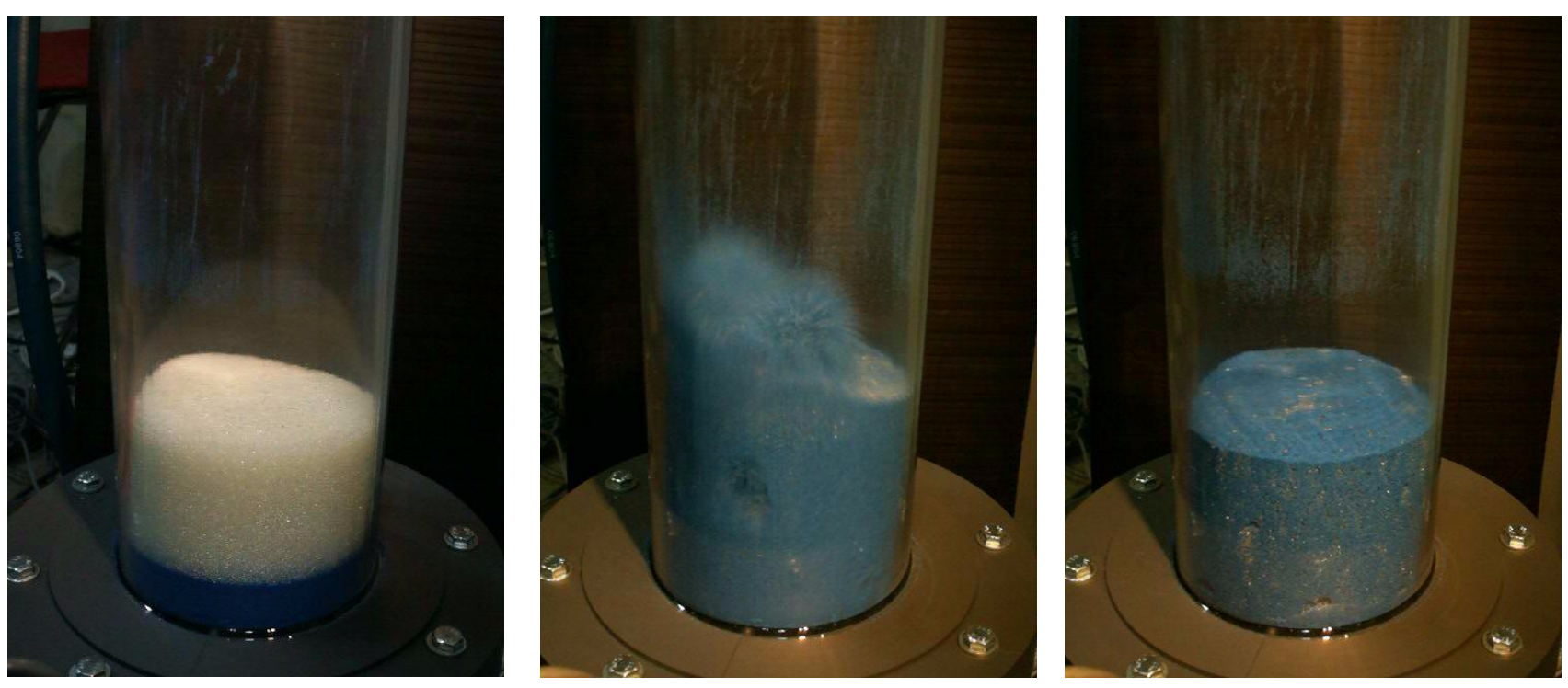

Figure 21. Photos of fluidized bed operating with glass beads of two distinct density and diameter ranges (blue is glass 120-180 $\mu \mathrm{m}, 2.5 \mathrm{~g} / \mathrm{cc}$ and white is polystyrene1000-1670 $\mathrm{m}, 1 \mathrm{~g} / \mathrm{cc}$ ) 


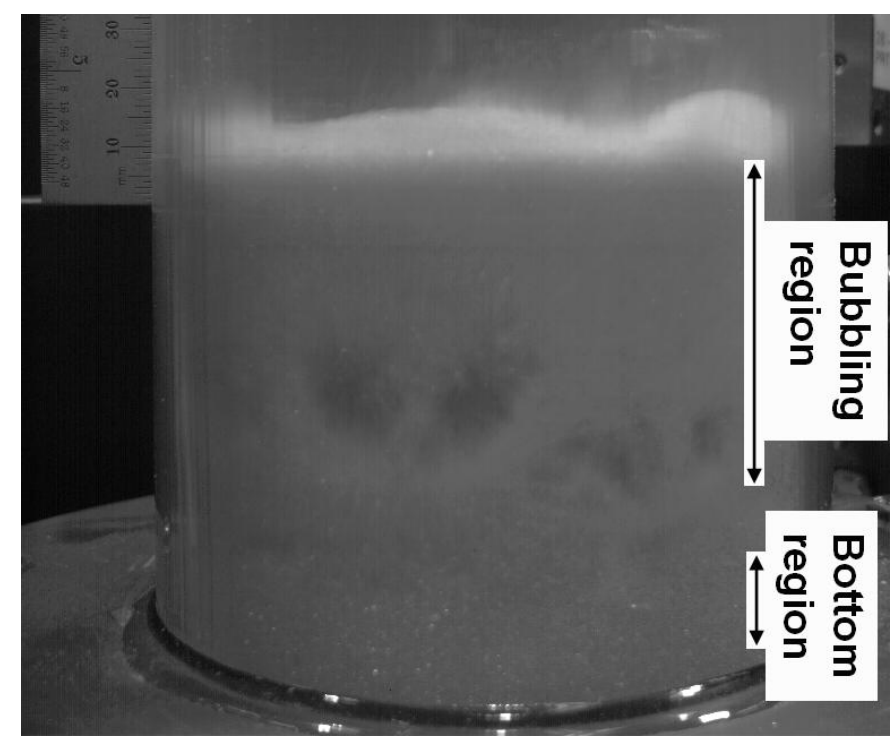

Figure 22. Photo of fluidized bed operating with glass beads of two distinct diameter ranges (300-430 $\mu \mathrm{m}$ and 600-710 $\mu \mathrm{m})$. Segregation measurements were made after the flow was stopped suddenly by venting the plenum

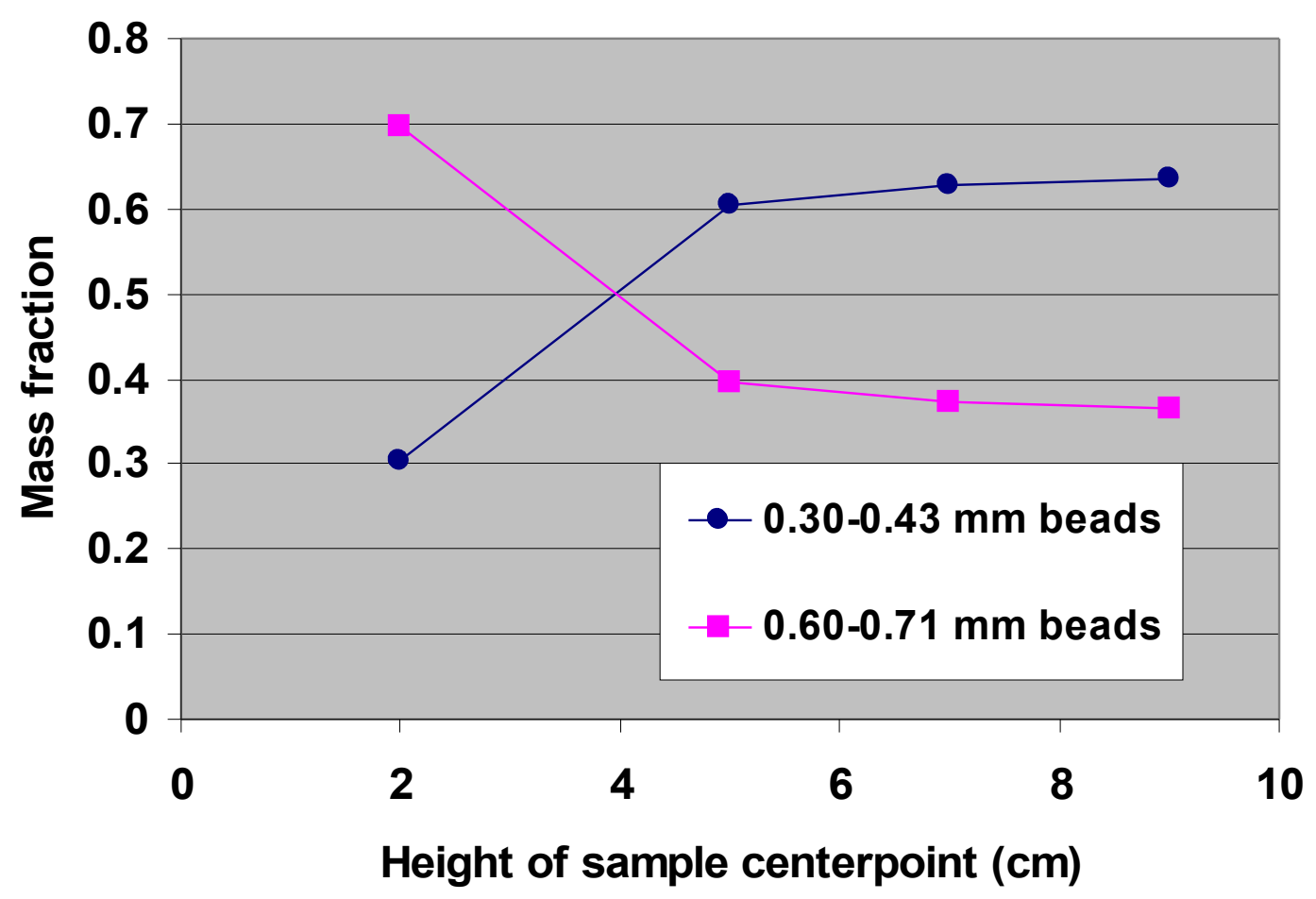

Figure 23. Mass fraction of different size-range glass beads as a function of height. Sample layers were $\sim 2 \mathrm{~cm}$ thick except bottom layer which was $\sim 4 \mathrm{~cm}$ thick 


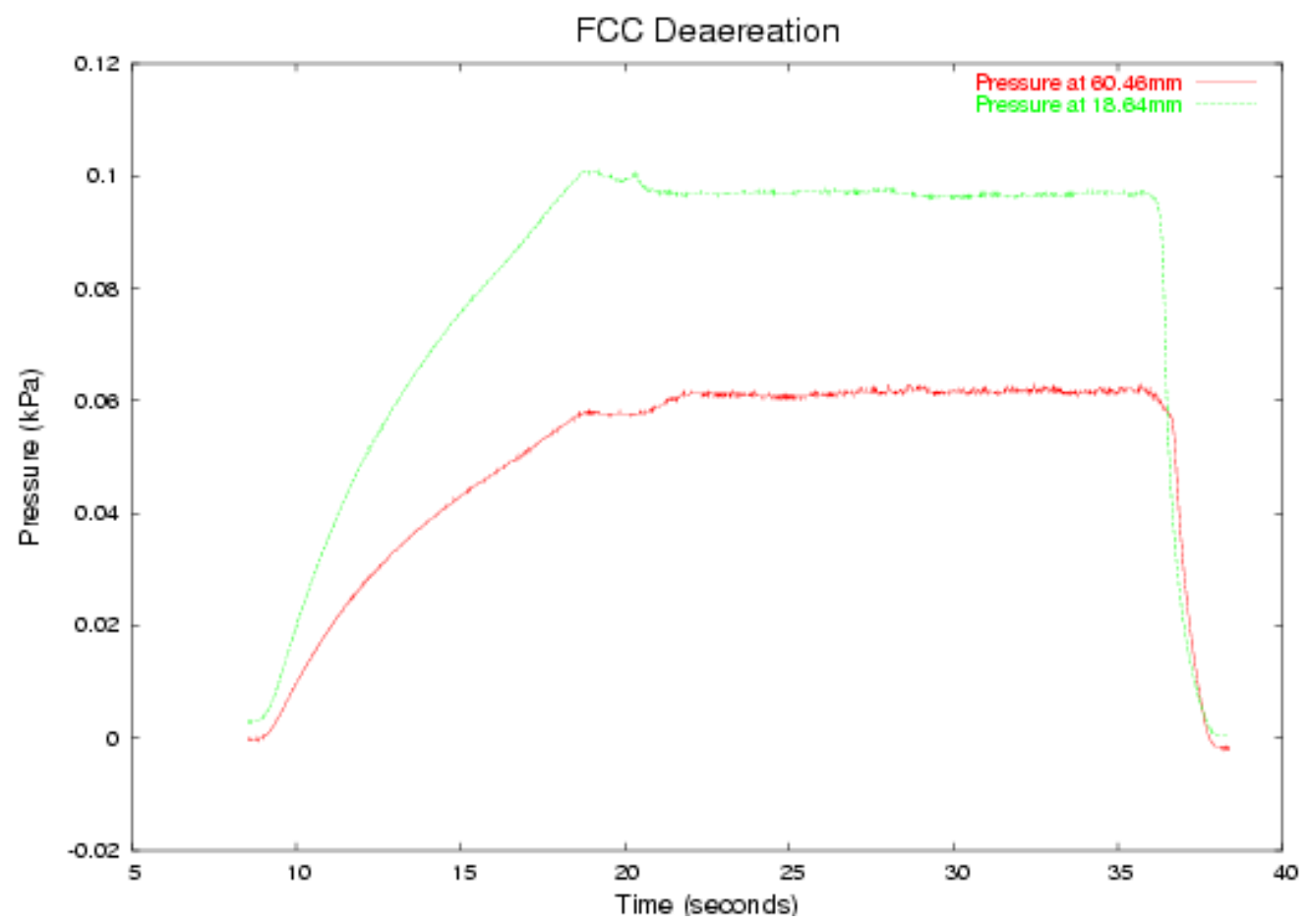

Figure 24. FCC catalyst fluidized at approximately minimum fluidization, then pressure was cut off at time $=36$ seconds and the plenum evacuated. Pressure fell to zero in 0.43 seconds

\section{Large-Scale Fluidized Bed (Design)}

The original intent was to build roughly 3 -ft diameter fluidized bed that would be used to acquire validation data, especially effects unique to large-scale systems such as the effect of nonuniform gas feed at the base and how to detect it, and the effectiveness of small scale carryover correlations to larger-scale flows, as well as to provide validation data sets at larger scale than typically available in the literature. However, delays in funding required that we proceed with small scale experiments, and, after several funding delays, it eventually became too late in the project to commit additional funds towards construction of the large-scale system, since insufficient time remained to use it to acquire data. A few details of the planned apparatus are included in this Final Report for completeness.

The design of the large-scale fluidized bed experiment (Figure 25) was made with input from the industrial partners. The designed bed diameter was $0.83 \mathrm{~m}$ (32.6 inches) inner diameter in order to minimize wall effects. The Sandia compressors can provide the needed air flowrates to operate such a fluidized bed at reasonably high superficial gas velocities. The acrylic cylinder, a supporting stand, a dust collector, and gamma analysis electronics were all purchased. Data acquisition hardware was selected and purchased and a preliminary LabVIEW ${ }^{\mathrm{TM}}$ data acquisition and analysis program were written. The existing gamma densitometry tomography traverse (Shollenberger et al., 1997) would have required modification to hold the gamma source and detectors around this large diameter vessel. That design was completed but the modifications were not made.

The dust collector was partially installed, with only final electronic installation of controls remaining. The first of two gas distributors (the porous distributor) was designed and constructed. When this part of the project was terminated, the tasks remaining included:

- Construction of a plenum for the porous distributor (design was completed)

- Completion of dust collector 
- Selection and installation of cyclone and particle capture system for carryover studies

- Installation of pressure transducers, gas flow controllers, humidification system, and flow meter.

- Selection of particle types

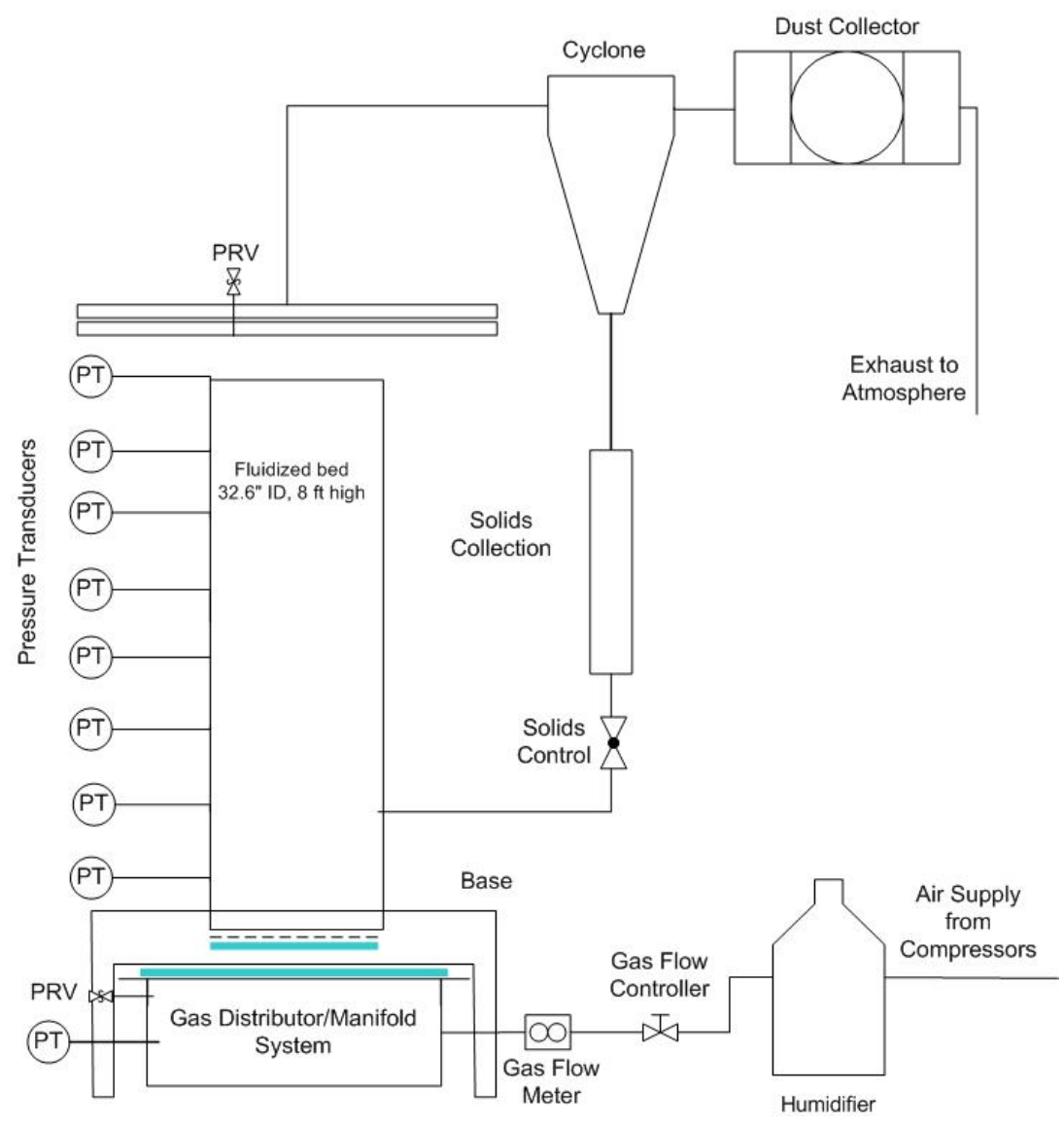

Figure 25. Design of large fluidized bed experiment 


\section{Appendix A: Experimental plan for Particle Drag}

\section{Overview}

Many particulate drag models appear in the literature, and are used in industry to predict basic flow parameters in fluidized beds and in computational simulations, where they may be applied cell-by-cell to predict flow behavior. Models typically involve a single particle diameter, and while it is possible to use an "effective diameter", there is uncertainty in the application of drag models to particle size distributions, even more so if a mixture of particles with distinct (i.e., non-overlapping) size distributions is involved. Some of these experiments were completed during this project and others had had to be shelved due to funding limitations.

\section{Basic idea}

By measuring the differential pressure across fluidized beds, the drag for different particles types and mixtures can be measured. Data can then be used for comparison with models. Experiments will be performed in the narrow (4") bed.

\section{Questions to be answered}

Can any drag models in the literature, or our own analysis, predict the drag across mixtures of particles knowing the drag across beds of single particle types? And related: Which drag models in the literature can reliably predict the drag across beds of single particle types?

\section{Experimental plan}

The experiments will be performed in the narrow bed. For a given air flow rate, pressure near the bottom of the particle bed will be measured, and the height of the bed will be estimated visually, to get $\Delta \mathrm{P} / \mathrm{L}$. Tests will be run at minimum fluidization velocity $\mathrm{u}_{\mathrm{mf}}$ and 2,3 and 4 times $\mathrm{u}_{\mathrm{mf}}$ (but not with the bed slugging). The plan is to use 3 size ranges of glass particles nominally $600-710 \mu \mathrm{m}, 300-430 \mu \mathrm{m}$, and $100 \mu \mathrm{m}$ and finer. The plan is to use each particle type individually, then 3 combinations of 2 types each, then 1 combination of all 3, mixed to provide approximately equal amounts by mass. "Monosized" particles were considered, but it turns out such particles are prohibitively expensive. The advantage of monosize particles would have been that drag models would be applied to a single size (rather than a narrow range) before applying them over size ranges.

The analysis will use drag relations to estimate the drag across the beds of the individual particle types, most likely a model in the literature such as a modified Stokes drag model fitted to some data. This will require determining how best to apply the relation to a range of sizes (in this case a narrow range). e.g., apply it for an average particle diameter, or integrate it over the range of diameters, or weight it in some other way.

This will then be done with mixtures, trying different ways if weighting by diameter and mass. The question to be answered is whether any way of applying drag models across distinct particle sizes works in predicting total drag.

The ability to size particles is available at SNL using a Beckman Coulter size analyzer. Initial samples of particles have already been sized and the results appear accurate. The only exception is for fine FCC particles taken from the dust collector of the MFDRC riser: the size distribution obtained appears wrong and may be due to agglomeration of particles in the sizing apparatus. The size distributions for all other particles appear correct. These include several size ranges of glass beads, similar to particles that may be used in the $3 \mathrm{D}$ bed. 


\section{Expected Data Sets}

The data sets for each run will include:

1. Measure of static bed height

2. Characterization of particles tested and the mass $\%$ of each type (in multiparticle mixtures)

3. Overall video of test including scale

4. Expanded bed height as a function of time (or superficial gas velocity) from 3.

5. Data showing bed DP as a function of superficial gas velocity

Literature review: There are many references on drag models. This review uses work by Syamlal \& O'Brien (1987), Gidaspow (1994), and Kunii \& Levenspiel (1991) as a starting point. Beware that the literature can get confusing even when referring to the same models, so this review will attempt to sort out different references' descriptions of the same models (mainly this is a matter of nomenclature, but some authors also choose to place constants differently).

There will be three areas of concentration (with corresponding experimental efforts):

a. Drag models for closely packed particles or dense beds, starting with the Ergun equation. There are varying opinions on the void fraction range over which it applies.

b. Prediction of minimum fluidization velocity. This is closely related to (a) but there are sometimes other assumptions used in predicting $\mathrm{u}_{\mathrm{mf}}$, so will be treated separately.

c. Drag models for more dilute beds. Again, there are various drag models and various opinions on the void fraction range of applicability. This review starts with models presented by Wen \& Yu (1966), Gidaspow (1994), and Syamlal \& O’Brien (1987).

In all of these cases, void fraction is one of the inputs to the model. There are many other references about drag on single particles that will not be reviewed here. Note that some drag models that include void fraction are designed to "reduce" to single particle drag models when void fraction approaches unity.

Experiments: The proposed experiments will be performed in the narrow $(10.16 \mathrm{~cm}$ ID) fluidized bed. The main measurements (corresponding to the inputs to the drag models) will be differential pressure across the bed, air velocity, and volume fraction. Pressures will be measured with transducers and velocities will be calculated from mass flow rate measurements. Void fraction will be calculated from bed height (knowing the void fraction of a packed bed and measuring the bed expansion). A line will be fitted through the points on a pressure vs. height plot (with measurements at three or more heights): The pressure at which this line intercepts zero height is the pressure at the bottom of the bed, and the height at which this line intercepts atmospheric pressure is the bed height. Video will be recorded and synchronized with the pressure data, and be used to visually verify bed height. 


\section{Drag models in the literature}

1. Drag force: Syamlal and O'Brien (1987) is the starting point. The drag force is expressed as: $\checkmark$ Drag force per unit volume $\left(\mathrm{N} / \mathbf{m}^{3}\right)$

$$
\mathrm{F}=\beta\left(\mathrm{v}_{\mathrm{f}}-\mathrm{v}_{\mathrm{s}}\right)
$$

and may also be expressed as the pressure drop per unit length, as per Snider \& Blaser (2004):

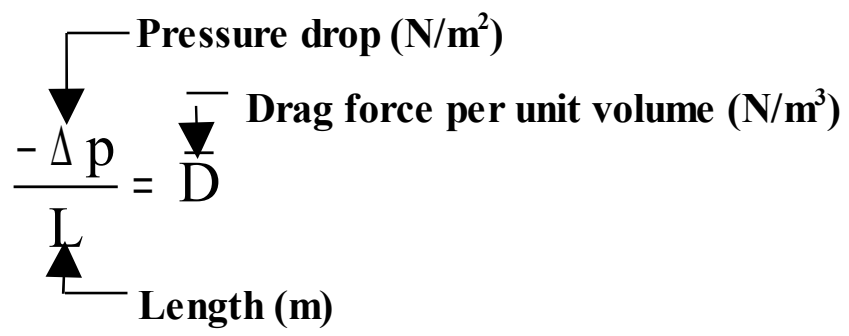

Syamlal and O'Brien (1987) express $\beta$ in terms of the drag coefficient:

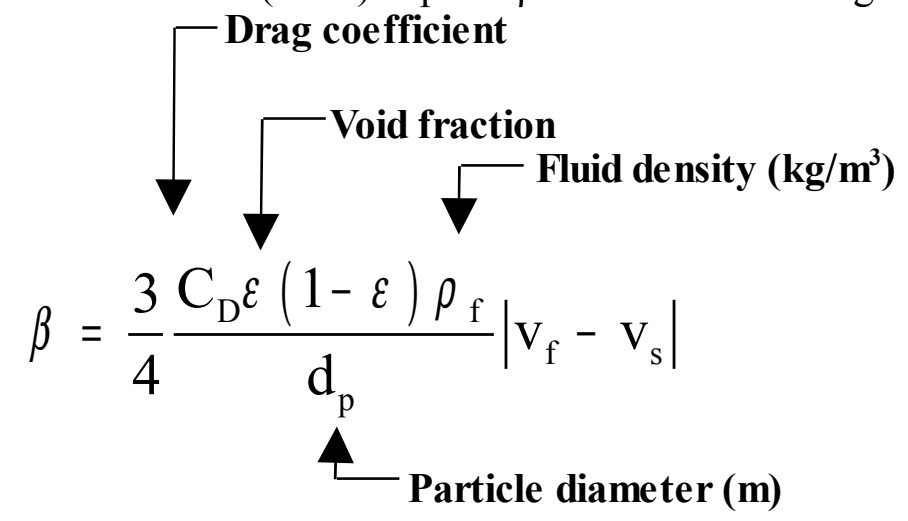

\section{Ergun equation}

As given by Syamlal and O'Brien (1987):

$$
C_{D}=\frac{200(1-\varepsilon)}{\varepsilon^{2} \operatorname{Re}}+\frac{7}{3 \varepsilon} \quad \begin{aligned}
& \text { To estimate } \mathbf{R e},\left|\mathbf{v}_{\mathbf{f}}-\mathbf{v}_{\mathbf{s}}\right| \text { may be estimated as } \\
& \text { (superficial gas velocity } \div \text { void fraction). (Also see } \\
& \text { Eq. 8.) }
\end{aligned}
$$

where:

$$
\operatorname{Re}=\frac{\rho_{\mathrm{f}}\left|\mathrm{v}_{\mathrm{f}}-\mathrm{v}_{\mathrm{s}}\right| \mathrm{d}_{\mathrm{p}}}{\mu_{\mathrm{f}}}
$$


As given by Gidaspow (1994):

$$
\beta_{\mathrm{A}}=150 \frac{(1-\varepsilon)^{2} \mu_{\mathrm{g}}}{\varepsilon\left(\mathrm{d}_{\mathrm{p}} \phi_{\mathrm{s}}\right)^{2}}+1.75 \frac{\rho_{\mathrm{g}}\left|\mathrm{v}_{\mathrm{g}}-\mathrm{v}_{\mathrm{s}}\right|(1-\varepsilon)}{\phi_{\mathrm{s}} \mathrm{d}_{\mathrm{p}}}
$$

or:

$$
\begin{aligned}
& \text { Superficial gas velocity }(\mathrm{m} / \mathbf{s}) \\
& \frac{\Delta \mathrm{p}}{\Delta \mathrm{x}}=150 \frac{\varepsilon_{\mathrm{s}}{ }^{2}}{\varepsilon^{3}} \frac{\mu_{\mathrm{g}} \mathrm{U}_{0}}{\left(\phi_{\mathrm{s}} \mathrm{d}_{\mathrm{p}}\right)}+1.75 \frac{\varepsilon_{\mathrm{s}} \rho_{\mathrm{g}} \mathrm{U}_{0}{ }^{2}}{\varepsilon^{3} \phi_{\mathrm{s}} \mathrm{d}_{\mathrm{p}}}
\end{aligned} \begin{aligned}
& \begin{array}{l}
\text { given by Kunii \& Levenspiel } \\
\text { (1991) and Fan \& Zhu (1998). }
\end{array} \\
& \hline
\end{aligned}
$$

where:

$$
\mathrm{U}_{0}=\varepsilon\left(\mathrm{V}_{\mathrm{g}}-\mathrm{V}_{\mathrm{s}}\right)
$$

As given by Snider \& Blaser (2004):

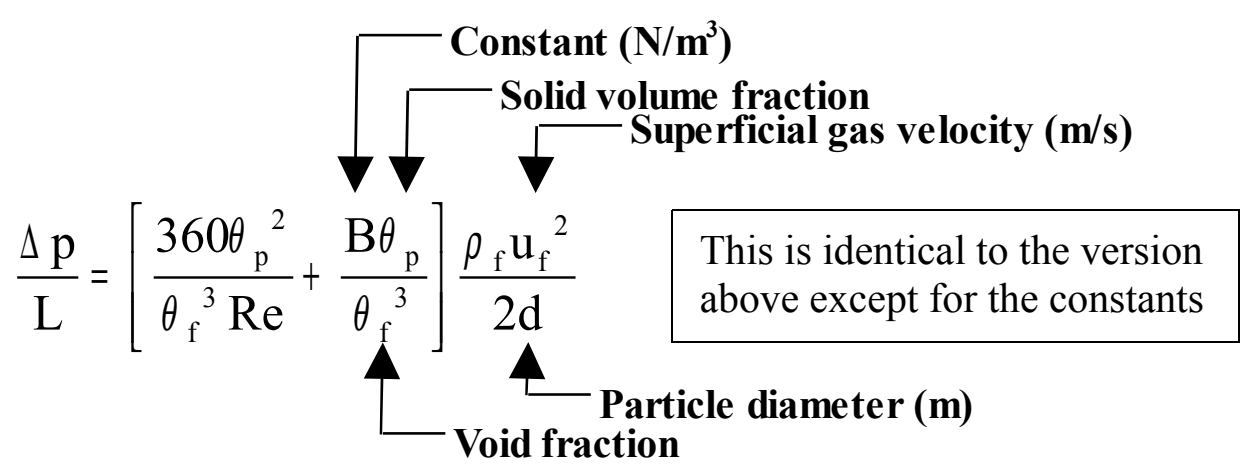

which can be rearranged into a "modified" form (combining constants to form $C_{L}$ and $C_{Q}$ ):

$$
\frac{\Delta \mathrm{p}}{\mathrm{L}}=\left[\mathrm{C}_{\mathrm{L}} \frac{\theta_{\mathrm{p}}^{2}}{\theta_{\mathrm{f}}{ }^{3} \mathrm{Re}}+\mathrm{C}_{\mathrm{Q}} \frac{\theta_{\mathrm{p}}}{\theta_{\mathrm{f}}{ }^{3}}\right] \frac{\rho_{\mathrm{f}} \mathrm{u}_{\mathrm{f}}{ }^{2}}{\mathrm{~d}}
$$

According to Kunii and Levenspiel (1991), when encountering a size distribution (instead of a single particle size), use the mean diameter:

$$
\overline{\mathrm{d}}_{\mathrm{p}}=\frac{1}{\sum_{\mathrm{i}}\left(\mathrm{x} / \mathrm{d}_{\mathrm{p}}\right)_{\mathrm{i}}}
$$




\section{Minimum fluidization velocity}

According to Kunii and Levenspiel (1991):

Identical versions are also given by Lippens \& Mulder (1993) and Fan \& Zhu (1998).

$$
\frac{1.75}{\varepsilon_{\mathrm{mf}}^{3} \phi_{\mathrm{s}}} \operatorname{Re}_{\mathrm{p}, \mathrm{mf}}{ }^{2}+\frac{150\left(1-\varepsilon_{\mathrm{mf}}\right)}{\varepsilon_{\mathrm{mf}}{ }^{3} \phi_{\mathrm{s}}{ }^{2}} \operatorname{Re}_{\mathrm{p}, \mathrm{mf}}=\mathrm{Ar}
$$

Where the subscript $\mathrm{mf}$ refers to minimum fluidization conditions, and:

$$
\begin{aligned}
& \operatorname{Re}_{\mathrm{p}}=\frac{\mathrm{d}_{\mathrm{p}} \rho_{\mathrm{g}} \mathrm{U}_{0}}{\mu} \quad \begin{array}{l}
\text { note that this Re is based } \\
\text { on superficial gas velocity }
\end{array} \\
& \mathrm{Ar}=\frac{\mathrm{d}_{\mathrm{p}}^{3} \rho_{\mathrm{g}}\left(\rho_{\mathrm{s}}-\rho_{\mathrm{g}}\right) \mathrm{g}}{\mu^{2}}
\end{aligned}
$$

For "very small particles" $(\operatorname{Re}<20)$, equation 12 simplifies to:

$$
\mathrm{u}_{\mathrm{mf}}=\frac{\mathrm{d}_{\mathrm{p}}^{2}\left(\rho_{\mathrm{s}}-\rho_{\mathrm{g}}\right) \mathrm{g}}{150 \mu} \frac{\varepsilon_{\mathrm{mf}}{ }^{3} \phi_{\mathrm{s}}^{2}}{1-\varepsilon_{\mathrm{mf}}}
$$

Gidaspow (1994) further simplifies this with an approximation from Wen and Yu (1966):

$$
\mathrm{u}_{\mathrm{mf}}=\frac{\mathrm{d}_{\mathrm{p}}^{2}\left(\rho_{\mathrm{s}}-\rho_{\mathrm{g}}\right) \mathrm{g}}{1650 \mu}
$$

For "very large particles" (Re>1000), equation 12 simplifies to:

$$
\mathrm{u}_{\mathrm{mf}}=\frac{\mathrm{d}_{\mathrm{p}}\left(\rho_{\mathrm{s}}-\rho_{\mathrm{g}}\right) \mathrm{g}}{1.75 \rho_{\mathrm{g}}} \varepsilon_{\mathrm{mf}}^{3} \phi_{\mathrm{s}}
$$

If $\varepsilon_{\mathrm{mf}}$ or $\phi_{\mathrm{s}}$ are not known, $\mathrm{u}_{\mathrm{mf}}$ can still be estimated. First, rewrite equation (12):

$$
\mathrm{K}_{1} \mathrm{Re}_{\mathrm{p}, \mathrm{mf}}^{2}+\mathrm{K}_{2} \mathrm{Re}_{\mathrm{p}, \mathrm{mf}}=\mathrm{Ar}
$$

A number of investigators have recommended values for $\mathrm{K}_{1}$ and $\mathrm{K}_{2}$. Kunii and Levenspiel (1991) report on one such recommendation from Chitester et al. (1984) for "coarse particles" that results in: 


$$
\operatorname{Re}_{\mathrm{p}, \mathrm{mf}}=\left[28.7^{2}+0.0494 \mathrm{Ar}\right]^{1 / 2}-28.7
$$

and another from Wen and Yu (1966a) for "fine particles" that results in:

$$
\operatorname{Re}_{\mathrm{p}, \mathrm{mf}}=\left[33.7^{2}+0.0408 \mathrm{Ar}\right]^{1 / 2}-33.7
$$

\section{Higher void fractions}

Syamlal and O'Brien (1987) present the following model - also presented by Gidaspow (1994) and Wen and Yu (1966) - for void fraction >0.8:

$$
C_{D}=\begin{aligned}
& \frac{24}{\varepsilon \operatorname{Re}}\left(1+0.15(\varepsilon \operatorname{Re})^{0.687}\right) ;(\varepsilon \operatorname{Re})<1000 \\
& 0.44 \varepsilon^{-2.65} ;(\varepsilon \operatorname{Re}) \geq 1000
\end{aligned}
$$

Syamlal and O'Brien (1987) present a relation (the primary conclusion of their paper) which covers the entire void fraction range. It matches Ergun where the void fraction approaches the packing void fraction, and reduces to single particle drag as void fraction approaches unity:

$$
\begin{aligned}
& \mathrm{C}_{\mathrm{D}}=\left(\frac{0.63}{\mathrm{~V}_{\mathrm{r}}}+\frac{4.8}{\sqrt{\mathrm{V}_{\mathrm{r}} \mathrm{Re}}}\right)^{2} \\
& \mathrm{~V}_{\mathrm{r}}=0.5\left[\mathrm{~A}-0.06 \mathrm{Re}+\sqrt{0.0036 \mathrm{Re}^{2}+0.12 \operatorname{Re}(2 \mathrm{~B}-\mathrm{A})+\mathrm{A}^{2}}\right] \\
& \mathrm{A}=\varepsilon^{4.14} \\
& \mathrm{~B}={ }_{\varepsilon^{2.65}}^{0.8 \varepsilon} ; \varepsilon>0.85
\end{aligned}
$$

\section{Experiments}

\section{Experimental measurements}

All experiments will be performed in the narrow $(10.16 \mathrm{~cm}$ ID) fluidized bed with a quiescent bed heights between $10.16 \mathrm{~cm}$ and $20.32 \mathrm{~cm}$ (aspect ratio between 1 and 2).

Pressures will be measured using pressure transducers at heights of $18 \mathrm{~mm}, 50 \mathrm{~mm}, 80 \mathrm{~mm}$, and 130 $\mathrm{mm}$ above the distributor. These will be plotted on a pressure vs. height plot and a line will be fitted through the plot. The pressure at the bottom of the bed will be taken where the line intercepts a zero height. The height of the bed will be taken where the line intercepts atmospheric pressure.

Bed height will be verified visually by averaging the video frames. This has been shown to become more difficult as air velocity is increased - probably useless past a few times $\mathrm{u}_{\mathrm{mf}}$. 
The void fraction of the bed will be calculated from the static bed height, flowing bed height, and void fraction of the static bed.

In most cases (e.g., for glass particles), the void fraction of the static bed will be measured by weighing a known volume of particles and with knowledge of the density of the solid material. In the case of particles where this approach is not valid (e.g., FCC catalyst), the void fraction measurement will be approached differently on a case-by-case basis.

The mass flow rate of air will be measured with a mass flow meter. This will be converted to the superficial gas velocity (i.e., velocity in the freeboard) using the ideal gas law and atmospheric pressure and temperature. Air will be humidified to $60-70 \% \mathrm{RH}$. There are two difficulties with mass flow measurements currently being addressed: first is the necessary correction for humid vs. dry air, and second is some difficulty ascertaining the accuracy of the instruments from the manufacturer. The current best estimate based on the mass flowmeter is a 5\% uncertainty in air flow rate (and thus air velocity).

\section{Initial experiments}

Based on some experiments performed already, the first step will be to make sure we can verify the Ergun equation. This will involve air velocities up to (and perhaps slightly above) $\mathrm{u}_{\mathrm{mf}}$. It will also require that measurements of bed height, packed bed solids volume fraction, and air velocity are very accurate. These experiments will involve the commonly used Potters Model P-0070 glass beads (Figure $3)$.

After this, a second set of initial experiments will be performed to ascertain if the measurement approach is valid. Beginning with a quiescent bed, the air flow will be increased incrementally by turning a needle valve. This will be done in small steps at first (increments a fraction of $\mathrm{u}_{\mathrm{mf}}$ ) and then in larger increments $\left(1 \times \mathrm{u}_{\mathrm{mf}}\right.$ increments above $\left.3 \times \mathrm{u}_{\mathrm{mf}}\right)$. Again, the purpose will be to ascertain the validity of the measurement approach - specifically, the measurement of void fraction. Will the pressure measurements give a good estimate of volume fraction? Comparisons with Barracuda ${ }^{\mathrm{TM}}$ simulation are expected to help here. Will this agree with visual observations? Will the three pressure measurements always fall on a line on the pressure vs. height plot? This process will also involve feedback and improvement with Arena-flow LLC and others.

\section{Main experiments}

Once the initial experiments are used to validate the measurement approach, they can essentially be repeated with different particle types and bed heights. Proposed bed heights would give aspect ratios of $1,1.5$, and 2 . The particle types that may be used include:

- $600-710 \mu \mathrm{m}$ glass beads

- 500-600 $\mu \mathrm{m}$ glass beads

- $300-430 \mu \mathrm{m}$ glass beads

- $120-180 \mu \mathrm{m}$ glass beads

- $\quad<100 \mu \mathrm{m}$ glass beads

- 990-1680 $\mu \mathrm{m}$ polystyrene beads

- Smaller polystyrene beads (have, need to size)

- FCC catalyst 
- FCC fines

- Ore

- Coke

After experiments with single particle types, mixtures will be used as this is where the real uncertainty in the use of drag models lies. Also, these experiments will naturally cross over into segregation experiments. The only additional procedures necessary for those will be the sudden cutoff of airflow followed by particle sampling (in layers) and sizing (likely by sieving).

Obviously, hundreds of experiments with all of these combinations could be performed, so part of this work will be to select the proper combinations that provide the best test cases for model validation.

Full data sets are available from the authors.

\section{Barracuda $^{\mathrm{TM}}$ simulations}

Since there will always be some level of experimental uncertainty, the sensitivity of the computational results to changes in certain experimental conditions, specifically fluidization air velocity and particle size distribution must be determined. If the output is sensitive to certain boundary conditions, extra effort will be spent to make sure that accurate measurements of those conditions are performed. 


\section{Sample Drag Data}

Narrow fluidized bed: inner diameter $=10.16 \mathrm{~cm}$

Bed height $=10.16 \mathrm{~cm}$ (aspect ratio is 1$)$

Volume is $823.7 \mathrm{cc}$

Procedure: Measured out $823.7 \mathrm{cc}$, weighed, poured into bed

Weight of particles: $1176.7 \mathrm{~g}$

Solid volume fraction: 0.571422

Uncertainty in surface measurement estimated to be $\pm 1 \mathrm{~mm}$, or $\pm 8.1 \mathrm{cc}$ in volume, or \pm 0.005 in volume fraction

BEFORE RUN 1

022106a
AFTER RUN 1

022106b

\section{BEFORE RUN 4}

022206a

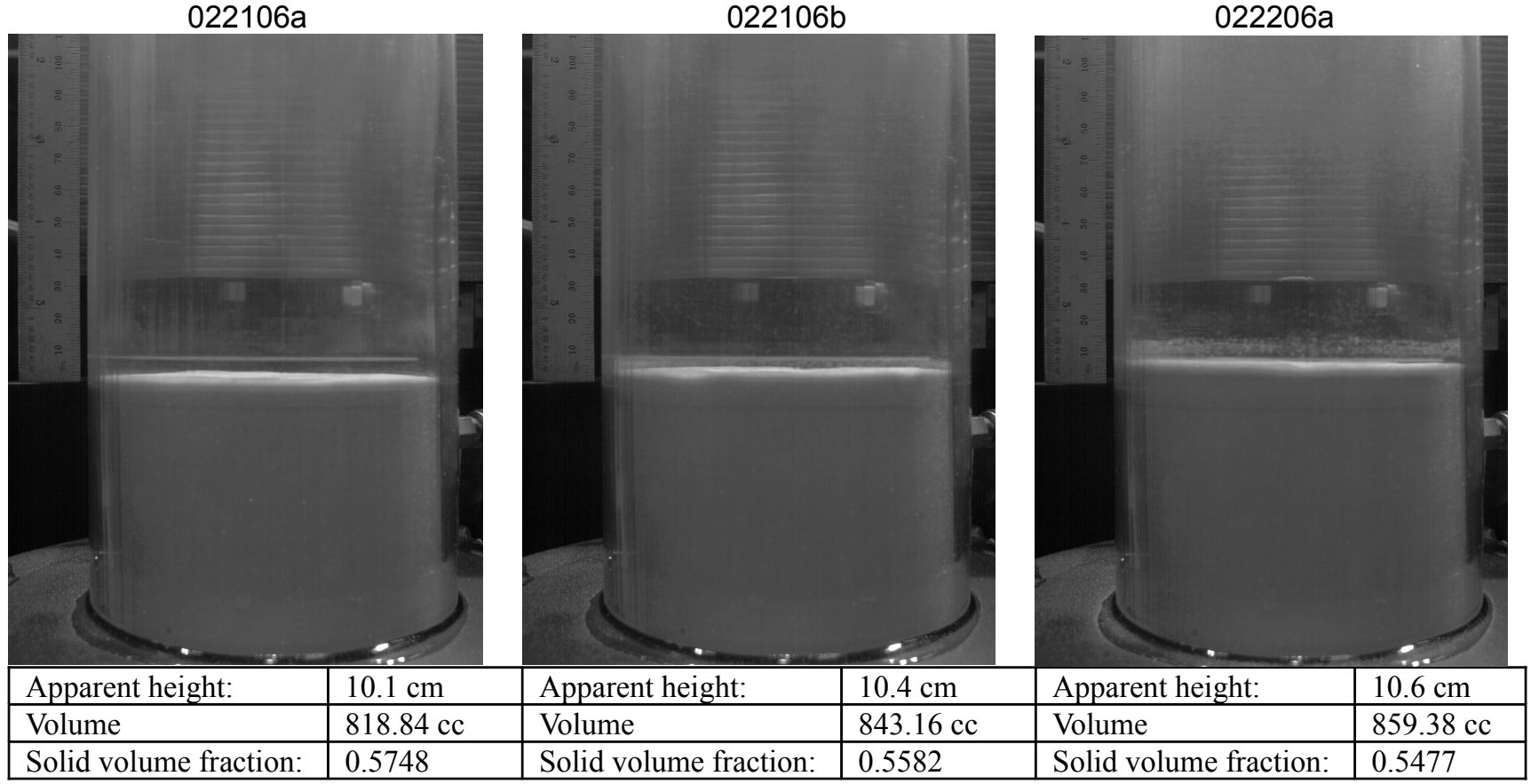

DURING RUN 4

022306b

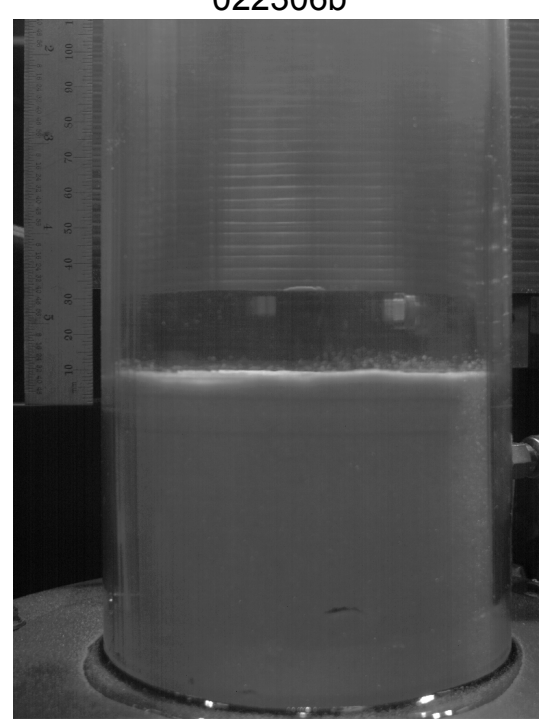

DURING RUN 4

022306d

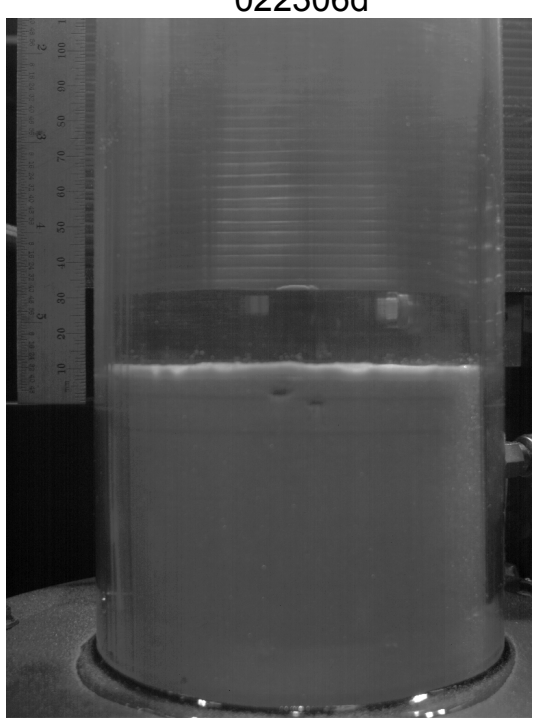

AFTER RUN 4

$022306 f$

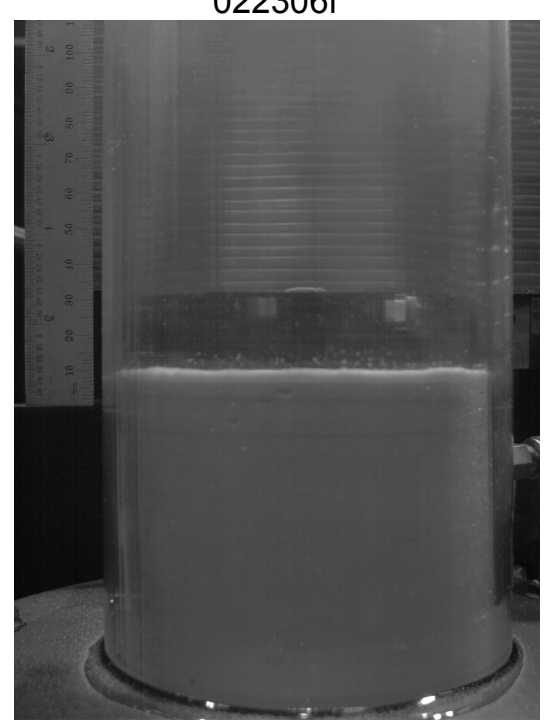

\begin{tabular}{|l|l|l|l|l|l|}
\hline Apparent height: & $10.9 \mathrm{~cm}$ & Apparent height: & $11.0 \mathrm{~cm}$ & Apparent height: & $10.9 \mathrm{~cm}$ \\
\hline Volume & $883.70 \mathrm{cc}$ & Volume & $891.80 \mathrm{cc}$ & Volume & $883.70 \mathrm{cc}$ \\
\hline Solid volume fraction: & 0.5326 & Solid volume fraction: & 0.5278 & Solid volume fraction: & 0.5326 \\
\hline
\end{tabular}




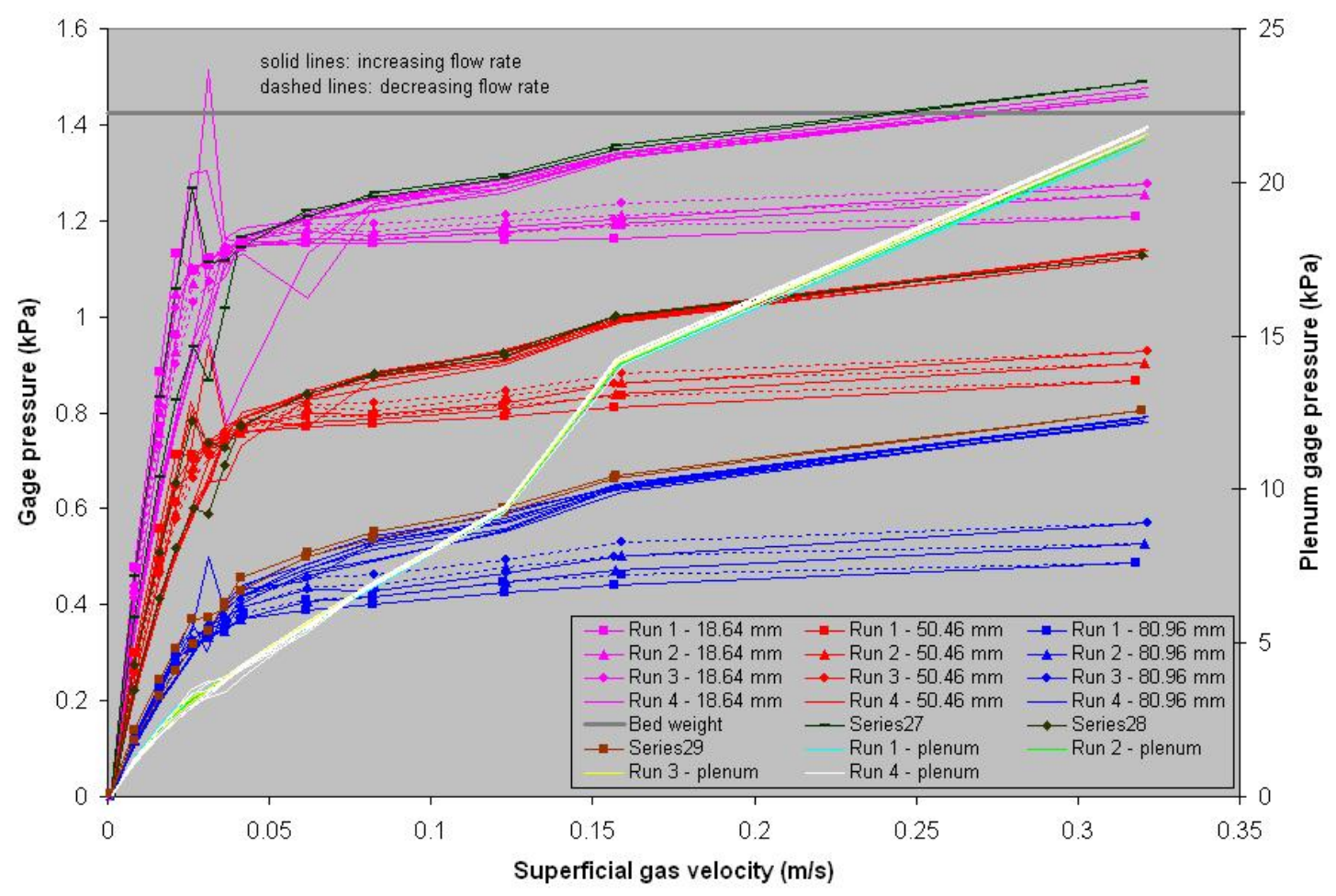

Figure A1. Fluidization Curves

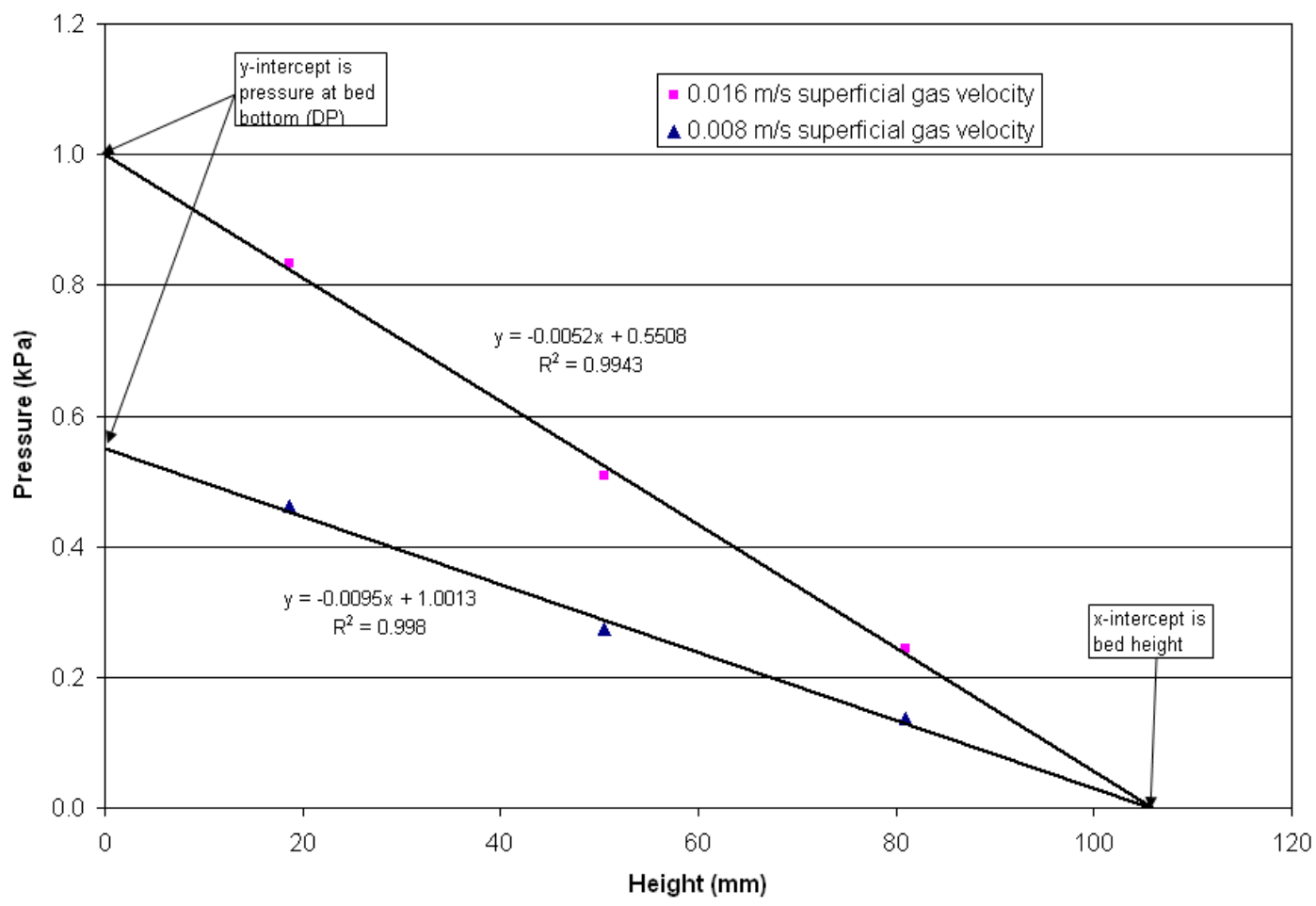

Figure A2. Pressure at Bottom of Bed 


\section{Appendix B: Experimental plan for Particle Segregation}

\section{Basic idea}

Find out how particles of different sizes and densities segregate vertically, using the narrow bed (4" $(10.2 \mathrm{~cm}) \mathrm{ID})$ for experiments.

\section{Questions to be answered}

1. Do certain particles float to the top or sink to the bottom of a fluidized bed?

a. How do particles of different size but equal density segregate?

b. How do particles of equal size but different density segregate?

c. How do particles of different size and different density segregate?

d. How do ore and coke segregate?

2. Do the simulations correctly predict segregation?

\section{Discussion}

Much of the literature investigates the segregation behavior of binary mixtures when the gas velocity lies above the $u_{m f}$ of the particle type with the lower $u_{m f}$, but below the velocity where there is vigorous bubbling and the particles mix well. The general result is that the larger particles with the larger $\mathrm{u}_{\mathrm{mf}}$ migrate downwards and the smaller particles migrate upwards. There is also work with continuous size distributions.

Most industrial processes operate in the turbulent regime, e.g., at higher air velocities than those which cause vigorous bubbling in the bed. This flow regime should be well mixed, but is there any indication of segregation in turbulent regimes? If so, methods of size sampling from turbulent flows will have to be evaluated. The methods listed in the literature - turning the bed off suddenly and sampling layers (see details below) - may not be of much use if additional segregation occurs during the settling process.

\section{Experimental plan}

The experiments will be performed in the narrow bed with a $60 \mathrm{~cm}$ deep bed of particles. At least two distinct particles types: 120-180 $\mu \mathrm{m}$ glass beads and steel shot will be tested. Particle shape effects may have to be considered as well.

There will be three initial particle distributions: (1) well mixed (before putting them in the bed); (2) smaller on top of larger; and (3) larger on top of smaller. The particles will be in approximately equal amounts by mass. A high fluidizing air flow rate will mix the particles well (so that the 3 initial distributions should produce the same result) but it will be kept low enough to avoid bed slugging.

There are several ways to sample the particles to be sized. The first method is commonly found in the literature, shutting down the bed and letting it settle, then drawing off particles a layer at a time. Care will have to be taken that in vacuuming off particles, lighter ones will be picked up easier than heavier ones and that could bias the results, i.e., there will not be neat lines between the layers. Other methods of particle sampling (drawing them off while the bed is still fluidized, or inserting a powder extractor into a quiescent bed) are possible 
1. Particle types:

a. (Equal density; different sizes.) Glass beads: One combination of two of the sizes currently in hand (120-180, 300-430, 600-710 $\mu \mathrm{m})$.

b. (Equal size; different densities) Particles that have a similar density ratio as coke and ore $\left(\rho_{\text {ore }} / \rho_{\text {coke }} \approx 4.2 / 1.45=2.9\right)$ like polystyrene and glass $\left(\rho_{\text {glass }} / \rho_{\text {polystyrene }} \approx 2.55 / 1.05=2.4\right)$. Most likely $150-250 \mu \mathrm{m}$ polystyrene beads and 150-210 $\mu \mathrm{m}$ glass beads.

c. (Different size; different density) 4 combinations of different-sized polystyrene and glass:

\begin{tabular}{|l|c|c|}
\hline & $\begin{array}{l}\text { Large polystyrene; } \\
\text { Small glass }\end{array}$ & $\begin{array}{l}\text { Small polystyrene; } \\
\text { large glass }\end{array}$ \\
\hline $\begin{array}{l}\mathrm{u}_{\mathrm{mf}} \text { of polystyrene larger } \\
\text { than } \mathrm{u}_{\mathrm{mf}} \text { of glass }\end{array}$ & 1 & 2 \\
\hline $\begin{array}{l}\mathrm{u}_{\mathrm{mf}} \text { of glass larger than } \\
\mathrm{u}_{\mathrm{mf}} \text { of polystyrene }\end{array}$ & 3 & 4 \\
\hline
\end{tabular}

d. Real ore and coke.

2. The particles will be mixed $50 / 50$ by mass. A single static bed height of $L / D=2$ will be used.

3. The particles will be sized using a Coulter LS-1320. For particles out of the range of this device ( $>2 \mathrm{~mm}$ ) sieving will be used.

4. Particles with different densities but the same size will be separated by water flotation. (This may be tricky - we'll need to use salt water so the polystyrene floats, and it will be only slightly buoyant.)

5. For turbulent experiments, a single air velocity approximately $10 \times$ the minimum fluidization velocity will be used. The initial placement of particles shouldn't matter for the turbulent flow.

6. Measuring segregation in a turbulent flow may be tricky. Defluidizing the bed and using the vacuum method may work, or even trying to vacuum particles while the bed is fluidized. Neither of those methods may reveal the true size distribution during in the turbulent flow (in the former case, because of segregation during settling). However, these appear to be the only reasonable options at this point. An attractive but unaffordable solution would be to build a bed that has plates that suddenly cut off the flow into layers. For non-turbulent experiments, the vacuum technique (Formisani et al., 2001) or the core-sampling technique (Wormsbecker et al., 2005) will be used.

7. Video, only for overall observation, will be taken of all experiments.

8. Pressure data will be taken at the 2 taps currently existing - in the plenum and just above the distributor.

9. Humidification will be done as in the $2 \mathrm{D}$ bed. 


\section{Literature Review}

Previous work on particle segregation has included both experimental and computational studies. Dahl and Hrenya (2005) performed simulations of continuous (i.e., Gaussian or lognormal) particle size distributions (single density) to determine the segregation behavior. Their results demonstrate the standard behavior of smaller particles floating to the top of the bed. An interesting result is that local samples of size distribution generally mimic the overall size distribution - i.e., if the overall size distribution is Gaussian, local distributions (subsets of the overall distribution) are also Gaussian in shape; the same is true for lognormal.

Delebarre et al. (1994) performed experiments using 8 different particle types, but they didn't mix any of them. The fluidization behavior of each was examined separately and the standard segregation behavior was observed. They used a $140 \mathrm{~mm}$ ID, $3 \mathrm{~m}$ high cylindrical bed and a $400 \mathrm{~mm}, 3 \mathrm{~m}$ high square bed, with particle mean diameters ranging from 293-553 $\mu \mathrm{m}$ and mean densities ranging from $1540-2960 \mathrm{~kg} / \mathrm{m}^{3}$. They measured pressure axially every $10 \mathrm{~cm}$. They covered a range of fluidization velocities including $\mathrm{u}_{\mathrm{mf}}, 150 \% \mathrm{u}_{\mathrm{mf}}$, and complete fluidization velocity $(\sim 100-800 \mathrm{~cm} / \mathrm{s})$. They sampled by sieving $10 \mathrm{~cm}$ "slices" of particles.

Formisani et al. (2001) performed segregation experiments using initial binary mixtures of 350-700, 200-375, and 125-225 micron glass particles. Segregation was measured using the method of vacuuming layers off of the fluidized bed (after turning it off suddenly) and sieving the samples ("vacuum technique"). Layers were 1 or $2 \mathrm{~cm}$ thick in this work. The bed used was $10.1 \mathrm{~cm} \mathrm{ID;H/D}$ was 1.7. The pressure drop across bed was recorded for a full range of fluidization velocities; up to $\sim 20$ $\mathrm{cm} / \mathrm{s}$. Experiments were performed both with initially well-mixed particles and completely segregated layers (fine on top of coarse).

Gilbertson and Eames (2001) reached an interesting result that none of the other papers do, i.e., that when a homogeneous mixture containing two size ranges of particles is first fluidized, vertical bands appear in the wake of bubbles, before horizontal bands appear in the standard segregation pattern. They also note that as gas flow rate is increased, the thickness of the lower layer of coarse particles decreases (when gas flow is further increased the band will disappear and the particles will be well-mixed), a result observed in other experiments as well. Their experiments were done in a rectangular $2 \mathrm{D}$ bed $(29.1 \times 0.6 \mathrm{~cm})$ and a $29 \mathrm{~cm}$ ID cylindrical bed with initially well-mixed particles. Gas flow was introduced suddenly for several velocities between 1.4 and $7.7 \mathrm{~cm} / \mathrm{s}$. They used binary mixtures of glass beads of three diameter ranges, all under 500 microns.

Goldschmidt et al. (2003) used an image-analysis technique to determine segregation in a 2D bed by using a color camera and red and yellow particles filmed against a blue background. The results presented are mainly concerned with segregation rates, i.e., how segregation changes over time in an initially homogeneous bed. Most of the other papers reviewed here report segregation only after the fluidized bed has been operated at a flow condition for a long time. The particles used in this work were relatively large $(1.5 \mathrm{~mm}$ and $2.5 \mathrm{~mm})$ and monodisperse. The beds were $2 \mathrm{D}, 15 \times 70 \times 1.5 \mathrm{~cm}$ and $57 \times 100 \times 1.5 \mathrm{~cm}$. Steam was added to air to reach $60-70 \%$ RH. The particles were initially well mixed. A pre-set mass flow of air was suddenly introduced at values between 0.95 and $1.45 \mathrm{~m} / \mathrm{s}$.

Hoffmann et al. (1993) include some modeling as well as experiments on binary particle mixtures. They used a $14.6 \mathrm{~cm}$ ID bed, humidified air $(50-60 \% \mathrm{RH})$, and particles including glass beads with mean diameters of 565, 365, and $285 \mu \mathrm{m}$; and bronze particles (very heavy: $8750 \mathrm{~kg} / \mathrm{m}^{3}$ ) with a mean diameter of $235 \mu \mathrm{m}$. Particles were sieved to obtain relatively narrow size distributions. The particles were initially well mixed by a high fluidization velocity; velocity was then lowered to the desired level, left for $5 \mathrm{~min}$, and suddenly stopped. Segregation was measured using the vacuum method. The fluidization velocities were in the range of $0.2-0.5 \mathrm{~m} / \mathrm{s}$ 
Hoffmann and Romp (1991) experimented with a continuous size distribution of particles and measured segregation using the vacuum method. They noted two "superimposed" layers with different size distributions (within each layer, the size distribution varied little). Other notable conclusions: (1) "The fact that bubbles are seen in the entire bed is no guarantee that the bed is "well mixed" and (2) the lower level, while remaining defluidized, "adjusts itself" to be very close to defluidization (based on using an analytical expression to calculate the $\mathrm{u}_{\mathrm{mf}}$ of the lower layer based on its distribution). They measured pressure drop across a $14.1 \mathrm{~cm}$ ID fluidized bed. Particles were sand with a wide size distribution $(\sim 200-500 \mu \mathrm{m}), 15.5 \mathrm{~cm}$ deep in bed. The particles were initially well mixed by a high fluidization velocity; velocity was then lowered to the desired level, then stopped suddenly for sampling. Fluidization velocities ranged from $0.148-0.384 \mathrm{~m} / \mathrm{s}$.

Huilin et al. (2003) measured segregation of binary mixtures with typical experimental results. Segregation was measured using the vacuum method. In addition, a model was used, and they noted that the selection of restitution coefficient in the model significantly effects the model's prediction of segregation. The bed was $10.0 \mathrm{~cm}$ ID, $1.2 \mathrm{~m}$ high. Particles were initially well mixed, and the gas velocity was gradually increased then decreased. A vacuum method was used to measure segregation. The particles were relatively large glass beads (mean diameters of 5.49, 4.26, 2.3, and $1.59 \mathrm{~mm}$ ); bed heights were 240-280 mm.

Marzocchella et al. (2000) is similar to others, in that they describe experiments involving binary mixtures of particle which segregate in the same way as other work. The method of measuring segregation was different. After the bed was stopped suddenly, it was disassembled one segment at a time, obtaining a layer of particles each time. There is also extra attention to detail in this paper, including attention to transient fluidization behavior. The fluidized bed was $12 \mathrm{~cm} \mathrm{ID,} 1.5 \mathrm{~m}$ high Plexiglas. The particles were binary mixtures of 100-150 $\mu \mathrm{m}$ silica particles and 400-600 $\mu \mathrm{m}$ glass beads. The air was dried; preliminary experiments showed humidification didn't matter. Particles were initially mixed in a rotary mixer then poured into the bed. Experiments were performed where the gas flow was brought up both gradually and suddenly. Pressures were measured at multiple locations along the bed. Some notable observations include:

- The minimum fluidization velocity of a binary mixture generally lies between the minimum fluidization velocities of the individual components but, depending on the initial state of the mixture, the minimum fluidization velocity of the mixture can lie outside that range. This wasn't observed in experiments, it was mentioned at the beginning of the paper in a discussion of other work.

- In one set of experiments, binary mixtures (produced in a rotary mixer) were slowly subjected to increasing air velocity. Pressures in the bed increased smoothly at first, then entered a "sawtooth" pattern where, as air velocity was increased, the pressures would rise, drop a little, and repeat. The velocity range within which this occurs has no direct relationship to the minimum fluidization velocities of the individual components.

- In another set of experiments where a binary mixture was suddenly subjected to a certain air velocity, a "defluidization wave" was observed moving bottom to top, at a velocity on the orders of 1 or $10 \mathrm{~mm} / \mathrm{s}$. [Possibly this "defluidization wave" follows layers of particles "sorting themselves out" into certain size distributions?]

- They never observed "full segregation" (complete separation of the two particle types)

- In an experiment with the bottom later defluidized and the top fluidized: the bottom layer had just enough of the large particles to stay defluidized, and the top layer had just enough of the small particles to stay fluidized. This happened in experiments both with the particles 
initially mixed and with them separated. See result \#2 in the discussion of Hoffmann and Romp (1991) above.

Naimer et al. (1982) presented a mostly analytical work on detailed examination of exactly how bubbles cause mixing. Their experiments were performed in a $14.8 \mathrm{~cm}$ ID fluidized bed using combinations of glass particles and metal shot: several sizes of each between 70 and $550 \mu \mathrm{m}$.

Rasul et al. (1999) describe the phenomenon of "inversion" where large, light particles (which ordinarily segregate to the top) migrate downwards. This only happens when the bed is "smoothly fluidized" (i.e. no bubbling) past a certain velocity. In experiments, acoustic pulses were used to keep the bed smoothly fluidized.

$\mathrm{Wu}$ and Baeyens (1998) present work on size segregation of binary mixtures of equal density particles, with typical results. In addition, the investigators experimented with a "thief" probe and found that the results were "misleading". Also, the authors state that segregation is more pronounced in shallow beds $(H / D<0.8)$. Their bed was $30 \mathrm{~cm} \mathrm{ID,} 155 \mathrm{~cm}$ high, with initially well mixed particles. The vacuum method was used for segregation measurement. Many particle types ranging from 100-2000 $\mu \mathrm{m}$ were tested.

Wormsbecker et al. (2005) performed segregation experiments on pharmaceutical granules which have a continuous bimodal size distribution $(\sim 50-3000 \mu \mathrm{m})$. They use a novel "core-sampling" technique - rapidly descending a tube, with suction, into a quiescent bed, then dividing the sample held in the tube. The bed had a conical bottom - the ID of cylindrical portion was $0.265 \mathrm{~m}$ and its height was $1.3 \mathrm{~m}$. Bed heights of $0.12 \mathrm{~m}$ and $0.17 \mathrm{~m}$ were used, with gas velocities of $0.5,0.75$, and $1.0 \mathrm{~m} / \mathrm{s}$. The particles were initially well mixed with a high velocity; velocity was then lowered to the desired level, and after operating for 15 minutes the bed was stopped suddenly for sampling.

\section{Expected Data Sets}

The data sets for each run will include:

1. Measure of static bed height

2. Characterization of particles tested and the mass $\%$ of each type

3. Overall video of test including scale

4. Expanded bed height as a function of time (or superficial gas velocity) from 3.

5. Data showing bed DP as a function of superficial gas velocity

6. Profiles of particle size distribution after running the column fluidized for several minutes. 


\section{Appendix C: Design of Experiments for Thermal and Liquid Jet Injection into Fluidized Beds}

\section{Problem Statement}

Typically a mixture of liquid and gas, or liquid alone is sprayed from the side of the fluidized bed in industrial processes in order to coat the particle in the fluidized bed or cause a reaction between the injected liquid and the particles. Gas injection alone is atypical. Experimental data are needed on penetration depth of the jets, and how the injected materials are distributed throughout the bed (how liquids spread throughout the bed and where they evaporate).

Jets are injected into fluidized beds for a number of applications, including ones of direct interest to our team. In order to develop and validate models for these cases, better data are needed. The two specific areas of immediate interest are 1) cool jet injected into a hot fluidized bed where gas expansion upon heating could affect the overall bed behavior and 2) liquid jet injected into a fluidized bed where liquid/particle interactions need to understood and modeled. Many of the experimental techniques are common between the two. This write-up covers both types of jets.

A number of experimental methods are briefly reviewed here that have been used in the literature and/or are available to examine the behavior of jets in fluidized beds. Currently, both the SNL 2D fluidized bed and 4-inch ID bed are up and running at Arena-flow and are available for jet experiments. Experiments could be performed either at Arena-flow or the equipment could be brought back to Sandia if needed for safety considerations (e.g., gamma) or electrical or other requirements (e.g., heated bed).

\section{Background}

A brief literature review shows a fair body of work in this general area, although as with much fluidization literature there seem to be gaps or unexplained boundary or initial conditions in many of the papers. In addition, little work has focused on the thermal jet problem (cold gas jet injected in hot bed, with subsequent gas expansion). This review is not exhaustive but was done first to see if the necessary data were already available and second to determine the state of the art in experimental techniques.

Merry (1971) studied horizontal jet injection into three different beds of sand, kale seeds, and steel shot using photography. From these data and others in the literature he developed the oft-cited semitheoretical correlation:

$$
\frac{L}{d_{0}}+4.5=5.25\left(\frac{\rho_{0} u_{0}^{2}}{(1-\varepsilon) \rho_{p} g d_{p}}\right)^{0.4}\left(\frac{\rho_{f}}{\rho_{p}}\right)^{0.2}\left(\frac{d_{p}}{d_{0}}\right)^{0.2}
$$

where $L$ is the jet penetration length, $d_{0}$ is the nozzle diameter, $\rho, u$, and $d$ are density, velocity, and diameter, respectively, with subscripts $0, p$, and $f$ indicating nozzle (initial) conditions, particle, and fluid, respectively. Merry (1975) derived a separate correlation for vertical, upward-facing jets, based on available literature data. Merry states that these correlations should be useful for design purposes.

Smith and Nienow (1982) acquired x-ray images of sprays and gas jets injected into roomtemperature or heated beds of alumina or glass beads and determined that there was no high voidage feed zone exiting a nozzle, but rather that the injected air forms discrete bubbles. When liquid was injected and temperature isotherms measured, the effect of porous (alumina) vs. non-porous (glass) particles could be seen. The porous material gave a much smaller measurable jet zone, presumably because liquid trapped in pores moved quickly and evenly throughout the bed, allowing evaporation to 
take place over a larger area and leading to smaller variations in bed temperature.

Xuereb et al. (1991ab, 1992) used a cinematographic technique and pitot probes on a 2D bed with a gas jet injected from the side. They measured jet penetration length, expansion angle, fluctuation frequencies, and particle entrainment rates using 3 different nozzle angles: inclined upwards, downwards, and horizontal, and examined the effect of fluidization velocity, gas injection velocity, and particle diameter. They divided the jet into a region characterized by a horizontal section of length $L_{h o r}$ followed by a section that tends to curve up (characterized by a radius $r_{c}$ ) and create a large bubble. They also defined 3 distinct zones in the jet: the Entrainment Zone near the jet injection point (where both the solid particles and gas of the emulsion phase are entrained), the Linear Expansion Region characterized by fully developed turbulent flow, and the Bubble Zone. They present and compare various empirical expressions for penetration depth and curvature radius. They note that increasing the bed superficial velocity causes more bubbles which can actually increase the penetration depth of the gas jet. The jets are systematically longer in a 2D bed than in a 3D bed for identical injection conditions because the jet cannot expand in all directions. They proposed a simple correlation for the velocity of the gas on the jet axis as a function of distance from the nozzle tip. Knowing the jet velocity profiles allows one to estimate the entrainment rates of interstitial gas and solid particles as well as the jet penetration length. Finally, they present a simple model that predicts various characteristics of a gaseous jet introduced horizontally into a 2D fluidized bed.

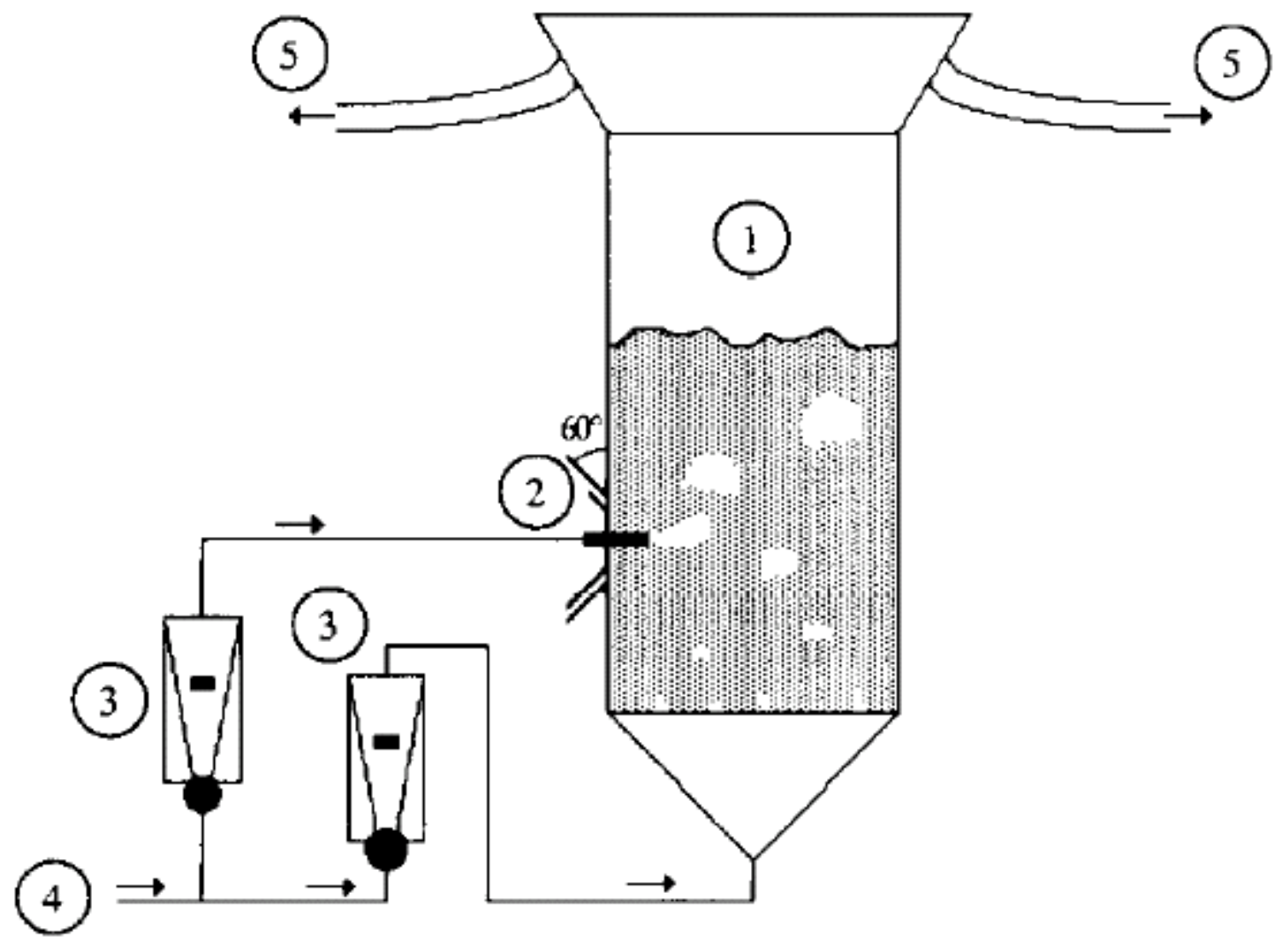

Figure C1. Xuereb et al. (1991ab, 1992) 2D fluidized bed apparatus for studying gas jet injection

Maronga and Wnukowski (1997) used a probe to simultaneously obtain temperature and humidity profiles while spraying water vertically downward into a bed of $69^{\circ} \mathrm{C}$ lactose particles. The temperature and humidity contours seem to agree pretty well 
Chen \& Weinstein (1997) injected a heated air jet horizontally into a fluidized bed of FCC catalyst and tracked the jet evolution using thermocouples. They compared their expansion angle data with their own previous x-ray measurements and their penetration data with literature correlations. One useful observation was that there was a fairly stable compaction zone below the jet, formed because the gas normally fluidizing this region was entrained into the jet. They found reasonable agreement of measured jet penetration length with that predicted by the Merry (1971) correlation.

Vaccaro (1997) discusses parameters that control the gas jet expansion angle when directed upward in a fluidized bed. He pulls together a lot of experimental data from the literature and performs dimensional analysis. He is also quite critical of the Merry (1975) correlation, stating that "it is also questionable since it is based on many assumptions that do not appear to be supported by any experimental evidence." Vaccaro et al. (1997) analyzed pressure signals to determine jet penetration length for the same upward gas jet orientation.

Zhu et al. (2000) injected a liquid nitrogen jet into a room temperature air flow which could be seeded with a light loading of FCC particles, and examined the jet using a digital camera with image analysis, and temperature measurements. They observed that the presence of solids strongly affected the liquid jet. However, this wasn't injection into a fluidized bed but rather into co-flowing pure gas or gas containing solids up to a solids volume concentration of only $1.5 \%$. They measured a reduction of liquid jet penetration distance (axial distance from injector to where thermocouples read room temperature) from $12 \mathrm{~cm}$ in pure gas co-flow to $7 \mathrm{~cm}$ with the very dilute $1.5 \%$ solids loading. Fan et al. (2001) added capacitance tomography and a fiber-optic probe to this flow to study void fractions in the vicinity of the jet.

Knapper et al. (2003) used a copper naphthenate tracer to measure the coating of atomized bitumen sprayed onto hot coke particles in a fluid coking pilot plant. The tracer reacted with the bitumen to form solid copper on the surface of the particles that either had been directly contacted by the doped bitumen or had been coated by interparticle contact. Sampling and fairly sophisticated chemical analysis techniques were used to map out where the liquid contacted the coke particles. The data indicated that solids mixing in the reactor was very strong and well modeled using a continuous stirredtank reactor (CSTR) model, but that contacting between the liquid feed and the coke particles was far from complete, with only about $40 \%$ of the particles being coated by one nozzle type, and only about $20 \%$ coated for a different nozzle type. They also made a coupled CSTR model of the system that gave good agreement with the experimental results.

Ariyapadi et al. (2003) acquired x-ray images of air, ethanol, and air/ethanol jets in a $0.2 \mathrm{~m}$ square fluidized bed containing FCC catalyst fluidized with air. In some of the experiments a radio-opaque iodine tracer was used (mixed with the ethanol). Ariyapadi et al. (2004) focused more on developing and improving correlation-based models. The experiments used x-ray imaging and a thermocouple rake in a cold $\left(-10^{\circ} \mathrm{C}\right)$ jet of air/ethanol or helium/ethanol sprayed into a hot bed $\left(40^{\circ} \mathrm{C}\right)$ of coke in a $1 \times 0.3$ $\mathrm{m}$ rectangular bed. Ariyapadi et al. (2005a) analyzed fast pressure signals to determine liquid jet stability and validated it with high-speed motion pictures in air and in a fluidized bed of coke particles. Ariyapadi et al. (2005b) used their previous results to develop jet injection models.

Hulet et al. (2003) discuss fluid cokers, which are used to process $15-20 \%$ of the crude oil in Canada, including the majority of the oil in the Alberta tar sands. They used two novel techniques to examine horizontal gas and gas-liquid jets injected into fluidized beds. First, they used triboelectric probes in the vicinity of the gas/liquid jet. These make a qualitative measurement, but indicate whether the jet pulses and, if so, the pulse frequency, as well as overall asymmetries between multiple probe locations. Second, they used a unique two chambered fluidized bed, with a gap between the two chambers through which the jet flows. Analysis of the pressure difference between the two chambers was used as a measure of the mass flow rate of solids entrained by the jet. They noted (as have others) 
that the gas-only jet has a greater expansion angle than a jet containing liquid. Like many of the University of Western Ontario/Syncrude papers, this one focuses on how the addition of a draft tube improves liquid-solids mixing.

Briens et al. (2003) tested various methods to extract a statistic useful for characterizing bed "fluidity" from a time-resolved pressure signal recorded in a pilot plant coker (Syncrude). They found that the "W- statistic" gave the best correlation with the "bogging index". The W-statistic is a measure of the relative amplitude of "small" fluctuations, given by:

$$
W_{\text {stat }}=\sqrt{\frac{\int_{0}^{T}\left(y_{s}(t)-\bar{y}_{s}\right)^{2} d t}{\int_{0}^{T}(y(t)-\bar{y})^{2} d t}}
$$

where $y(t)$ is the raw pressure signal, $\bar{y}$ is its average, $y_{s}(t)$ is the small fluctuations component, $\bar{y}_{s}$ is the average of the small fluctuations, and $T$ is the total sampling time. The "bogging index" is determined by examination of coke samples withdrawn from the reactor. The 9 indicators making up the quantitative bogging index number (0-100, with 0 indicating no bogging to 100 indicating fully bogged) include visual, flowability, and analytical characteristics of the coke. McDougall et al. (2005) used the same $\mathrm{W}$-statistic to monitor fluidization quality in a lab unit ( $0.3 \mathrm{~m}$ diameter, $3 \mathrm{~m} \mathrm{high}$ ), with a vertically downward-facing nozzle spraying 1-propanol, 1-butanol, and water. They also showed that the W-statistic was sensitive to fluidity while other diagnostics (falling ball, deaeration) were sensitive to agglomeration so in a lab bed the combination of diagnostics can quantify the hydrodynamics of the liquid-solid interaction. However, the agglomeration techniques were only applicable in the lab, not in a commercial reactor.

House et al. (2004) discuss the coker application and state that the actual temperature difference of interest in a coker is $300^{\circ} \mathrm{C}$ (coke particles up to $650^{\circ} \mathrm{C}$, bitumen feed $350^{\circ} \mathrm{C}$ ). They developed a technique to measure how much liquid initially contacts coke particles when sprayed into a fluidized bed. This involved spraying a sucrose binding solution into the bed, stopping fluidization (10 seconds later), allowing the agglomerated particles to dry under fixed bed conditions for 3 hours, collecting the solid agglomerates, measuring the sucrose concentration in the agglomerates, and using a mass balance to determine the amount of liquid that initially contacted the coke particles. Because of the time scales, this technique does not map out the liquid spray distribution, but rather gives data on the amount of liquid trapped in agglomerates. Much of this work is focused on the benefits of surrounding the nozzle with a draft tube.

Leclère et al. (2004) didn't study the jet/bed interaction, but rather the evaporation kinetics of ethanol droplets sprayed onto the surface of a heated, non-bubbling, bed of $120^{\circ} \mathrm{C} \mathrm{FCC} \mathrm{catalyst}$ particles fluidized with nitrogen. The ethanol contained $1 \%$ glycol as a non-evaporating marker. After the ethanol was sprayed onto the bed, a second nozzle sprayed water to cool the bed and thus quench the evaporation. Analysis of the remaining ethanol as a function of time exposed to the heated bed gave the vaporization kinetics, e.g., for $60 \mu \mathrm{m}$ spray droplets, $50 \%$ of the liquid vaporizes in $100 \mathrm{~ms}$, whereas for $30 \mu \mathrm{m}$ droplets that time is cut in half.

Song et al. (2004, 2005) performed experiments in a geometrically scaled model of a Syncrude commercial coker. The gas (no liquid) was injected into fluidized bed of FCC particles, which they used because they claim that they are dynamically similar to coke particles in the commercial reactors. The 2004 paper presents results on the solids distributions, measured using fiber optic probes. The 2005 paper used helium as a tracer gas to measure gas mixing and gas residence times. Helium 
concentrations were measured both upstream and downstream of the helium injection rings. They found that the core-annular solids flow structure in the bed (similar to that in the riser of a CFB) dragged gas down along the walls but that the gas rose rapidly in the core region.

McMillan et al. (2005) used fast response thermocouples to measure a cold ethanol spray (approximately $-10^{\circ} \mathrm{C}$ ) into a fluidized bed of heated coke particles $\left(40^{\circ} \mathrm{C}\right)$. They used a simple heat balance based on the time-averaged local temperatures to map out the liquid-to-solid ratio throughout the jet and determine the extent of liquid-solid mixing. They determined that adding a draft tube mixer to a free jet improved the liquid-solid mixing.

Bruhns and Werther (2005) used a pilot scale facility $(5 \mathrm{~m}$ high bed, $1 \times 0.5 \mathrm{~m}$ fluidized bed section), and measured local temperatures using fast-response thermocouples and local concentrations of vaporized feed and/or tracer gas using sampling probes and oxygen or carbon dioxide gas analysis. In addition, local solids concentration and the presence of liquids were measured using a needle capacitance probe. Water and ethanol were injected through 4 different feed nozzles into beds of quartz sand or FCC catalyst heated to $120-180^{\circ} \mathrm{C}$. The found that there was no instantaneous evaporation of liquid as some authors have proposed, and that in fact the bed solids prevent atomization of the injected liquids. The model that Bruhns and Werther propose is one in which injected liquid is stripped off the nozzle by particles, immediately forming agglomerates. The agglomerates mix by overall bed circulation and eventually evaporate. If the bed particles are porous, evaporation is slowed down.

While this literature review is by no means complete, it was useful in pointing out common techniques, operations, and assumptions about jets injected into fluidized beds. The table provides a brief summary of these works.

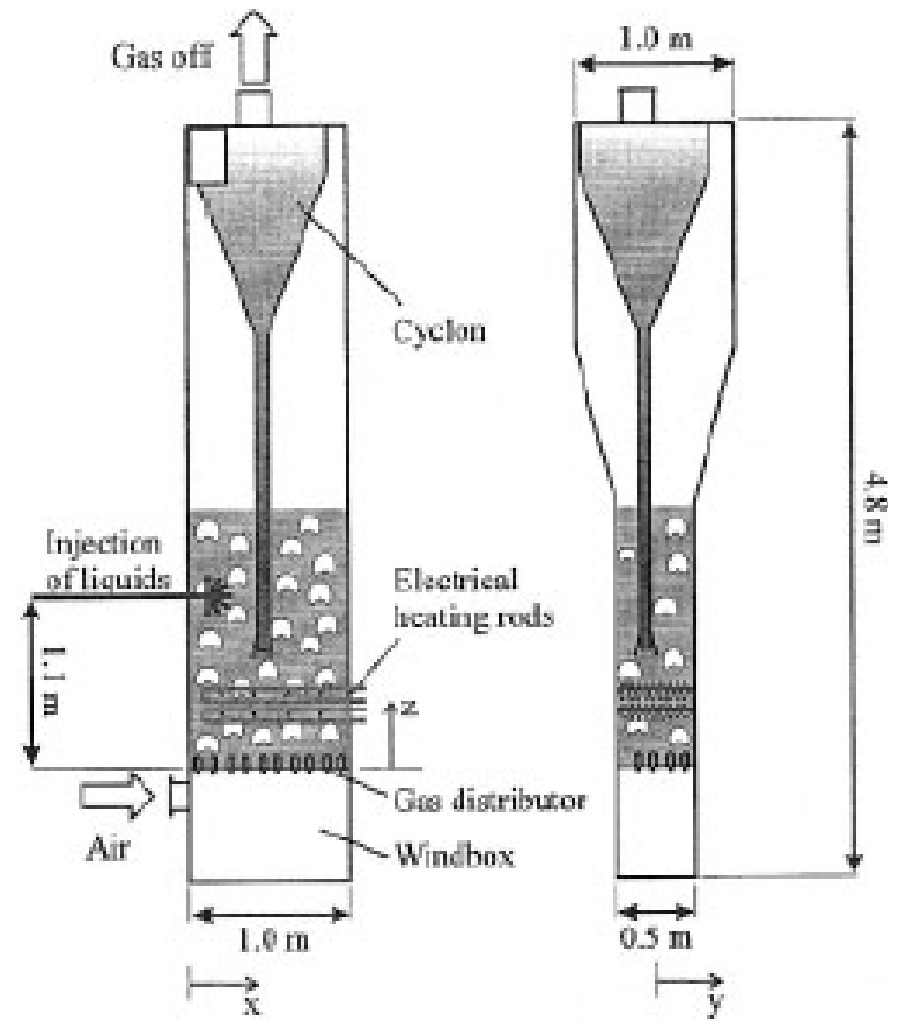

Figure C2. Bruhns and Werther (2005) pilot scale fluidized bed apparatus. They used thermocouples and a capacitance probe to measure liquid injection into this fluidized bed, and gas analysis to study evaporation and vapor transport 


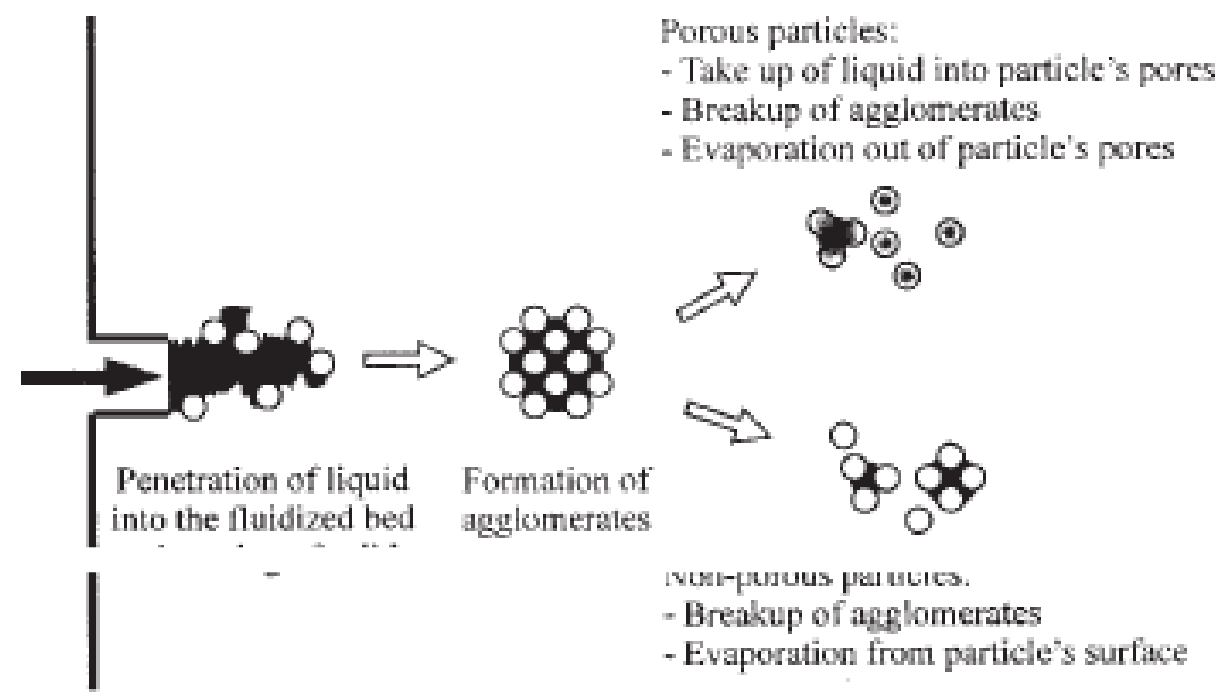

Figure C3. Bruhns and Werther (2005) proposed mechanism of liquid spray into a dense fluidized bed, showing suppression of atomization and liquid transport by overall bed circulation of agglomerated particles 


\begin{tabular}{|c|c|c|c|}
\hline Reference & Jet type & Diagnostics & Test Facility \\
\hline $\begin{array}{l}\text { Merry }(1971 \\
1975)\end{array}$ & $\begin{array}{l}\text { Gas: } \\
\text { horizontal (1971), } \\
\text { vertical (1975) }\end{array}$ & Motion pictures & $\begin{array}{l}\text { Different bed types and particle types. } \\
\text { Mostly development of penetration } \\
\text { correlations. }\end{array}$ \\
\hline $\begin{array}{l}\text { Smith and Nienow } \\
(1982)\end{array}$ & $\begin{array}{l}\text { Liquid, vertical } \\
\text { downward }\end{array}$ & $\begin{array}{l}\text { X-ray movies, } \\
\text { thermocouples }\end{array}$ & $\begin{array}{l}\text { Methanol/methanol doped for } x \text {-ray into } \\
\text { warm bed of alumina or glass }\end{array}$ \\
\hline \begin{tabular}{|l} 
Xuereb et al. \\
$(1991 \mathrm{ab}, 1992)$
\end{tabular} & Gas, horizontal & Cinematographic & 2D \\
\hline $\begin{array}{l}\text { Chen \& Weinstein } \\
\text { (1997) }\end{array}$ & Gas, horizontal & Temperature & $\begin{array}{l}\text { "previously described" but seemingly } 6 \text { inch } \\
\text { with FCC. Heated air jet evolution tracked. }\end{array}$ \\
\hline $\begin{array}{l}\text { Maronga and } \\
\text { Wnukowski } \\
(1997)\end{array}$ & $\begin{array}{l}\text { Liquid, vertically } \\
\text { downward }\end{array}$ & $\begin{array}{l}\text { Temperature and humidity } \\
\text { probe }\end{array}$ & $\begin{array}{l}0.3 \mathrm{~m} \text { dia bed of lactose particles Water } \\
\text { spray vertically downward. }\end{array}$ \\
\hline $\begin{array}{l}\text { Vaccaro et al. } \\
\text { (1997) }\end{array}$ & Gas, vertical upward & $\begin{array}{l}\text { Penetration length by } \\
\text { analysis of pressure } \\
\text { difference between the jet } \\
\text { axis and the bed wall }\end{array}$ & $\begin{array}{l}20 \mathrm{~cm} \text { ID column, } 2 \mathrm{~m} \text { high. Air jet injected } \\
\text { upward into fluidized glass ballotini } \\
(800-1200 \mu \mathrm{m})\end{array}$ \\
\hline $\begin{array}{l}\text { Zhu et al. (2000); } \\
\text { Fan et al. (2001) }\end{array}$ & $\begin{array}{l}\text { Liquid, mostly vertical } \\
\text { upward }\end{array}$ & $\begin{array}{l}\text { High speed camera, } \\
\text { thermocouples, ECT, fiber } \\
\text { probes }\end{array}$ & Very dilute \\
\hline $\begin{array}{l}\text { Briens et al. } \\
(2003)\end{array}$ & Liquid, horizontal & $\begin{array}{l}\text { Pressure fluctuations and } \\
\text { W-statistic }\end{array}$ & $\begin{array}{l}\text { Hot pilot scale fluid coker, bed } 1 \mathrm{~m} \text { diameter, } \\
2 \mathrm{~m} \text { high. Oil sprayed in. }\end{array}$ \\
\hline $\begin{array}{l}\text { Knapper et al. } \\
(2003)\end{array}$ & Liquid & $\begin{array}{l}\text { Copper naphthenate } \\
\text { tracer, chemical analysis }\end{array}$ & $\begin{array}{l}\text { Hot fluid coker pilot scale. Bitumen sprayed } \\
\text { into hot coke particles. }\end{array}$ \\
\hline $\begin{array}{l}\text { Ariyapadi et al. } \\
(2003)\end{array}$ & Gas, liquid, horizontal & $\begin{array}{l}\text { X-ray imaging of ethanol } \\
\text { and ethanol with radio- } \\
\text { opaque iodine tracer. }\end{array}$ & $\begin{array}{l}20 \times 20 \mathrm{~cm} \text { cross section, } 100 \mathrm{~cm} \text { high bed } \\
\text { of FCC catalyst. }\end{array}$ \\
\hline $\begin{array}{l}\text { Ariyapadi et al. } \\
(2004,2005 a)\end{array}$ & $\begin{array}{l}\text { Liquid, horizontal, } \\
\text { including } 50^{\circ} \mathrm{C} \Delta \mathrm{T}\end{array}$ & $\begin{array}{l}\text { Temperature, jet stability } \\
\text { via analysis of pressure } \\
\text { signals and validation with } \\
\text { movies }\end{array}$ & $\begin{array}{l}\text { Ethanol sprayed in fluidized bed }(100 \times 30 \\
\mathrm{cm} \text { cross section) of coke particles }\end{array}$ \\
\hline $\begin{array}{l}\text { Knapper et al. } \\
(2003)\end{array}$ & Liquid, horizontal & $\begin{array}{l}\text { Copper naphthenate solid } \\
\text { tracer }\end{array}$ & 0.7 and $1.0 \mathrm{~m}$ diameter beds of coke \\
\hline Hulet at al. (2003) & $\begin{array}{l}\text { Gas and liquid, } \\
\text { horizontal }\end{array}$ & $\begin{array}{l}\text { Triboelectric probe, } \\
\text { ethanol detection }\end{array}$ & $\begin{array}{l}\text { Ethanol sprayed into small bed }(12 \times 10 \mathrm{~cm}) \\
\text { of } 135 \mu \mathrm{m} \text { coke }\end{array}$ \\
\hline $\begin{array}{l}\text { House et al. } \\
(2004)\end{array}$ & Liquid, horizontal & $\begin{array}{l}\text { Sucrose binding solution } \\
\text { measures liquid contacting } \\
\text { coke particles }\end{array}$ & $10 \times 50 \mathrm{~cm}$ cross section, $50 \mathrm{~cm}$ high. \\
\hline $\begin{array}{l}\text { Bruhns and } \\
\text { Werther (2005) }\end{array}$ & $\begin{array}{l}\text { Liquid, horizontal, } \\
\sim 100^{\circ} \mathrm{C} \Delta \mathrm{T}\end{array}$ & $\begin{array}{l}\text { Thermocouples, gas } \\
\text { sampling, capacitance } \\
\text { probe }\end{array}$ & $\begin{array}{l}\text { Pilot scale. Water and ethanol jets sprayed } \\
\text { into beds of FCC or quartz sand particles. }\end{array}$ \\
\hline $\begin{array}{l}\text { McDougall et al. } \\
(2005)\end{array}$ & $\begin{array}{l}\text { Liquid, vertical } \\
\text { downward }\end{array}$ & $\begin{array}{l}\text { Pressure fluctuations } \\
(1000 \mathrm{~Hz} \text { acquisition }) \text { and } \\
\text { W-statistic, falling ball, } \\
\text { deaeration }\end{array}$ & $\begin{array}{l}0.3 \mathrm{~m} \text { diameter, } 3 \mathrm{~m} \text { high bed. Vertically } \\
\text { downward-facing nozzle spraying 1- } \\
\text { propanol, 1-butanol, and water }\end{array}$ \\
\hline $\begin{array}{l}\text { McMillan et al. } \\
(2005)\end{array}$ & $\begin{array}{l}\text { Liquid, horizontal, } \\
50^{\circ} \mathrm{C} \Delta \mathrm{T}\end{array}$ & Thermocouples & $\begin{array}{l}\text { Large rectangular bed, cold ethanol sprayed } \\
\text { into warm coke particles }\end{array}$ \\
\hline $\begin{array}{l}\text { Song et al. }(2004, \\
2005)\end{array}$ & $\begin{array}{l}\text { Gas, horizontal } \\
\text { through feed ring }\end{array}$ & $\begin{array}{l}\text { Helium gas tracer, optical } \\
\text { fiber probe }\end{array}$ & $\begin{array}{l}\text { Geometrically 1:20 scaled model of } \\
\text { Syncrude commercial cokers }\end{array}$ \\
\hline
\end{tabular}




\section{Summary}

The brief literature review above shows that, while there have been many papers written on the jet injection into fluidized beds, much work remains. Many of the papers have been narrowly focused on testing correlations or quantifying nozzle improvements, and many of the observations and data needed to develop and validate improved models are still lacking. Also, few of these papers address the thermal jet issue, i.e., effects of jet gas expansion when colder gas is injected into a warmer bed. The basic questions still to be answered seem to be:

1) What is the penetration depth and overall jet behavior for a cold jet injected into a warmer bed as a function of jet velocity, fluidized bed conditions, and temperature difference between the jet gas and the fluidized bed?

a. What is the most meaningful definition of penetration depth for an unsteady jet that sometimes sheds large bubbles?

b. Do any of the existing correlations for jet penetration length work for the conditions of interest?

2) How is liquid injected into a bed transported through the bed?

3) What is the impact of a jet on the surrounding bed (defluidization due to entrainment, etc.)?

4) How do bed properties change with changing ratio of fluidizing gas entering at base vs. provided by jet?

The ideal data sets for validation would include:

1. Characterization of initial conditions

a. Measure of static bed height

b. Characterization of particles tested and the mass \% of each type (if multiparticle mixtures are tested)

c. Initial packing level

2. Overall video of test before, during, and after jet injection including scale (dual cameras, up to 500 frames/sec)

a. This is best suited to the $2 \mathrm{D}$ bed but could be performed in the 4 " bed as well, although details of jet will be obscured.

b. A semi-cylindrical bed could be fabricated but its jet behavior will still be strongly affected by the wall.

3. Expanded bed height as a function of superficial gas velocity.

4. Bed pressures (usual axial locations above the distributor) and plenum and atmospheric pressure.

5. Jet inlet pressure and temperature

a. Liquid properties (density, viscosity) when applicable

6. Temperature profiles and time history in vicinity of jet from rake of submerged thermocouples

7. $\mathrm{P}$ ' indicator of bed fluidity, see Briens et al. (2003)

8. Void fraction around jet using gamma system (additional time and cost). 
Experimental parameters

1. Particle type

a. Glass beads

i. 120-180 microns

ii. 600-710 microns

b. FCC catalyst

c. Others if desired

2. Jet gas (air, nitrogen, helium?)

3. Jet injection flowrate

a. $1,10,30 \mathrm{~m} / \mathrm{s}$, others?

4. Bed superficial velocity

a. Has fairly significant effect on jet characteristics

5. Temperature difference $\Delta \mathrm{T}$ between bed and jet

a. According to House et al. (2004) the $\Delta \mathrm{T}$ of interest for fluid coking is around $300^{\circ} \mathrm{C}$.

b. Start with low $\Delta \mathrm{T}$, increase in steps to maximum achievable (TBD).

6. Liquid viscosity for liquid injection

c. Nozzle types for liquid injection?

\section{Jets}

\section{Basic idea}

There is a high degree of interest in jets (both gas and liquid) injected into fluidized beds. Basic data on jet behavior will be acquired mainly by filming or making void fraction measurements in the $2 \mathrm{D}$ bed before, during, and after jet injection.

\section{Questions to be answered}

The basic questions are:

- What is the penetration depth and overall plume behavior as a function of jet velocity and fluidized bed conditions. What is the most meaningful definition of penetration depth? How is a liquid injected into a bed transported throughout after coating particles? Does the jet defluidize certain regions as in the simulations?

- Effect of gas expansion (cold gas injection)

- Liquid injection, evaporation?

- Tradeoff between fluidization air at base and fluidization air provided by jet - design experiment to test this.

- Where do liquids in jet go (some fraction does not evaporate? - Bruhns and Werther, 2005)

\section{Experimental plan}

Measuring volume fractions will be difficult. Voidage probes will probably not be effective, because they will be too invasive (since the bed is so narrow a probe will block the flow). Image-analysis-based methods in the literature (e.g., Goldschmidt et al., 2003) are quite advanced and would take a more time and effort to implement than remains available in the program. Gamma or X-ray attenuation is another possibility that could be implemented but, again, the cost and setup effort will be significant.

It was decided that cold nitrogen was unnecessary and that cold air would suffice. (Nitrogen was 
originally suggested because very cold gaseous nitrogen can be extracted from liquid nitrogen.) A cold air injection system has been designed that allows the air to be cooled to sub-freezing temperatures using a vortex tube while accurately metering the flow. Equipment for heating the fluidization air was also purchased but never installed. With this combination of equipment, the capability now exists to produce temperature differences of at least $100^{\circ} \mathrm{C}$ between the cold injected jet and the hot fluidization gas. This temperature difference will give a jet gas volumetric expansion on the order of $25 \%$.

\section{Expected Data Sets}

The data sets for each run will include:

1. Measure of static bed height

2. Characterization of particles tested and the mass \% of each type (in multiparticle mixtures)

3. Overall video of test including scale

4. Expanded bed height as a function of time (or superficial gas velocity) from 3.

5. Data showing bed DP as a function of superficial gas velocity

6. Data showing jet pressure and temperature

7. Void fraction around jet 


\section{ACKNOWLEDGMENTS}

John Oelfke and Ray Cote performed much of the design, fabrication, and operation of the various fluidized beds discussed in this report.

Two summer interns at Sandia National Laboratories deserve special acknowledgement. Kathryn Sy was an undergraduate student at Texas A\&M University who developed and instrumented the first generation of the 2D fluidized bed and acquired and analyzed much of the PIV data. Thomas Dimiduk was an undergraduate at Cornell University who performed many of the small bed pressure drop experiments and developed data analysis algorithms for them.

Of course, this work would not have been possible without the financial support of the Department of Energy Industrial Technologies Program.

\section{REFERENCES}

1. Ariyapadi, S., Holdsworth, D. W., Norley, C. J. D., Berruti, F., and Briens, C., (2003), "Digital Xray Imaging Technique to Study the Horizontal Injection of Gas-Liquid Jets into Fluidized Beds," International Journal of Chemical Reactor Engineering, 1, Article A56.

2. Ariyapadi, S., Berruti, F., Briens, C., McMillan, J., and Zhou, D., (2004), "Horizontal Penetration of Gas-Liquid Spray Jets in Gas-Solid Fluidized Beds," International Journal of Chemical Reactor Engineering, 2, Article A22.

3. Ariyapadi, S., Berruti, F., Briens, C., Knapper, B., Skwarok, R., and Chan, E., (2005a), "Stability of Horizontal Gas-Liquid Sprays in Open-Air and in a Gas-Solid Fluidized Bed," Powder Technology, 155, 161-174.

4. Ariyapadi, S., McMillan, J., Zhou, D., Berruti, F., Briens, C., and Chan, E., (2005b), "Modeling the Mixing Of a Gas-Liquid Spray Jet Injected in a Gas-Solid Fluidized Bed: The Effect of the Draft Tube," Chemical Engineering Science, 60, 5738-5750.

5. Bokkers, G.A., van Sint Annaland, M., and Kuipers, J.A.M., (2004), "Mixing and segregation in a bidisperse gas-solid fluidised bed: a numerical and experimental study," Powder Technology, 140, 176-186.

6. Briens, C., McDougall, S., and Chan, E., (2003), "On-line Detection of Bed Fluidity in a Fluidized Bed Coker," Powder Technology, 138, 160-168.

7. Brown, R.C. and Brue, E., (2001), "Resolving dynamical features of fluidized beds from pressure fluctuations," Powder Technology, 119, 68-80.

8. Bruhns, S. and Werther, J., (2005), "An Investigation of the Mechanism of Liquid Injection into Fluidized Beds," AIChE Journal, 51(30, 766-775.

9. Chen, L. and Weinstein, H., (1997), "Temperature Distribution Around Heated Horizontal Jet in Fluidized Bed," AIChE Journal, 43(9), 2373-2375.

10. Chitester, D.C., Kornosky, R.M., Fan, L.-S. and Danko, J.P., (1984), "Characteristics of fluidization at high pressure," Chemical Engineering Science, 39, 253-261.

11. Dahl, S.R. and Hrenya, C.M., (2005), "Size segregation in gas-solid fluidized beds with continuous size distributions," Chemical Engineering Science, 60, 6658-6673.

12. Daw, C.S., Halow, J.S., Finney, C.E.A., and Nguyen, K., (2000), "Characterizing the hydrodynamics of bubbling fluidized beds with multivariate pressure measurements", AIChE 
Annual Meeting, Los Angeles, CA.

13. Delebarre, A.B., Pavinato, A., and Leroy, J.C., (1994), "Fluidization and mixing of solids distributed in size and density," Powder Technology, 80, 227-233.

14. Fan, L.-S. and Zhu, C., (1998), Principles of Gas-Solid Flows, Cambridge University Press, UK.

15. Fan, L.-S., Lau, R., Zhu, C., Vuong, K., Warsito, W., Wang, X., and Liu, G., (2001), "Evaporative Liquid Jets in Gas-Liquid-Solid Flow System," Chemical Engineering Science, 56, 5871-5891.

16. Formisani, B., De Cristofaro, G., and Girimonte, R., (2001), "A fundamental approach to the phenomenology of fluidization of size segregating binary mixtures of solids," Chemical Engineering Science, 56, 109-119.

17. Gibilaro, L.G., Di Felice, R., Waldram, S.P., and Foscolo, P.U., (1986), "A predictive model for the equilibrium composition and inversion of binary-solid liquid fluidized beds," Chemical Engineering Science, 41:2, 379-387.

18. Gilbertson, M.A. and Eames, I., (2001), "Segregation patterns in gas-fluidized systems," Journal of Fluid Mechanics, 433, 347-356.

19. Goldschmidt, M.J.V., Link, J.M., Mellema, S., and Kuipers, J.A.M., (2003), "Digital image analysis measurements of bed expansion and segregation dynamics in dense gas-fluidised beds," Powder Technology, 138, 135-159.

20. Gidaspow, D., (1994), Multiphase Flow and Fluidization, Academic Press, Boston.

21. Hoffmann, A.C., Janssen, L.P.B.M., and Prins, J., (1993), "Particle segregation in fluidised binary mixtures," Chemical Engineering Science, 48:9, 1583-1592.

22. Hoffmann, A.C. and Romp, E.J., (1991), "Segregation in a fluidised powder of a continuous size distribution," Powder Technology, 66, 119-126.

23. House, P.K., Saberian, M., Briens, C.L., Berruti, F., and Chan, E., (2004), "Injection of a Liquid Spray into a Fluidized Bed: Particle-Liquid Mixing and Impact on Fluid Coker Yields," Industrial and Engineering Chemistry Research, 43, 5663-5669.

24. Huilin, L., Yurong, H., Gidaspow, D., Lidan, Y., and Yukun, Q., (2003), "Size segregation of binary mixture of solids in bubbling fluidized beds," Powder Technology, 134, 86-97.

25. Hulet, C., Briens, C., Berruti, F., Chan, E.W., and Ariyapadi, S., (2003), "Entrainment and Stability of a Horizontal Gas-Liquid Jet in a Fluidized Bed," International Journal of Chemical Reactor Engineering, 1, A60.

26. Kage, H., Funaoka, S., Kohno, H., Zhou, T., and Yamamura, M., (2004), "Effect of vibration addition on bubble size and velocity in two-dimensional fluidized bed" in Fluidization XI (ed. U. Arena, R. Chirone, M. Miccio, and P. Salatino), Engineering Conferences Foundation, New York.

27. Knapper, B. A., Gray, M. R., Chan, E. W., and Mikula, R., (2003) "Measurement of Efficiency of Distribution of Liquid Feed in a Gas-Solid Fluidized Bed Reactor," International Journal of Chemical Reactor Engineering, 1, Article A35.

28. Kuipers, J.A.M., Prins, W., and van Swaaj, W.P.M., (1991), "Theoretical and experimental bubble formation at a single orifice in a two-dimensional gas-fluidized bed," Chemical Engineering Science, 46, 2881-2894.

29. Kunii, D. and Levenspiel, O., (1991), Fluidization Engineering, Second Edition, ButterworthHeinemann, Boston. 
30. Leclère, K., Briens, C., Gauthier, T., Bayle, J., Guignon, P., and Bergougnou, M., (2004), "Experimental Measurement of Droplet Vaporization Kinetics in a Fluidized Bed," Chemical Engineering and Processing, 43, 693-699.

31. Lippens, B.C. and Mulder, J., (1993), "Prediction of the minimum fluidization velocity," Powder Technology, 75, 67-78.

32. Maronga, S. J. and Wnukowski, P1, (1997), "Establishing Temperature and Humidity Profiles in Fluidized Bed Particulate Coating,: Powder Technology, 94, 181-185.

33. Marzocchella, A., Salatino, P., Di Pastena, V., and Lirer, L., (2000), "Transient fluidization and segregation of binary mixtures of particles," AIChE Journal, 46:11, 2175-2182.

34. McDougall, S., Saberian, M., Briens, C., Berruti, F., and Chan, E., (2005), "Using Dynamic Pressure Signals to Assess the Effects of Injected Liquid on Fluidized Bed Properties," Chemical Engineering and Processing, 44, 701-708.

35. McMillan, J., Zhou, D., Ariyapadi, S., Briens, C., Berruti, F., and Chan, E., (2005), "Characterization of the Contact between Liquid Spray Droplets and Particles in a Fluidized Bed," Industrial and Engineering Chemistry Research, 44, 4931-4939.

36. Merry, J. M. D., (1971), "Penetration of a Horizontal Gas Jet into a Fluidised Bed," Trans. Inst. Chem. Engr., 49, 189-195.

37. Merry, J. M. D., (1975), "Penetration of Vertical Jets into Fluidized Beds," AIChE Journal, 21(3), 507-510.

38. Naimer, N.S., Chiba, T., and Nienow, A.W., (1982), "Parameter estimation for a solids mixing/segregation model for gas fluidised beds," Chemical Engineering Science, 37:7, 1047-1057.

39. O’Hern, T. J., Trujillo, S. M., Torczynski, J. R., Tortora, P. R., Oelfke, J. B., and Bhusarapu, S., (2006), "Circulating Fluidized Bed Hydrodynamics Experiments for the Multiphase Fluid Dynamics Research Consortium (MFDRC)," Sandia National Laboratories Report SAND2006-4914.

40. Olivieri, G., Marzocchella, A., and Salatino, P., (2004), "Segregation of fluidized binary mixtures of granular solids," AIChE Journal, 50:12, 3095-3106.

41. Rasul, M.G., Rudolph, V., and Carsky, M., (1999), "Segregation potential in binary gas fluidized beds," Powder Technology, 103, 175-181.

42. Shen, L., Johnsson, F., and Leckner, B., (2004), "Digital image analysis of hydrodynamics twodimensional bubbling fluidized beds," Chemical Engineering Science 59, 2607-2617.

43. Shollenberger, K. A., Torczynski, J. R., Adkins, D. R., O'Hern, T. J., and Jackson, N. B., (1997), "Gamma Densitometry Tomography of Gas Holdup Spatial Distribution in Industrial Scale Bubble Columns," Chemical Engineering Science, 52(13), 2037-2048.

44. Smith, P.G. and Nienow, A.W., (1982), "On Atomising a Liquid into a Gas Fluidised Bed," Chemical Engineering Science, 37:6, 950-954.

45. Snider, D. and Blaser, P., (2004), “Arena-flow implementation of drag models (a look at Ergun's equation)," Arena-Flow Technical Note 73.

46. Song, X., Bi, H., Lim, C.J., Grace, J.R., Chan, E., Knapper, B., and McKnight, C., (2004), "Hydrodynamics of the Reactor Section in Fluid Cokers," Powder Technology, 147, 126-136. 
47. Song, X., Grace, J.R., Hsiaotao, B., Lim, C.J., Chan, E., Knapper, B., and McKnight, C.A., (2005), "Gas Mixing in the Reactor Section of Fluid Cokers," Industrial and Engineering Chemistry Research, 44, 6067-6074.

48. Syamlal, M. and O'Brien, T.J., (1987), "The derivation of a drag coefficient formula from velocity-voidage correlations," unpublished report.

49. Vaccaro, S., (1997), "Analysis of the Variables Controlling Gas Jet Expansion Angles in Fluidized Beds," Powder Technology, 92, 213-222.

50. Vaccaro, S., Musmarra, D, Petrecca, M., (1997), "A Technique for Measurement of the Jet Penetration Height in Fluidized Beds by Pressure Signal Analysis," Powder Technology, 92, 223-231.

51. Wen, C.Y. and Yu, Y.H., (1966), "Mechanics of fluidization," Chemical Engineering Progress Symposium Series 62, 100-111.

52. Wen, C.Y. and Yu, Y.H., (1966a), "A generalized method for predicting the minimum fluidization velocity," AIChE Journal, 12, 610-612.

53. Wu, S.Y. and Baeyens, J., (1998), "Segregation by size difference in gas fluidized beds," Powder Technology, 98, 139-150.

54. Wu, W. Y., Saxena, S. C., Trojnarski, R. L., and Morris, M. V., (1996), "Fluidization Characteristics of Two- and Three-Dimensional Fluidized Beds," Energy, 21(10), 825-833.

55. Wormsbecker, M., Adams, A., Pugsley, T., and Winters, C., (2005), "Segregation by size difference in a conical fluidized bed of pharmaceutical granulate," Powder Technology, 153, 72-80.

56. Xuereb C., Laguérie, C., and Baron, T., (1991a), "Etude du comportement de jets continues horizontaux ou inclines introduits dans un lit fluidize par un gas," Powder Technology, 67, 43-56 (in French).

57. Xuereb C., Laguérie, C., and Baron, T., (1991b), "Etude du comportement de jets continues horizontaux ou inclines introduits dans un lit fluidise par un gas. Deuxieme partie: profiles de vitesse du gaz dans les jets horizontaux," Powder Technology, 64, 271-283 (in French).

58. Xuereb C., Laguérie, C., and Baron, T., (1992), "Etude du comportement de jets continues horizontaux ou inclines introduits dans un lit fluidise par un gas. Troiseme partie: Modelisation de la zone d'ecoulement developpe du jet," Powder Technology, 72, 7-16 (in French).

59. Zhu, C., Wang, X., and Fan, L-S., (2000), "Effect of Solids Concentration on Evaporative Liquid Jets in Gas-Solid Flows," Powder Technology, 111, 79-82. 